\title{
FCRD Transmutation Fuels Handbook 2015
}

Dawn E. Janney, Cynthia A. Papesch

With contributions from R. Fielding, T. Hartmann, T. Hyde, J.R. Kennedy, R. Mariani, T.P. O'Holleran, B.H. Sencer, and L. Squires

September 2015

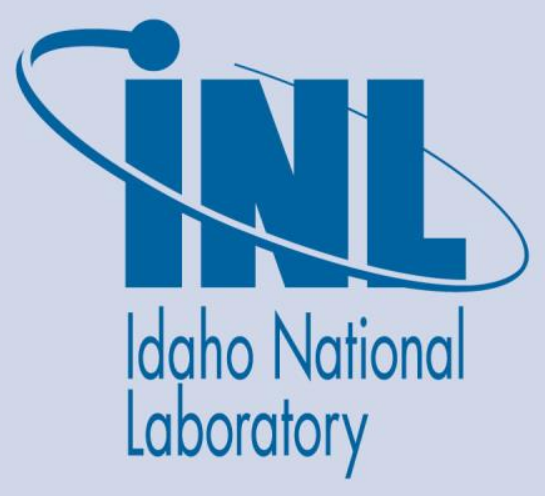

The INL is a U.S. Department of Energy National Laboratory operated by Battelle Energy Alliance 


\section{DISCLAIMER}

This information was prepared as an account of work sponsored by an agency of the U.S. Government. Neither the U.S. Government nor any agency thereof, nor any of their employees, makes any warranty, expressed or implied, or assumes any legal liability or responsibility for the accuracy, completeness, or usefulness, of any information, apparatus, product, or process disclosed, or represents that its use would not infringe privately owned rights. References herein to any specific commercial product, process, or service by trade name, trade mark, manufacturer, or otherwise, does not necessarily constitute or imply its endorsement, recommendation, or favoring by the U.S. Government or any agency thereof. The views and opinions of authors expressed herein do not necessarily state or reflect those of the U.S. Government or any agency thereof. 
INL/EXT-15-36520

Revision 0

\title{
FCRD Transmutation Fuels Handbook 2015
}

\author{
Dawn E. Janney, Cynthia A. Papesch \\ With contributions from R. Fielding, T. Hartmann, T. Hyde, J.R. Kennedy, \\ R. Mariani, T.P. O'Holleran, B.H. Sencer, and L. Squires
}

September 2015

Idaho National Laboratory Idaho Falls, Idaho 83415

http://www.inl.gov

Prepared for the

U.S. Department of Energy

Office of Nuclear Energy

Under DOE Idaho Operations Office

Contract DE-AC07-05ID14517 
INTENTIONALLY BLANK 


\section{SUMMARY}

Transmutation of minor actinides such as $\mathrm{Np}, \mathrm{Am}$, and $\mathrm{Cm}$ in spent nuclear fuel is of international interest because of its potential for reducing the long-term health and safety hazards caused by the radioactivity of the spent fuel. One important approach to transmutation (currently being pursued by the DOE Fuel Cycle Research \& Development Advanced Fuels Campaign) involves incorporating the minor actinides into U-Pu-Zr alloys, which can be used as fuel in fast reactors. It is, therefore, important to understand the properties of $\mathrm{U}-\mathrm{Pu}-\mathrm{Zr}$ alloys, both with and without minor actinide additions.

In addition to requiring extensive safety precautions, alloys containing $U$ and $\mathrm{Pu}$ are difficult to study for numerous reasons, including their complex phase transformations, characteristically sluggish phase-transformation kinetics, tendency to produce experimental results that vary depending on the histories of individual samples, and sensitivity to contaminants such as oxygen in concentrations below a hundred parts per million. Many of the experimental measurements were made before 1980, and the level of documentation for experimental methods and results varies widely. It is, therefore, not surprising that little is known with certainty about U-Pu-Zr alloys, and that general acceptance of results sometimes indicates that there is only a single measurement for a particular property.

This handbook summarizes currently available information about $\mathrm{U}, \mathrm{Pu}, \mathrm{Zr}$, and alloys of two or three of these elements. It contains information about phase diagrams and related information (including phases and phase transformations); heat capacity, entropy, and enthalpy; thermal expansion; and thermal conductivity and diffusivity. In addition to presenting information about materials properties, it attempts to provide information about how well the property is known and how much variation exists between measurements. Although the handbook includes some references to publications about modeling, its primary focus is experimental data.

Most of the data has been published elsewhere (although scattered throughout numerous references, some quite obscure); however, some data is presented here for the first time. 
INTENTIONALLY BLANK 


\section{ACKNOWLEDGEMENTS}

We would like to thank the staff of the INL Research Library. Their ability to find even the most obscure documents is truly outstanding. This work would not have been possible without their enthusiastic help and expertise.

We would also like to thank Dr. Steven L. Hayes for his support and insightful comments.

Funding for researching and writing the handbook was provided by the U.S. Department of Energy, Office of Nuclear Energy, under DOE Idaho Operations Office Contract DE-AC07-05ID14517. 
INTENTIONALLY BLANK 


\section{CONTENTS}

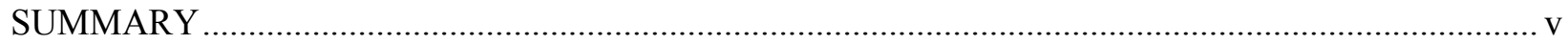

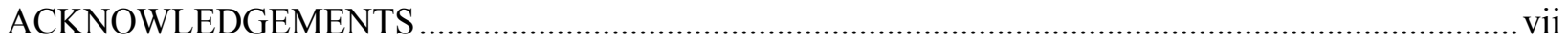

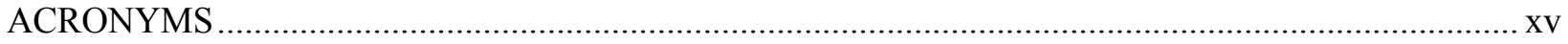

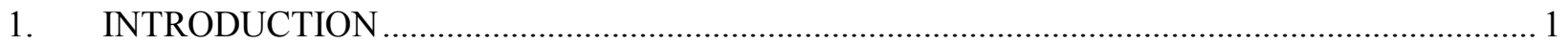

2. BASIC CONSTANTS, UNITS, AND CONVERSION FACTORS …......................................... 2

3. PHASES, PHASE DIAGRAMS, PHASE TRANSFORMATIONS,

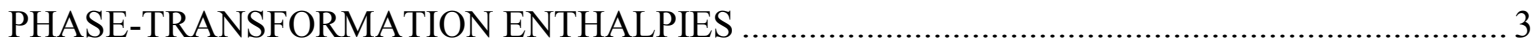

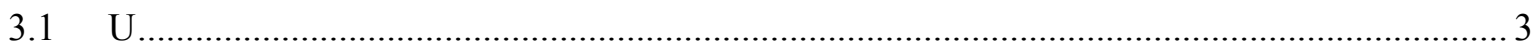

$3.2 \mathrm{Pu}$

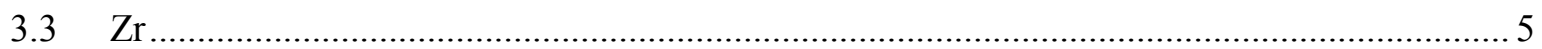

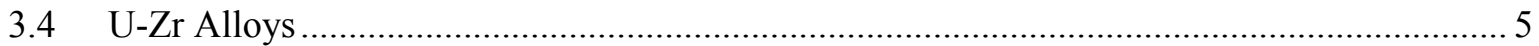

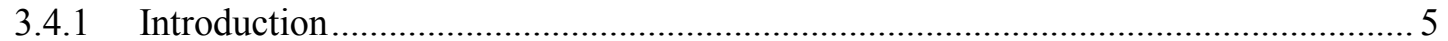

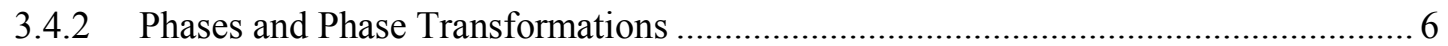

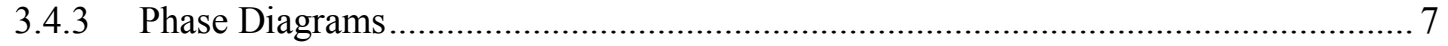

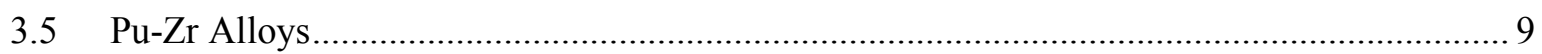

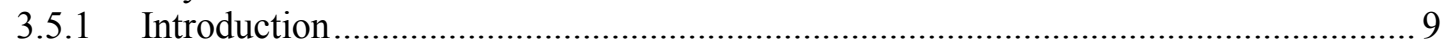

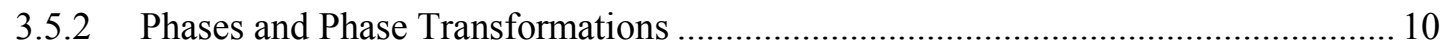

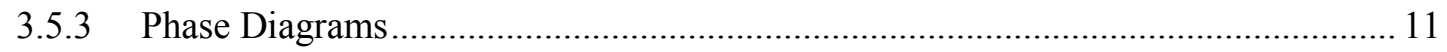

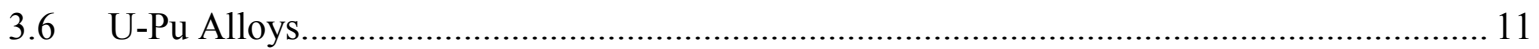

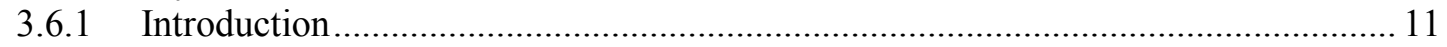

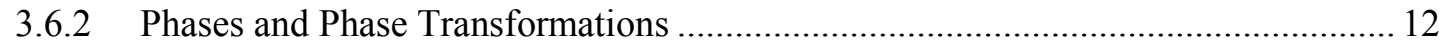

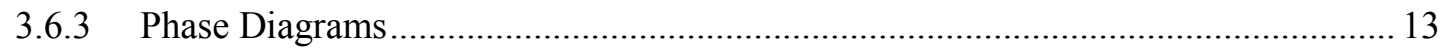

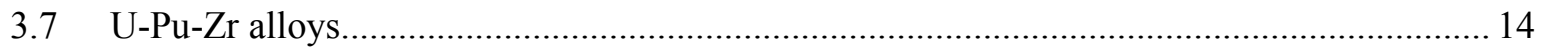

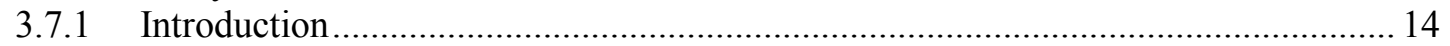

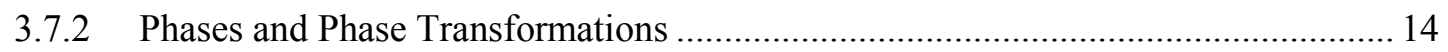

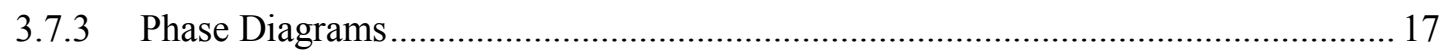

4. HEAT CAPACITY AND RELATED PROPERTIES (ENTROPY, ENTHALPY,

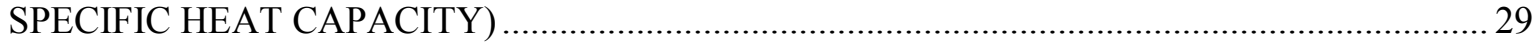

$4.1 \quad \mathrm{U}$

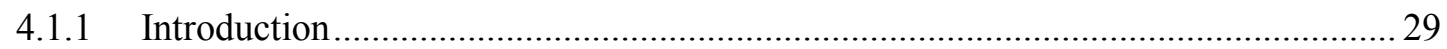

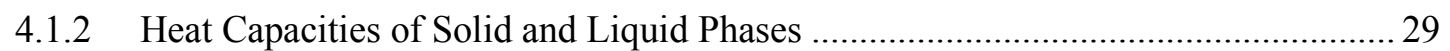

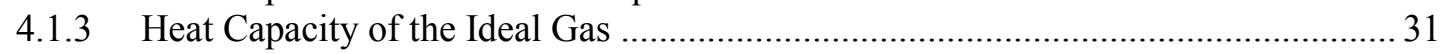

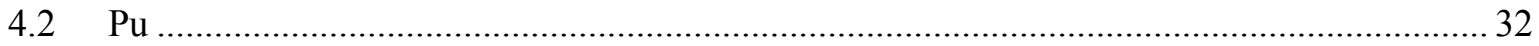

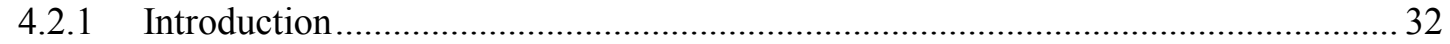

4.2.2 Heat Capacities of Solid and Liquid Phases …........................................................ 32

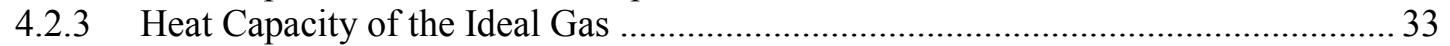

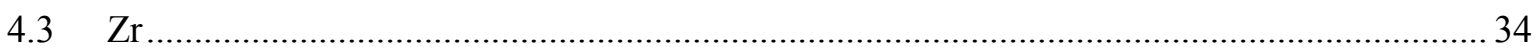

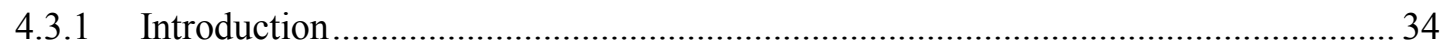

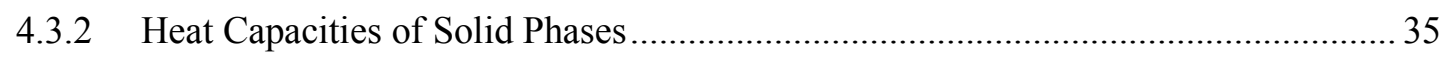




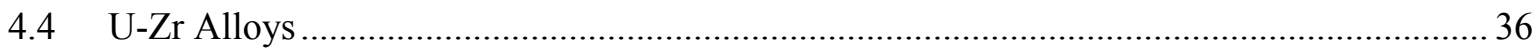

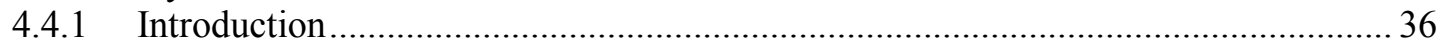

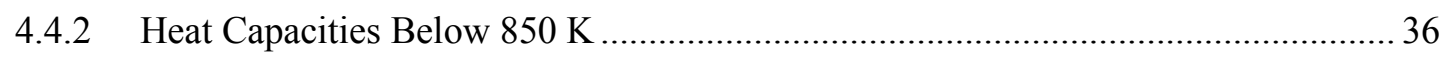

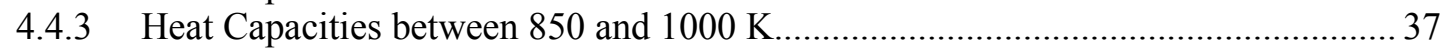

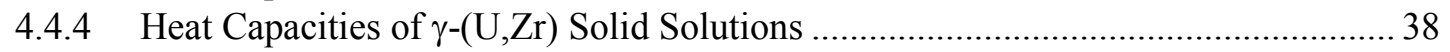

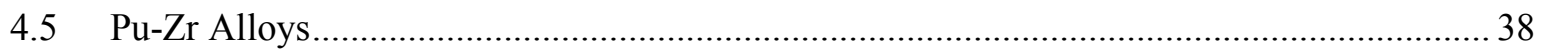

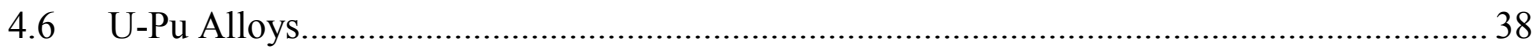

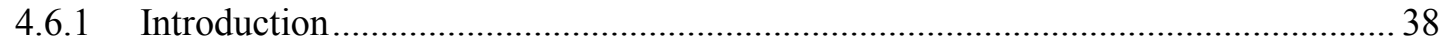

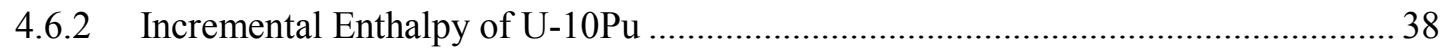

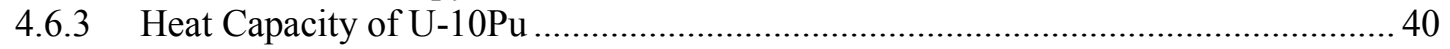

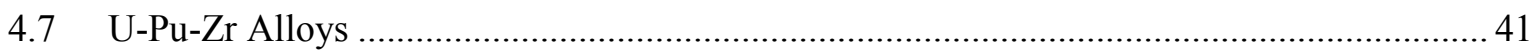

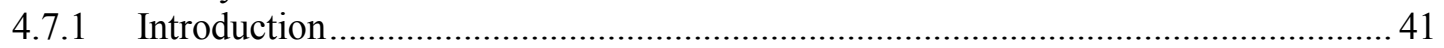

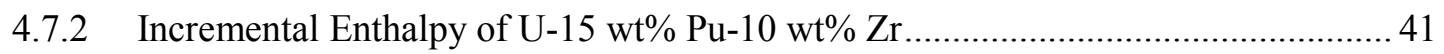

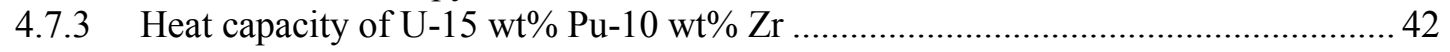

5. THERMAL EXPANSION, THERMAL EXPANSION COEFFICIENTS, AND

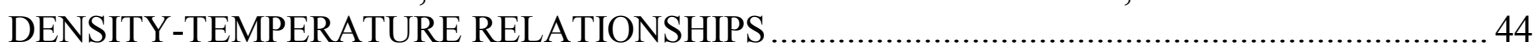

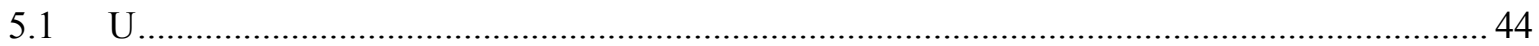

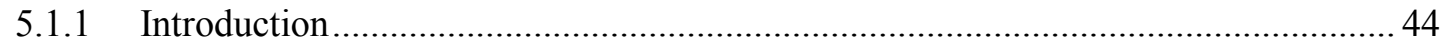

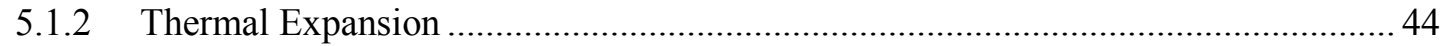

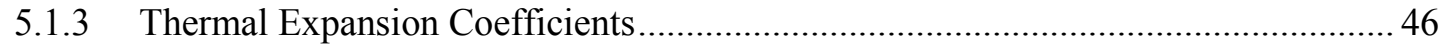

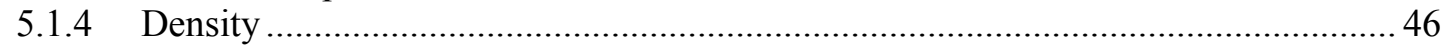

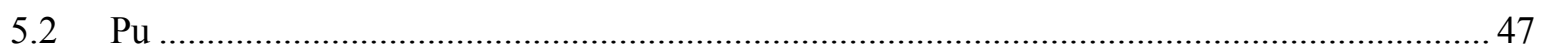

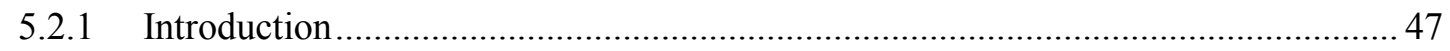

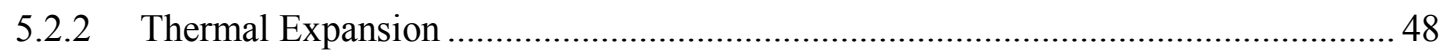

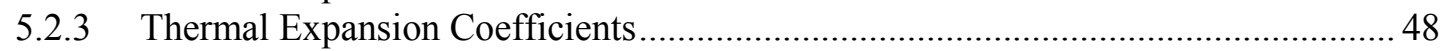

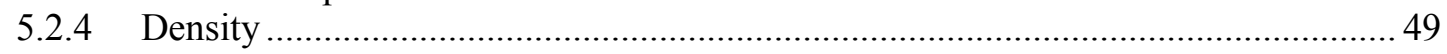

$5.3 \quad \mathrm{Zr}$

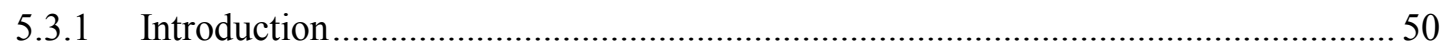

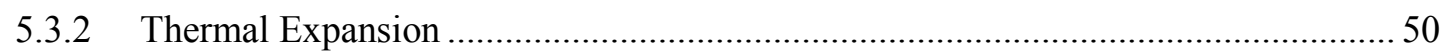

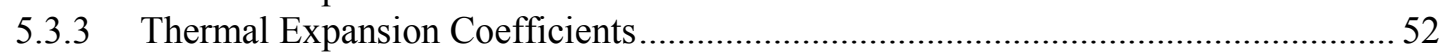

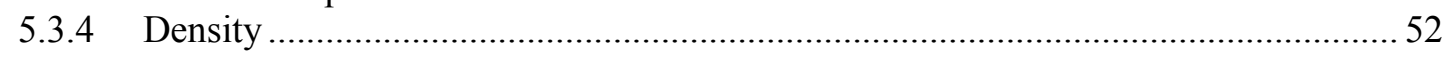

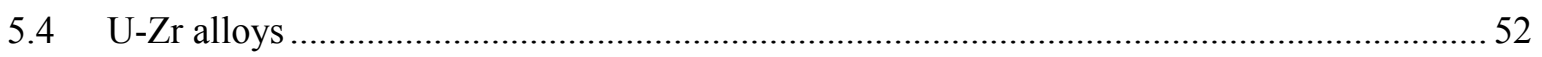

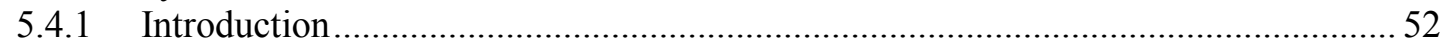

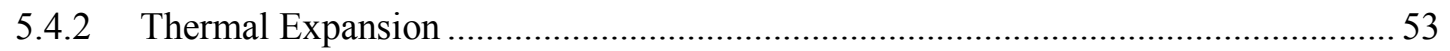

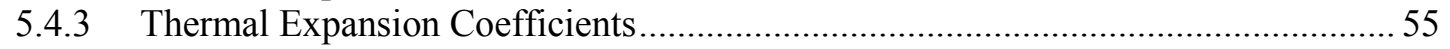

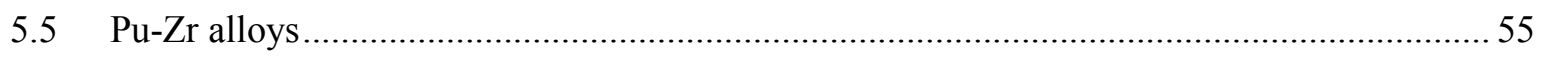

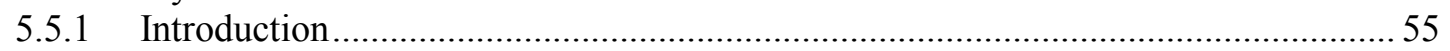

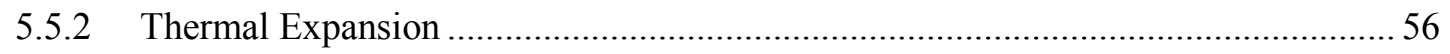

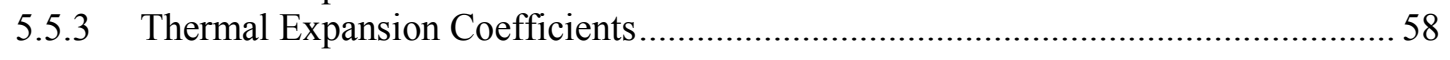

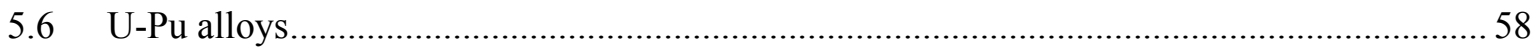

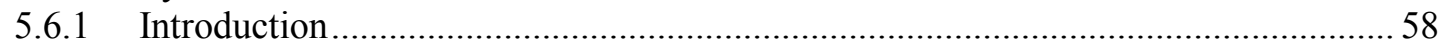

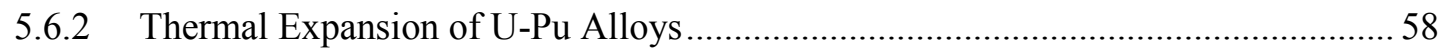

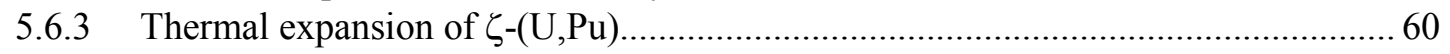

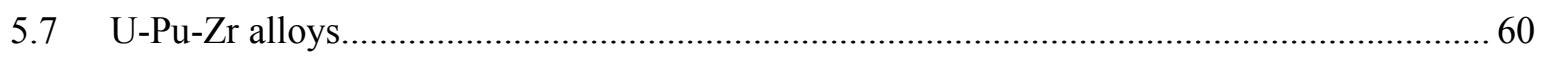

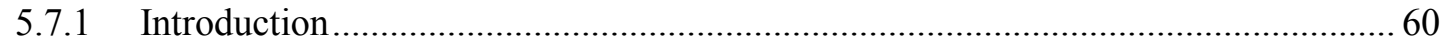

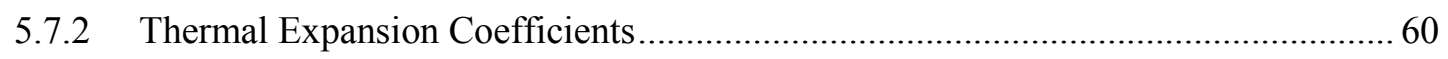

5.7.3 Thermal Expansion as a Result of Phase Transformations ................................................. 61 


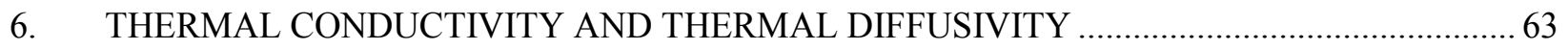

$6.1 \quad \mathrm{U}$

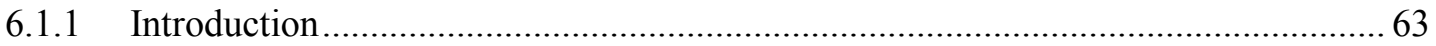

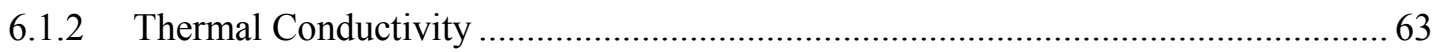

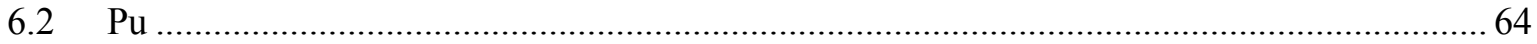

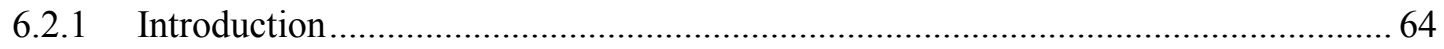

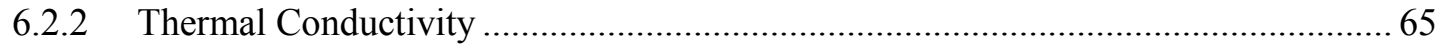

$6.3 \mathrm{Zr}$

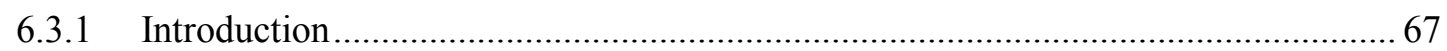

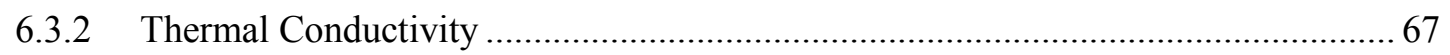

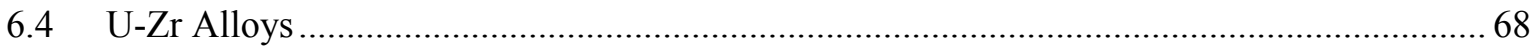

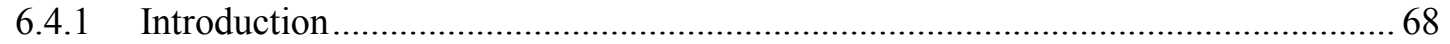

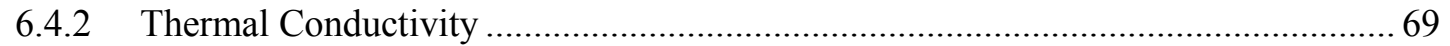

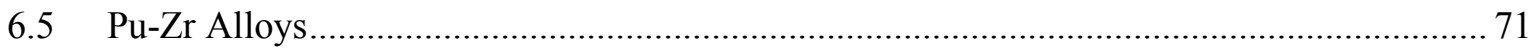

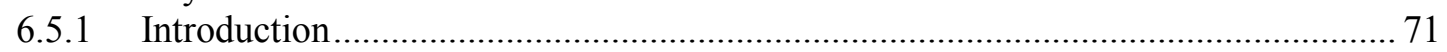

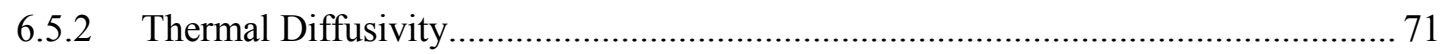

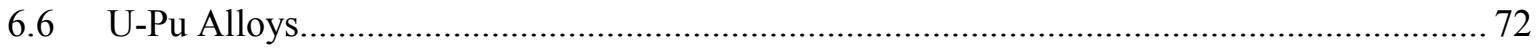

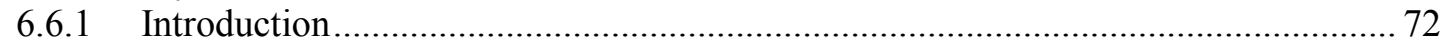

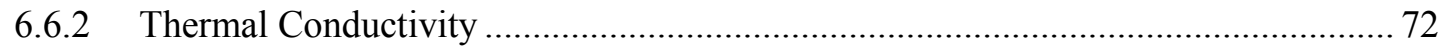

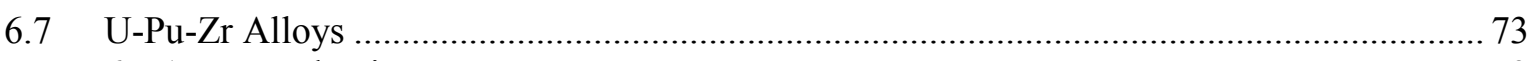

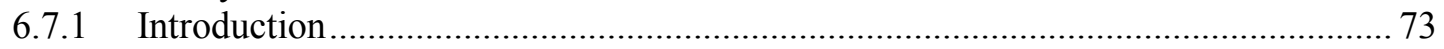

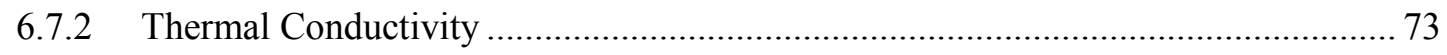

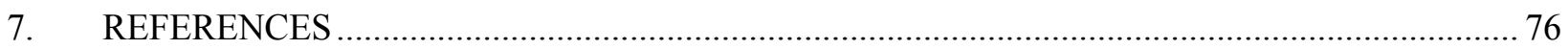

\section{FIGURES}

Figure 1. U-Zr phase diagram according to Sheldon and Peterson [30], with changes suggested by

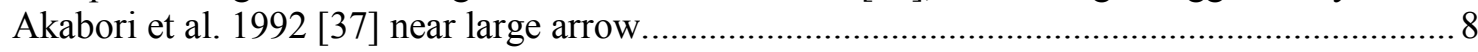

Figure 2. Partial U-Zr phase diagram based on Rough and Bauer [35] ................................................. 9

Figure 3. Pu-Zr phase diagram simplified from Okamoto [69]. High-Pu phases (allotropes of

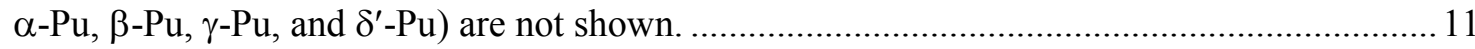

Figure 4. U-Pu phase diagram simplified from Peterson and Foltyn [83]. High-Pu phases (allotropes of $\alpha-\mathrm{Pu}, \beta-\mathrm{Pu}, \gamma-\mathrm{Pu}, \delta-\mathrm{Pu}$, and $\delta^{\prime}-\mathrm{Pu}$ ) are not shown for simplicity, but have at most a few at $\% \mathrm{U}$.

Figure 5. Compositions (in at $\%$ ) of alloys whose phase-transition temperatures and enthalpies were recently measured at INL

Figure 6. Compositions (in wt $\%$ ) of alloys whose phase-transition temperatures and enthalpies were recently measured at INL.

Figure 7. Experimentally determined liquidus temperatures in ${ }^{\circ} \mathrm{C}$, with melting temperatures of $\mathrm{U}, \mathrm{Pu}$, and $\mathrm{Zr}$ for comparison [53, 67, 96, 101, 112].......

Figure 8. Experimentally determined solidus temperatures in ${ }^{\circ} \mathrm{C}$, with melting temperatures of $\mathrm{U}$, $\mathrm{Pu}$, and $\mathrm{Zr}$ for comparison $[53,96,101,112]$. 
Figure 9. Liquidus temperatures $\left({ }^{\circ} \mathrm{C}\right)$ from models of Leibowitz et al. [53] (solid lines), Kurata [49] (dotted lines), and Ogata [4] (colored symbols showing examples of calculated points, with each color indicating a different temperature). Melting temperatures of $U$, $\mathrm{Pu}$, and $\mathrm{Zr}$ are shown for comparison.

Figure 10. Solidus temperatures $\left({ }^{\circ} \mathrm{C}\right)$ from models of Leibowitz et al. [53] (solid lines), Kurata [49] (dotted lines), and Ogata [4] (colored symbols showing examples of calculated points).

Figure 11. Ternary projection of low-temperature limit of $(\gamma-\mathrm{U})$ solid solution from Mound Laboratory [75, 107] (solid lines) with corresponding temperature contours from O’Boyle and Dwight [98] (dotted lines).

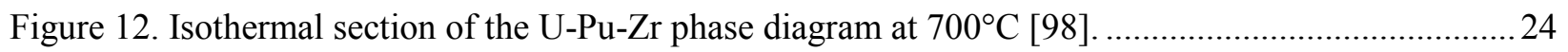

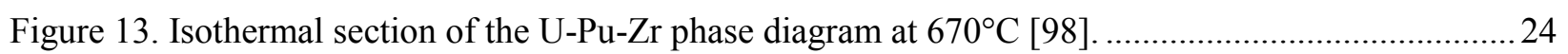

Figure 14. Isothermal section of the U-Pu-Zr phase diagram at $660^{\circ} \mathrm{C}$ [98]. ......................................25

Figure 15. Isothermal section of the U-Pu-Zr phase diagram at $650^{\circ} \mathrm{C}$ [98] ......................................25

Figure 16. Isothermal section of the U-Pu-Zr phase diagram at $640^{\circ} \mathrm{C}$ [98] ......................................26

Figure 17. Isothermal section of the U-Pu-Zr phase diagram at $595^{\circ} \mathrm{C}$ [98] ......................................26

Figure 18. Isothermal section of the U-Pu-Zr phase diagram at $580^{\circ} \mathrm{C}$ [98] ......................................2

Figure 19. Isothermal section of the U-Pu-Zr phase diagram at $550^{\circ} \mathrm{C}$ [98]. ......................................2

Figure 20. Isothermal section of the U-Pu-Zr phase diagram at $500^{\circ} \mathrm{C}$ [98]. .......................................2.

Figure 21. Heat capacities of solid and liquid U. Values from Konings and Beneš [1] (Equation 3, Equation 4, and Equation 5) are preferred ..................................................................... 30

Figure 22. Heat capacity of $U$ as an ideal gas. Values from Konings and Beneš were calculated from Equation 7 and Equation 8.

Figure 23. Heat capacities of solid and liquid Pu. Values from Konings and Beneš [1] (solid black lines, Equation 9 through Equation 15) are preferred.

Figure 24. Heat capacity of ${ }^{239} \mathrm{Pu}$ as an ideal gas, calculated using Equation 16 and Equation $17 \ldots \ldots \ldots \ldots . . . .34$

Figure 25. Heat capacities of solid Zr phases (IAEA data calculated using Equation 18 and Equation 19)

Figure 26. Measured heat capacities for U-Zr alloys with 13-41 at $\% \mathrm{Zr}(\sim 5.5-21 \mathrm{wt} \% \mathrm{Zr})$ at temperatures from 300-850 K [61-63, 119, 120]. Different line types indicate different references.

Figure 27. Incremental enthalpy $(\mathrm{H}(\mathrm{T})-\mathrm{H}(298))$ of $\mathrm{U}-10 \mathrm{Pu}$, calculated from Equation 21, Equation 22, Equation 23, and Equation 24 [83].

Figure 28. Heat capacity of U-10Pu (calculated from Equation 25, Equation 26, Equation 27, and Equation 28), with the heat capacity of $U$ [1] for comparison.

Figure 29. Incremental enthalpy $(\mathrm{H}(\mathrm{T})-\mathrm{H}(25))$ of $\mathrm{U}-15 \mathrm{Pu}-10 \mathrm{Zr}$ [94]. Note that temperature is in ${ }^{\circ} \mathrm{C}$. Triangles are measured data points, and lines are calculated from Equation 29 and Equation 30

Figure 30. Heat capacity of U-15Pu-10Zr (by weight), calculated from Equation 31 and Equation 32 [94]. The heat capacity of pure $U$ [1] is provided for comparison. 
Figure 31. Thermal expansion of polycrystalline $U[5,125]$, calculated using Equation 33 through Equation 37.

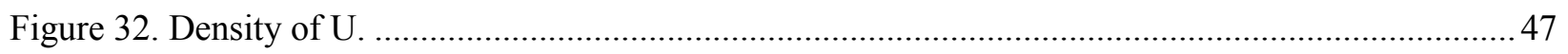

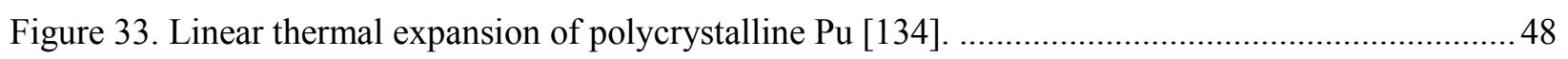

Figure 34. Thermal expansion of polycrystalline Zr, calculated from Equation 41 and Equation 42 [136]

Figure 35. Thermal expansion of U-Zr alloys according to Saller et al. and Touloukian et al. [5, 141], with thermal expansion of $U$ and $\operatorname{Zr}[5,136]$ for comparison. Values for $10 \mathrm{wt} \%$ and $20 \mathrm{wt} \% \mathrm{Zr}$ are polynomial fits to tabulated data from Touloukian et al. [5] .53

Figure 36. Thermal expansion of $U$ and $U-Z r$ alloys according to Basak et al. [125] ......

Figure 37. Thermal expansion of $\mathrm{Pu}-\mathrm{Zr}$ alloys, calculated from data in reference [142] using a reference temperature of $400^{\circ} \mathrm{C}$......

Figure 38. Thermal expansion of U-15 wt\% (15 at\%) Pu, calculated using Equation 56, Equation 57, and Equation 58 .59

Figure 39. Thermal conductivity of $U$ (Equation 59, Equation 60, and Equation 61). 64

Figure 40. Thermal conductivity of Pu. Data from Alexander and Wood were calculated from Equation 62 through Equation 66. .66

Figure 41. Thermal conductivity of $\operatorname{Zr}$ [150], plotted using Equation 68.

Figure 42. Thermal conductivity of $\mathrm{U}-\mathrm{Zr}$ alloys, with conductivity of $\mathrm{U}$ and $\mathrm{Zr}$ for comparison [7, $62,146,148,151]$

Figure 43. Measured and predicted thermal conductivity for U-Zr alloys with 6-17 wt $\% \mathrm{Zr}$. Ogata's predicted value is from Equation 69. .70

Figure 44. Thermal diffusivity of Pu-10 wt $\% \mathrm{Zr}$ and $\mathrm{Pu}-30 \mathrm{wt} \% \mathrm{Zr}$ alloys (INL preliminary data). Data for Pu-10 wt\% alloy are the average of two measurements. .72

Figure 45. Thermal conductivity of U-Pu-Zr alloys. [101, 105, 144, 153] ......................................... 74

Figure 46. Comparison of measured and predicted thermal conductivity of U-Pu-Zr alloys. .75

\section{TABLES}

Table 1. Transformation temperatures and enthalpies of U-Zr alloys. 7

Table 2. Onset temperatures for peaks at temperatures above $400^{\circ} \mathrm{C}$ in recent INL data, measured during heating

Table 3. Combined enthalpies for all transformations at temperatures between 400 and $800^{\circ} \mathrm{C}$ corresponding to data summarized in Table 2 .

Table 4. Experimental and calculated liquidus temperatures $\left({ }^{\circ} \mathrm{C}\right)$ for $\mathrm{U}-\mathrm{Zr}$ and $\mathrm{U}-\mathrm{Pu}-\mathrm{Zr}$ alloys. .............2 21

Table 5. Experimental and calculated solidus temperatures $\left({ }^{\circ} \mathrm{C}\right)$ for $\mathrm{U}-\mathrm{Zr}$ and $\mathrm{U}-\mathrm{Pu}-\mathrm{Zr}$ alloys................2 22

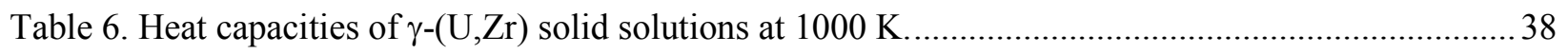

Table 7. Thermal expansion coefficients $\left(10^{-6} / \mathrm{K}\right)$ of solid and liquid $\mathrm{Pu}[5,13,134]$.

Table 8. Mean linear coefficients of thermal expansion along single directions for anisotropic $\mathrm{Pu}$ phases [13]. 
Table 9. Coefficients for equations expressing lengths of $U-P u$ alloys, $L=a+b \times T+c \times T^{2}$, where $\mathrm{L}$ is a length and $\mathrm{T}$ is a temperature in ${ }^{\circ} \mathrm{C}$ [142]. Coefficients should only be used within the stated temperature ranges.

Table 10. Coefficients of thermal expansion for $\delta-(\mathrm{Pu}, \mathrm{Zr})$. Data for $\mathrm{Pu}$ are from reference [13]; other data are from reference [142]. Coefficients should not be used outside the listed temperature ranges.

Table 11. Lattice parameters and unit-cell volume for $\zeta_{-}(\mathrm{U}, \mathrm{Pu})$ as a function of temperature, based on data read from [93 Figure 8].

Table 12. Thermal expansion coefficients for U-Pu-Zr alloys between room temperature and $600^{\circ} \mathrm{C}$.

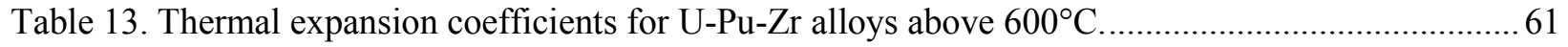

Table 14. Length changes (in \%) from phase transformations in $\mathrm{U}-\mathrm{Pu}-\mathrm{Zr}$ alloys. ...................................62

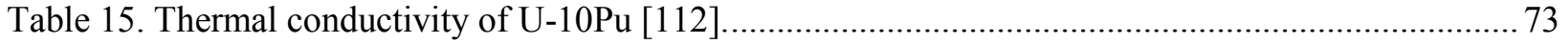


INTENTIONALLY BLANK 


\section{ACRONYMS}

AFC

ANL

CALPHAD

CEA

DOE

DSC

FCRD

IAEA

INL

NIST-JANAF

OECD/NEA

SI
Advanced Fuels Campaign

Argonne National Laboratory

CALculation of PHAse Diagrams

Commissariat a l'Energie Atomique (French Atomic Energy Commission)

U. S. Department of Energy

Differential scanning calorimetry

Fuel Cycle Research and Development

International Atomic Energy Agency

Idaho National Laboratory

National Institute of Standards and Technology - Joint Army, Navy, Air Force

Organisation for Economic Co-Operation and Development, Nuclear Energy Agency

Systeme International d'Unites (French) (International System of Units) 
INTENTIONALLY BLANK 


\section{FCRD Transmutation Fuels Handbook 2015}

\section{INTRODUCTION}

Transmutation of minor actinides such as $\mathrm{Np}, \mathrm{Am}$, and $\mathrm{Cm}$ in spent nuclear fuel is of international interest because of its potential for reducing the long-term health and safety hazards caused by the radioactivity of the spent fuel. For this reason, the DOE Fuel Cycle Research \& Development (FCRD) Advanced Fuels Campaign (AFC) has been performing research on nuclear fuel technologies that could be used in conjunction with a future actinide transmutation mission. One important approach to transmutation involves incorporating the minor actinides into U-Pu-Zr alloys, which can be used as fuel in fast reactors. It is, therefore, important to understand the properties of $\mathrm{U}-\mathrm{Pu}-\mathrm{Zr}$ alloys.

This handbook focuses on phases and key thermophysical properties of elements and alloys in the U-Pu-Zr system. It is envisioned as the first of an annual series, which will serve as a summary of current knowledge about important properties of transmutation fuels. Future volumes will include information about properties and materials not covered here, as well as updates to information in this edition of the handbook.

The handbook is intended to serve two audiences. One audience is researchers, who may find it useful to know what has been measured, where it has been published, and what kinds of information are needed. A second audience is modelers, who need a concise summary of information about specific properties and the accuracy with which they are known. The two audiences have different needs, and the handbook is a compromise intended to be useful to both. Therefore, it includes summaries of research results and needs, but generally does not present the original data. It also includes numerous graphs and, where available, equations that provide convenient approximations to materials properties for modelers. It is important to understand that most of the equations provided in this handbook are derived by fitting polynomials to data and have no physical basis; while they can be used with caution for design studies, fuel modelers will probably want to use the original experimental data to develop or validate their own equations and/or models. Although the handbook includes some citations to research involving development of models, its primary focus is experimental data.

Many of the measurements of the U-Pu-Zr system were made before 1980 . Where possible, the handbook relies on previous reviews of experimental data (e.g., references [1-7]) rather than presenting new interpretations of the old information. It is expected that researchers will refer to the original literature for details that are not presented here.

The handbook is not intended to be a comprehensive guide for all information about FCRD fuels and fuel materials. Topics that are specifically excluded (at least in the current version) include: fuel types not specifically intended for transmutation in a fast neutron spectrum (e.g., fuels for light-water and high-conversion water reactors); properties not relevant to fuels (e.g., low-temperature or high-pressure measurements); spatially varying properties (e.g., microstructures); changes due to irradiation; issues involved in materials supplies and fuel fabrication; and (to the extent that they can be avoided) properties whose values depend on characteristics or histories of specific samples.

Metals and alloys in the U-Pu-Zr system are uniquely difficult to study for a number of reasons. Experimental designs may need to be modified to allow researchers to work with these hazardous materials safely. Kinetics of phase transformations are commonly sluggish, and it is highly unlikely that all of the samples in previous research had equilibrium phases and microstructures. Thermal cycling effects (changes in sample characteristics that are not fully reversed during cooling) are commonly reported and may be significant. Careful control of impurities (particularly oxygen) during sample fabrication and data collection is both crucial and difficult, and concentrations below $100 \mathrm{ppm}$ in samples may significantly affect thermophysical properties. For all of these reasons, differences between measured values for similar alloys are commonly far larger than the estimated errors for individual measurements. 
Further research on well-characterized materials with careful control of impurities is needed for all of the alloys discussed here.

\section{BASIC CONSTANTS, UNITS, AND CONVERSION FACTORS}

Much of the experimental data on the U-Pu-Zr system were reported in the 1940s through 1970s, before SI units and the Kelvin temperature scale were generally adopted. Therefore, it is sometimes necessary to convert between units.

Useful unit conversions include [8]:

- $\quad$ Temperature in Kelvin $(\mathrm{K})=$ Temperature in Celsius $\left({ }^{\circ} \mathrm{C}\right)+273.15$

- 1 calorie $(\mathrm{cal})=4.1868$ Joules $(\mathrm{J})$

- 1 calorie/second $(\mathrm{cal} / \mathrm{sec})=4.183076 \mathrm{Watts}(\mathrm{W})$.

Numerical values of properties that vary with temperature (e.g., heat capacities and thermal expansion coefficients) do not change when temperatures are converted between ${ }^{\circ} \mathrm{C}$ and $\mathrm{K}$.

Most of the references in the bibliography count "moles" in a material based on the number of atoms it contains, even if those atoms are of different elements. However, a few references count formula units rather than atoms in defining moles, and, therefore, consider that a mole of $\mathrm{UZr}_{2}$ has three times as many atoms as a mole of $U$. This handbook assumes that all moles have the same number of atoms.

Allotropic solid solutions may be indicated by parentheses. For example, $(\alpha-\mathrm{Zr})$ has the same structure as pure $\alpha-\mathrm{Zr}$, but may contain other elements such as $\mathrm{U}$ and $\mathrm{Pu}$.

Compositions of alloys are commonly expressed in one of four units: Weight fractions, weight percentages, atomic fractions, and atomic percentages. Weight fractions can be converted to atomic fractions and vice versa using Equation 1 and Equation 2, where $w_{i}$ and $x_{i}$ are the weight and atomic fractions of element $i$ and $M_{i}$ is the atomic weight of the element.

Equation 1. Conversion of weight fractions to mole fractions.

$$
x_{i}=\frac{\frac{w_{i}}{M_{i}}}{\sum_{i}\left(\frac{w_{i}}{M_{i}}\right)}
$$

Equation 2. Conversion of mole fractions to weight fractions.

$$
w_{i}=\frac{x_{i} \times M_{i}}{\sum_{i}\left(x_{i} \times M_{i}\right)}
$$

Weight fractions can be converted to weight percent, and atomic fractions to atomic percent, by multiplying by 100 . 


\section{PHASES, PHASE DIAGRAMS, PHASE TRANSFORMATIONS, PHASE-TRANSFORMATION ENTHALPIES}

\section{$3.1 \mathrm{U}$}

U has three phases that are stable atmospheric pressure. With the exception of the space group for $\beta-U$, crystal structures and lattice parameters have been known for decades, and there is little variation between references. The values presented here are based on one of the few new studies since the 1970s, and were obtained using high-resolution neutron-diffraction data [9].

- $\alpha-\mathrm{U}$, orthorhombic (space group Cmcm), $a=2.8359 \AA, b=5.8678 \AA, c=4.9554 \AA$ at $298 \mathrm{~K}$

- $\beta$-U, tetragonal (space group $P 4_{2} / m n m$ ), $a=10.7589 \AA, c=5.6531 \AA$ at $955 \mathrm{~K}$

- $\gamma$-U, body-centered cubic (space group $\operatorname{Im} \overline{3} m$ ), $a=3.5355 \AA$ at $1060 \mathrm{~K}$.

Most of the experimental measurements of phase-transformation and melting temperatures were made before 1970, and later references are based on interpretation of the earlier data. Major reviews include those by Oetting et al. [3] (for the IAEA), Ward et al. [10], Grenthe et al. [11] (for the OECD/NEA), and Konings and Beneš [1] (with key results repeated in [2]). Recommended transformation temperatures and enthalpies from all of the reviews are similar.

Recommended phase-transformation temperatures and range of measured values are [1]:

- $\quad \alpha-\beta, 941 \pm 2 \mathrm{~K}$ (based on 10 publications with original measurements, which range from 933 to $943 \mathrm{~K}$ )

- $\beta-\gamma, 1049 \pm 2 \mathrm{~K}$ (based on 9 publications with original measurements, which range from 1037 to $1050 \mathrm{~K})$

- $\gamma$-liquid, $1407 \pm 2$ (based on 7 publications with original measurements, which range from 1401 to $1406 \mathrm{~K})$.

The recommended phase-transformation enthalpies $\left(\Delta \mathrm{H}_{\mathrm{t}}\right)$ and range of measured values are [1]:

- $\quad \alpha-\beta, 2.85 \pm 0.15 \mathrm{~kJ} / \mathrm{mol}$ (based on 6 publications with original measurements, which range from 2.63 to $3.26 \mathrm{~kJ} / \mathrm{mol}$ )

- $\quad \beta-\gamma, 4.62 \pm 0.5 \mathrm{~kJ} / \mathrm{mol}$ (based on 6 publications with original measurements, which range from 4.18 to $4.87 \mathrm{~kJ} / \mathrm{mol}$ )

- $\gamma$-liquid, $8.47 \pm 1.00 \mathrm{~kJ} / \mathrm{mol}$ (based on 6 publications with original measurements, which range from 7.03 to $12.1 \mathrm{~kJ} / \mathrm{mol})$.

\section{$3.2 \mathrm{Pu}$}

Pure $\mathrm{Pu}$ has six phases that are stable at atmospheric pressure. Crystal structures and lattice parameters are well known, and there is little variation between references. Recommended phase-transformation temperatures and enthalpies from major reviews agree to within a few degrees.

$\mathrm{Pu}$ phase transformations are sensitive to small amounts of alloying elements. Some elements ( $\mathrm{Al}, \mathrm{Ga}$, $\mathrm{Ce}, \mathrm{Am}, \mathrm{In}, \mathrm{Tl}$, and $\mathrm{Sc}$ ) stabilize the $\delta$-Pu structure so that it is retained at room temperature, and others ( $\mathrm{Si}, \mathrm{Zn}, \mathrm{Zr}$, Hf, and perhaps Th and trivalent lanthanides such as $\mathrm{Dy}, \mathrm{Er}, \mathrm{Tm}, \mathrm{Lu}$, and $\mathrm{Tb}$ ) allow the $\delta$-Pu structure to be retained as a metastable phase during rapid cooling [12]. Np extends the stability of the $\alpha-\mathrm{Pu}$ structure [12]. The stability of Pu phases is significantly affected by high pressures, with $\gamma, \delta$, and $\delta^{\prime}$ becoming unstable at pressures of a few hundred MPa [13]. 
Recent modeling research includes calculations of Landau free energies associated with phase transformations [14] and development and evaluation of atomic-scale models for a number of alloys (e.g., [15-18]).

Space groups and lattice parameters of the pure $\mathrm{Pu}$ phases stable at atmospheric pressure are [13]:

- $\alpha-P u$, monoclinic (space group $P 2_{1} / m$ ), $a=6.183 \AA, b=4.822 \AA, c=10.963 \AA, \beta=101.79^{\circ}$

- $\quad \beta-P u$, monoclinic (space group $I 2 / m$ ), $a=9.284 \AA, b=10.463 \AA, c=7.859 \AA, \beta=93.13^{\circ}$ (The unconventional space group $I 2 / m$ is equivalent to space group $C 2 / m$ with origin choice 3 [19])

- $\quad \gamma$-Pu, orthorhombic, space group Fddd, $a=3.159 \AA, b=5.768 \AA, c=10.162 \AA$

- $\delta$-Pu, face-centered cubic (space group $F m \overline{3} m$ ), $a=4.637 \AA$

- $\quad \delta^{\prime}-\mathrm{Pu}$, body-centered tetragonal (space group $\mathrm{I} / \mathrm{mmm}$ ), $a=3.34 \AA, c=4.44 \AA$

- $\varepsilon$-Pu, body-centered cubic (space group $\operatorname{Im} \overline{3} m$ ), $a=3.636 \AA$.

Most of the experimental measurements of phase-transformation and melting temperatures were made before 1970, and later references are based on new interpretations of the earlier data. Major reviews include those by Oetting et al. [3] (for the IAEA), Ward et al. [10], Lemire et al. [20] (for the $\mathrm{OECD} / \mathrm{NEA}$ ), and Konings and Beneš [1] (with key results repeated in [2]). Recommended transformation temperatures from all of the reviews are in general agreement.

The recommended phase-transformation temperatures and range of measured values are [1]:

- $\alpha-\beta, 399 \pm 1 \mathrm{~K}$ (based on 23 publications with original measurements, which range from 383 to $406 \mathrm{~K}$ )

- $\quad \beta-\gamma, 488 \pm 1 \mathrm{~K}$ (based on 21 publications with original measurements, which range from 457 to $490 \mathrm{~K}$ )

- $\gamma-\delta, 596 \pm 2 \mathrm{~K}$ (based on 20 publications with original measurements, which range from 579 to $599 \mathrm{~K}$ )

- $\delta-\delta^{\prime}, 741 \pm 2 \mathrm{~K}$ (based on 19 publications with original measurements, which range from 713 to $745 \mathrm{~K}$ )

- $\quad \delta^{\prime}-\varepsilon, 759 \pm 4 \mathrm{~K}$ (based on 19 publications with original measurements, which range from 733 to $759 \mathrm{~K}$ )

- $\varepsilon$-liquid, $913 \pm 2 \mathrm{~K}$ (based on 10 publications with original measurements, which range from 907 to $914 \mathrm{~K})$.

However, more recent work by Ennaceur [21-24] showed that phase-transformation temperatures differ by several degrees in samples with different thermal histories. Ennaceur also demonstrated that phase-transition kinetics are strongly influenced by thermal history, presumably because of internal strain accumulated during earlier phase transitions.

Recommended phase-transformation enthalpies $\left(\Delta \mathrm{H}_{\mathrm{t}}\right)$ from the reviews of Ward et al. [10], Lemire et al. [20], and Konings and Beneš [1] similar, and are somewhat higher than those of Oetting et al. [3]. Values from Konings and Beneš are repeated here because they are recent and are based on a thorough analysis of all of the available data. The recommended phase-transformation enthalpies and range of measured values are [1]:

- $\alpha-\beta, 3.706 \pm 0.03 \mathrm{~kJ} / \mathrm{mol}$ (based on 13 publications with original measurements, which range from $3.16-5.02 \mathrm{~kJ} / \mathrm{mol}$ )

- $\quad \beta-\gamma, 0.478 \pm 0.02 \mathrm{~kJ} / \mathrm{mol}$ (based on 11 publications with original measurements, which range from $0.51-0.70 \mathrm{~kJ} / \mathrm{mol})$

- $\gamma-\delta, 0.713 \pm 0.05 \mathrm{~kJ} / \mathrm{mol}$ (based on 11 publications with original measurements, which range from $0.52-0.80 \mathrm{~kJ} / \mathrm{mol}$ ) 
- $\delta-\delta^{\prime}, 0.065 \pm 0.02 \mathrm{~kJ} / \mathrm{mol}$ (based on 10 publications with original measurements, which range from $0-0.10 \mathrm{~kJ} / \mathrm{mol}$ )

- $\quad \delta^{\prime}-\varepsilon, 1.711 \pm 0.05 \mathrm{~kJ} / \mathrm{mol}$ (based on 11 publications with original measurements, which range from $1.59-2.12 \mathrm{~kJ} / \mathrm{mol}$ )

- $\varepsilon$-liquid, $2.766 \pm 0.1 \mathrm{~kJ} / \mathrm{mol}$ (based on 6 publications with original measurements, which range from $2.22-3.30 \mathrm{~kJ} / \mathrm{mol})$.

\section{$3.3 \mathrm{Zr}$}

$\mathrm{Zr}$ has two equilibrium solid phases at atmospheric pressure. (A third phase, $\omega-\mathrm{Zr}$, is not stable in pure $\mathrm{Zr}$ at atmospheric pressure but is commonly mentioned in discussions of actinide-Zr phases because of its structural similarity to $\delta-\mathrm{UZr}_{2}$.) Crystal structures and lattice parameters of both of the equilibrium phases of $\mathrm{Zr}$ are well known, and there is little variation between references.

The crystal structures and lattice parameters of $\mathrm{Zr}$ phases stable at atmospheric pressure are [25]:

- $\alpha-Z r$, hexagonal close packed (space group $P 6_{3} / m m c$ ), $a=3.2316 \AA, c=5.1475 \AA$

- $\quad \beta-Z r$, body-centered cubic (space group $\operatorname{Im} \overline{3} m$ ), $a=3.6090 \AA$.

The generally accepted temperatures and enthalpies for $\mathrm{Zr}$ phase transformations are:

- $\quad \alpha-\beta, 863{ }^{\circ} \mathrm{C}(1136 \mathrm{~K})$ [25], enthalpy $3.98 \mathrm{~kJ} / \mathrm{mol}$ [26].

- $\quad \beta$-liquid, $1855^{\circ} \mathrm{C}(2127 \mathrm{~K})$ [27, 28], enthalpy $21.00 \mathrm{~kJ} / \mathrm{mol}[29]$.

\subsection{U-Zr Alloys}

\subsubsection{Introduction}

Many features of the U-Zr phase diagram have been known since the 1950s, and a widely accepted phase diagram was developed by Sheldon and Peterson in the late 1980s [30,31]. Key features of U-Zr phase diagrams include a high-temperature body-centered cubic solid solution between $\gamma-\mathrm{U}$ and $\beta-\mathrm{Zr}$ that separates into two body-centered cubic phases $\left(\gamma_{1}\right.$ and $\left.\gamma_{2}\right)$ at lower temperatures, the existence of a single intermediate phase $\left(\delta-\mathrm{UZr}_{2}\right)$ that is stable at room temperature, and limited solubility of $\mathrm{U}$ in $\alpha-\mathrm{Zr}$ and of $\mathrm{Zr}$ in $\alpha-\mathrm{U}$ and $\beta-\mathrm{U}$. However, recent work by Ahn and colleagues [32, 33] suggests that the Sheldon and Peterson phase diagrams may not be a correct representation of the transformation from ( $\alpha-U)$ to $(\beta-U)$ solid solutions, and that an early phase diagram by Rough and Bauer [34-36] may represent this transformation more accurately. The $(\alpha-\mathrm{U})$ to $(\beta-\mathrm{U})$ transformation occurs in alloys with at most $\sim 1$ at $\%$ $\mathrm{Zr}$, but has implications for phase transformation histories in alloys with $\mathrm{Zr}$ concentrations up to $\sim 60$ at $\%$. Further work is needed to resolve this issue. Regardless of the outcome of this work, the boundaries for $\delta$-UZr $r_{2}$ established by Akabori et al. $[37,38]$ should be considered more accurate than those in the original Rough and Bauer phase diagram.

Work on $\mathrm{U}-\mathrm{Zr}$ alloys is complicated by sluggish kinetics at a spatial scale large enough for measurement by optical or microprobe techniques (but perhaps not on a scale of nanometers [39]), a high degree of sensitivity to impurities such as $\mathrm{O}$ and $\mathrm{N}$ in concentrations of a few hundred ppm (e.g., [30, 40]), and a tendency to form significant quantities of a high-Zr phase not expected from phase diagrams. Phases and microstructures may differ between samples with the same nominal composition and different thermal histories [32, 41-43].

Models of the U-Zr phase diagram have been developed by numerous researchers using thermodynamic modeling, ab-initio approaches, and CALPHAD (e.g., [42, 44-57]). Ogata [4, 58] developed empirical equations for liquidus and solidus temperatures for alloys with less than $80 \mathrm{at} \% \mathrm{Zr}$ based on the thermodynamic model of Kurata [47]. 


\subsubsection{Phases and Phase Transformations}

Stable phases in the U-Zr system are:

- $\quad \gamma-(\mathrm{U}, \mathrm{Zr})$ ): Body-centered cubic (space group $\operatorname{Im} \overline{3} m$ ) solid solution between $\gamma-\mathrm{U}$ and $\beta-Z \mathrm{r}$, which separates into $\gamma_{1}$ (U-rich) and $\gamma_{2}$ (Zr-rich) phases as a result of a miscibility gap whose maximum is at $\sim 722^{\circ} \mathrm{C}$ and 30 at $\% \mathrm{Zr}$ [30]. Lattice parameters of $\gamma-(\mathrm{U}, \mathrm{Zr})$ are reported to vary linearly between those of $\gamma-\mathrm{U}$ and $\beta-\mathrm{Zr}$ as a function of the concentration of $\mathrm{Zr}[30,59]$.

- $\quad(\alpha-Z r)$ : Allotropic modification of $\alpha-Z r$ that can dissolve up to 1 at $\% U$ [30].

- $\quad(\alpha-U)$ : Allotropic modification of $\alpha-U$ that can dissolve up to 0.5 at $\% \operatorname{Zr}[30]$.

- $\quad(\beta-\mathrm{U})$ : Allotropic modification of $\beta-\mathrm{U}$ that can dissolve up to $1.1 \mathrm{at} \% \mathrm{Zr}[30]$.

- $\delta$ (commonly referred to as $\delta-\mathrm{UZr}_{2}$ ): Hexagonal intermediate phase (space group $P 6 / \mathrm{mmm}, a=5.03 \AA$, $c=3.09$ for a sample with $\sim 70.7$ at $\% \operatorname{Zr}$ [38]). Lattice parameters increase with increasing temperature or concentration of $\mathrm{Zr}[37,38]$. The stability range for this phase is $\sim 64-80 \mathrm{at} \% \mathrm{Zr}$ [37], but is strongly dependent on concentrations of impurities such as $\mathrm{O}$ and $\mathrm{N}$ [30]. The phases actually present in a given sample are also strongly dependent on thermal history (e.g., [42, 43]).

$\mathrm{U}-\mathrm{Zr}$ alloys commonly have U-bearing high-Zr inclusions in alloys that phase diagrams indicate have too little $\mathrm{Zr}$ to form $\alpha-\mathrm{Zr}$ or $\beta-\mathrm{Zr}$ (e.g., [60]). These inclusions are commonly referred to as "oxygen-stabilized $\alpha$-Zr." Little is known about them, and further research is needed to determine what they are, why they form, and whether they are stable.

The peritectoid reaction $(\alpha-\mathrm{U})+\gamma_{2} \leftrightarrow \delta$ occurs at $\sim 615^{\circ} \mathrm{C}$, and the eutectoid reaction $\gamma_{2} \leftrightarrow(\alpha-\mathrm{Zr})+\delta$ occurs at $\sim 606^{\circ} \mathrm{C}[30,37]$. The mechanism by which $\gamma_{2}$ becomes $\delta-\mathrm{UZr}_{2}$ is an $\omega$-transformation analogous to that in $\mathrm{Ti}, \mathrm{Zr}$, and $\mathrm{Hf}$, and involves ordering of $\mathrm{Zr}$ atoms in the $\gamma_{2}$ crystal structure followed by collapse of the $\gamma_{2}$ lattice planes $[42,43]$.

Table 1 lists measured phase-transformation temperatures and enthalpies of associated reactions. Transformation temperatures reported by different researchers are in generally good agreement [32, 33, 38, 61-63]. Enthalpy values in Table 1 were measured by Matsui et al. [61] or Akabori et al. [38]. Values reported by these research groups are similar, and are significantly lower than those reported by Ahn et al. $[32,33]$. The enthalpy measurements of Ahn et al. are not included in the table because they show significant variations between samples with the same nominal composition and different thermal histories, and also require relatively large corrections to compensate for oxidation during measurement.

Table 1 also lists tentative reactions for each range of temperatures and compositions based on the phase diagram of Sheldon and Peterson (Figure 1). Enthalpies of reactions involving $(\alpha-U)$ or $(\alpha-\mathrm{Zr})$ are related to the proportions of the phases in the alloys [38]. 
Table 1. Transformation temperatures and enthalpies of U-Zr alloys.

\begin{tabular}{ccccc}
$\mathrm{T}\left({ }^{\circ} \mathrm{C}\right)$ & at $\% \mathrm{Zr}$ & $\Delta \mathrm{H}(\mathrm{kJ} / \mathrm{mol})$ & $\begin{array}{c}\text { Probable reaction } \\
(\alpha-\mathrm{U})+\delta \leftrightarrow(\alpha-\mathrm{U})+\gamma\end{array}$ & $\begin{array}{c}\text { Reference } \\
{[38]}\end{array}$ \\
584 & 5 & 0.32 & & {$[38]$} \\
602 & 12 & 0.94 & & {$[61]$} \\
606 & 20 & 1.57 & & {$[38]$} \\
601 & 30 & 2.63 & & {$[38]$} \\
606 & 51 & 3.95 & & {$[38]$} \\
612 & 62 & 5.35 & & {$[38]$} \\
\hline 609 & 67 & 5.56 & $\delta \leftrightarrow \gamma$ & {$[38]$} \\
606 & 71 & 5.17 & & {$[38]$} \\
584 & 81 & 4.41 & & {$[38]$} \\
\hline 594 & 85 & 3.98 & $\delta+(\alpha-\mathrm{U})+\leftrightarrow \gamma+(\alpha-\mathrm{Zr})$ & {$[38]$} \\
598 & 90 & 2.51 & & {$[38]$} \\
597 & 95 & 1.04 & & {$[61]$} \\
\hline 684 & 20 & 1.43 & $\left(\alpha+\gamma_{2} \leftrightarrow \beta+\gamma_{2}\right)$ & {$[61]$} \\
\hline 698 & 20 & 0.19 & $\beta+\gamma_{2} \leftrightarrow \gamma_{1}+\gamma_{2}$ & {$[61]$}
\end{tabular}

\subsubsection{Phase Diagrams}

Important features of the U-Zr phase diagram have been known since the 1950s (e.g., [34, 40]). Chiotti [64] and Sheldon and Peterson [30] suggested phase diagrams based on a review of the available data. Okamoto modified the original Sheldon and Peterson phase diagram (Figure 1) by substituting the calculated liquidus and solidus from Leibowitz et al. [54] for the original experimentally determined curves to produce the 1990 "Sheldon and Peterson" phase diagram [31] The Sheldon and Peterson phase diagrams (both versions) were widely accepted for many years, although Akabori et al. [37] suggested small changes for alloys with $\sim 80-85 \mathrm{at} \% \mathrm{Zr}$. 


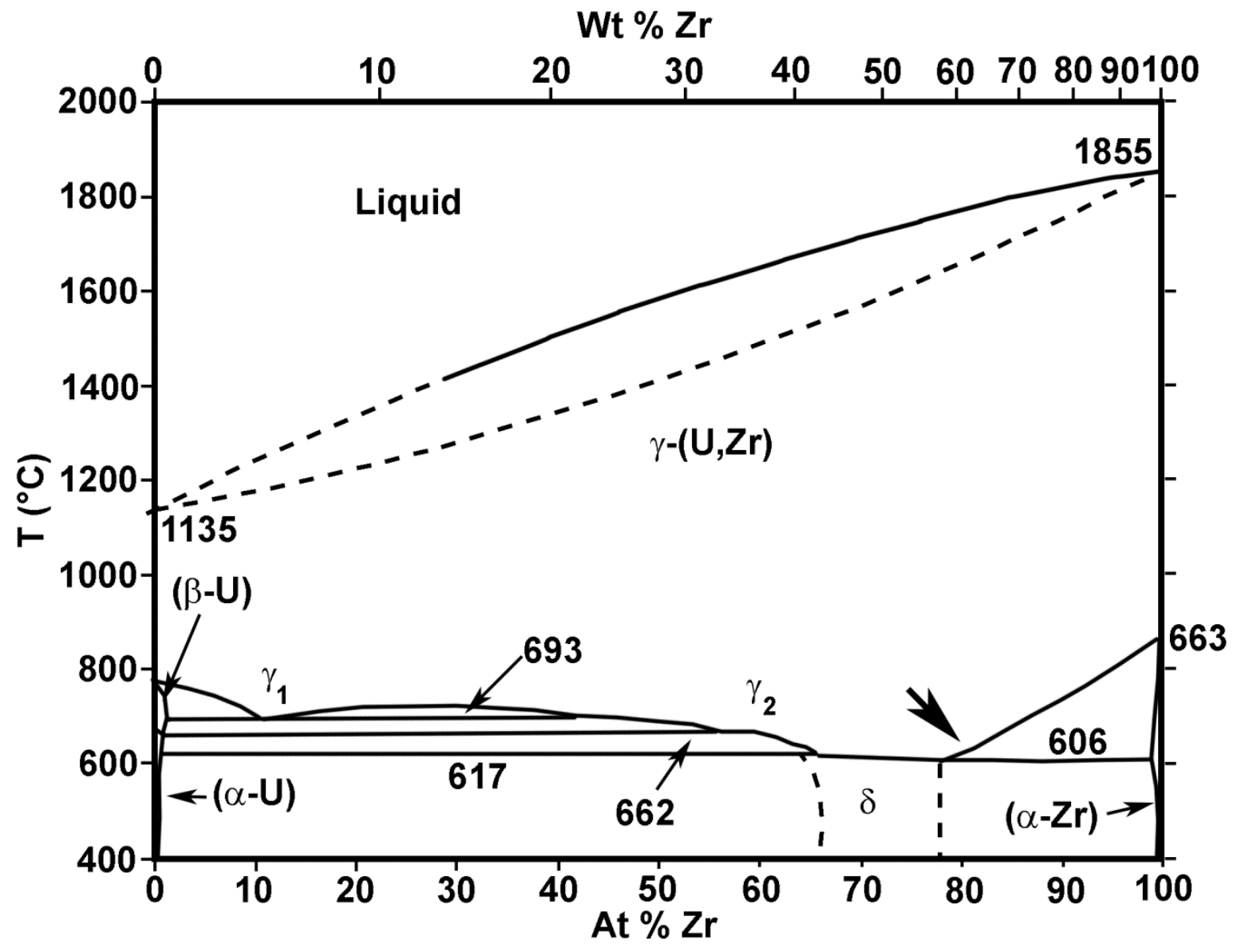

Figure 1. U-Zr phase diagram according to Sheldon and Peterson [30], with changes suggested by Akabori et al. 1992 [37] near large arrow.

Recently, however, Ahn and colleagues $[32,33]$ have suggested that the Sheldon and Peterson phase diagrams do not represent transitions in high-U compositions correctly, and that an earlier phase diagram proposed by Rough and Bauer $[34,36]$ may be more accurate. The primary difference between the two phase diagrams involves the nature of the phase transformation involving $\alpha-\mathrm{U}, \beta-\mathrm{U}$ and $\gamma-(\mathrm{U}, \mathrm{Zr})$ : in the Sheldon and Peterson phase diagrams (e.g., Figure 1), this reaction is $(\beta-U) \leftrightarrow(\alpha-U)+\gamma_{2}$ (eutectoid); in the Rough and Bauer phase diagrams (e.g., Figure 2), it is $(\beta-U)+\gamma_{1} \leftrightarrow(\alpha-U)$ (peritectoid). Although the transformation occurs only in alloys with less than $\sim 1 \mathrm{at} \% \mathrm{Zr}$, it has implications for phase relationships in all alloys with more than $\sim 40$ at $\%$ U. If the Sheldon and Peterson phase diagram is correct, there is a broad $(\beta-U)+\gamma_{2}$ field, and the transformation at $684^{\circ} \mathrm{C}$ corresponds to the $\left(\alpha+\gamma_{2} \leftrightarrow \beta+\gamma_{2}\right)$ reaction; if the Rough and Bauer phase diagram is correct, there is no $(\beta-\mathrm{U})+\gamma_{2}$ field and the transformation at $684^{\circ} \mathrm{C}$ corresponds to the $\left(\alpha+\gamma_{2} \leftrightarrow \alpha+\gamma_{1}\right)$ reaction. 


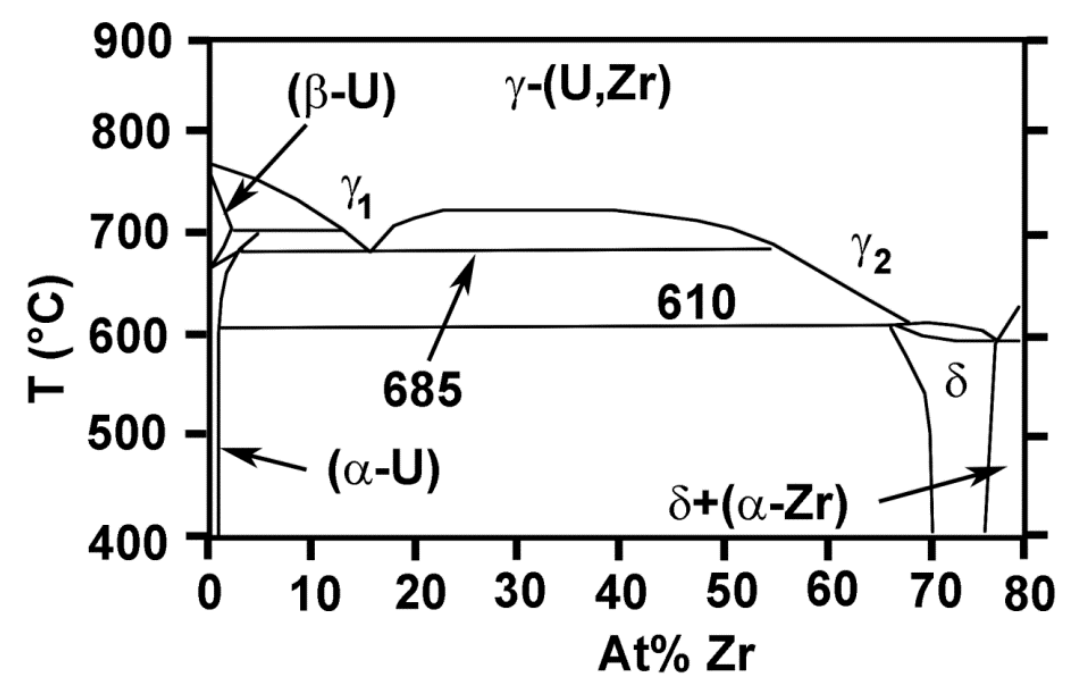

Figure 2. Partial U-Zr phase diagram based on Rough and Bauer [35].

Another consequence of the difference between phase diagrams is that alloys with $10-20 \mathrm{wt} \%(\sim 22-$ 40 at $\%$ ) $\mathrm{Zr}$ will undergo three phase transformations at temperatures below $\sim 700^{\circ} \mathrm{C}$ if the Sheldon and Peterson phase diagrams are correct, but only two if the Bauer and Rough phase diagram is correct [32, 33]. The experimental data are inconclusive. TGA traces from two of the three samples whose nominal compositions have $10 \mathrm{wt} \% \mathrm{Zr}$ measured by Ahn et al. [32] show two peaks, and one shows three. Measurements by Ahn et al. of an alloy with $20 \mathrm{wt} \% \mathrm{Zr}$ show only two peaks, but a measurement of an alloy with the same nominal composition by Matsui et al. [61] shows three. Takahashi et al. [63] found only two peaks at temperatures below $700^{\circ} \mathrm{C}$ in their work on an alloy with 35 at $\%(\sim 17 \mathrm{wt} \%) \mathrm{Zr}$. Kaity et al. [62] found three peaks below $700^{\circ} \mathrm{C}$ in a sample with $6 \mathrm{wt} \% \mathrm{Zr}$, but attributed one of them (at $\left.570^{\circ} \mathrm{C}\right)$ to a martensitic transformation in $(\alpha-\mathrm{U})$. Clearly, further work is required to understand this issue.

Solidus and liquidus temperatures in the original Sheldon and Peterson phase diagram [30]and the Rough and Bauer phase diagram [34, 36] are both based on experimental data from Summers-Smith [65]. More recent measurements $[53,62,66,67]$ suggest that these solidus and liquidus temperatures may be too high by a few tens of ${ }^{\circ} \mathrm{C}$ for intermediate compositions. Measurements by Kaity et al. [62] from an alloy with $6 \mathrm{wt} \% \mathrm{Zr}$ are consistent with the solidus temperature in the Sheldon and Peterson phase diagram but suggest that the liquidus temperature is too high by several tens of degrees.

\subsection{Pu-Zr Alloys}

\subsubsection{Introduction}

$\mathrm{Pu}-\mathrm{Zr}$ alloys have been investigated for almost 60 years, with much of the experimental data collected during the 1950s and 1960s. Key features of the Pu-Zr phase diagram include continuous solubility between the body-centered cubic phases $\beta-\mathrm{Zr}$ and $\varepsilon$-Pu, extensive solubility of $\mathrm{Zr}$ in $\delta$-Pu and limited solubility in $\alpha-\mathrm{Pu}, \beta-\mathrm{Pu}, \gamma-\mathrm{Pu}$, and $\delta^{\prime}-\mathrm{Pu}$, and the existence of $\theta-(\mathrm{Pu}-\mathrm{Zr})$ as an intermediate phase that is stable at room-temperature. The available experimental data were synthesized by Okamoto $[68,69]$ to produce a single phase diagram. However, many details of the phase diagram remain poorly known, particularly those involving temperatures below $\sim 400^{\circ} \mathrm{C}$ or concentrations of $\mathrm{Zr}$ below $\sim 30$ at $\%$ or above $\sim 65$ at $\%$. 
A calculated $\mathrm{Pu}-\mathrm{Zr}$ phase diagram by Kurata $[44,49]$ is in reasonable agreement with experimentally determined boundaries for the $\delta$ - $(\mathrm{Pu}-\mathrm{Zr})$ and $\alpha-\mathrm{Zr}$ phases at temperatures above $\sim 500^{\circ} \mathrm{C}$. This phase diagram does not include lower-temperature phases such as $\theta-(\mathrm{Pu}-\mathrm{Zr})$ because of a lack of thermodynamic data.

Work on Pu-Zr alloys is complicated by sluggish kinetics, high sensitivity to low concentrations of oxygen and other impurities (leading to the possible formation of oxygen-stabilized low-temperature phases), and the metallurgical complexity and unique characteristics of $\mathrm{Pu}$. As a result of these difficulties, the identities of some possible $\mathrm{Pu}-\mathrm{Zr}$ phases are controversial, and there is little published data on phase transformations.

\subsubsection{Phases and Phase Transformations}

The generally accepted $\mathrm{Pu}-\mathrm{Zr}$ phases are:

- $\quad(\alpha-\mathrm{Pu})$ :Allotropic modification of $\alpha-\mathrm{Pu}$ with a low solubility for $\mathrm{Zr}$ [69]

- $\quad(\beta-\mathrm{Pu})$ :Allotropic modification of $\beta$-Pu with a low solubility for $\mathrm{Zr}$ [69]

- $\quad(\delta-\mathrm{Pu}, \mathrm{Zr}$ ):Allotropic modification of $\delta$-Pu with an extensive solubility for $\mathrm{Zr}$. The crystal structure is body-centered cubic (space group $F m \overline{3} m$ ),$a=4.640 \AA$ for an alloy with 10 at\% $\operatorname{Zr}[70]$ and $4.572 \AA$ for an alloy with 55 at $\% \operatorname{Zr}[70])$

- $\quad\left(\delta^{\prime}-\mathrm{Pu}\right)$ :Allotropic modification of $\delta^{\prime}-\mathrm{Pu}$ with a low solubility for $\mathrm{Zr}$ [69]

- $\quad(\alpha-Z r)$ :Allotropic modification of $\alpha-Z r$ with a low solubility for Pu [69]

- $\quad \varepsilon-(\mathrm{Pu}, \mathrm{Zr})$ : Body-centered cubic (space group $\operatorname{Im} \overline{3} m)$ solid solution between $\varepsilon-\mathrm{Pu}$ and $\beta$-Zr. Lattice parameters increase with increasing concentration of $\mathrm{Zr}$ for alloys with less than $\sim 14 \mathrm{at} \% \mathrm{Zr}$, contrary to predictions from Vegard's law [71].

- $\quad \theta-\left(\mathrm{Pu}-\mathrm{Zr}\right.$ ), sometimes called $\mathrm{Pu}_{4} \mathrm{Zr}$ or $\mathrm{Pu}_{6} \mathrm{Zr}$ : Tetragonal (space group $P_{4} / n c c, a=10.89 \AA, c=14.89$ $\AA$ [72]) phase with $\sim 10-30 \mathrm{at} \% \mathrm{Zr}$.

Other Pu phases that have been suggested but do not appear in the phase diagram of Okamoto [69] include:

- $\quad \kappa-\mathrm{PuZr}_{2}$ : Hexagonal (space group $P_{6} / \mathrm{mmm}, a=5.055 \AA, c=3.123 \AA$ [70], contains $\sim 75$ at $\% \mathrm{Zr}$ ). This phase is isostructural with $\delta-\mathrm{UZr}_{2}$. Marples synthesized this phase from filings and reported that it was slow to form and decomposed peritectoidally to $\alpha-\mathrm{Zr}$ and $\delta-(\mathrm{Pu}, \mathrm{Zr})$ at $380^{\circ} \mathrm{C}[70]$. Although this phase appears in early phase diagrams $[70,73]$, later researchers have been unable to synthesize it, and have suggested that it is oxygen-stabilized [74-78].

- $\quad$ - $(\mathrm{Pu}, \mathrm{Zr}$ ) (structure unknown, contains $~ 19-24 \mathrm{at} \% \mathrm{Zr}$ ). The phase diagram of Ellinger and Land [78] shows that this phase decomposes congruently into $\delta-(\mathrm{Pu}, \mathrm{Zr})$ at $\sim 335^{\circ} \mathrm{C}$. There are apparently no other published reports of this phase.

- $\quad \zeta-\mathrm{Pu}_{28} \mathrm{Zr}$ (tetragonal, space group $I_{1} / a, a=18.1899 \AA, c=7.8576 \AA$ [79], contains $\sim 2.5-3 \mathrm{at} \% \mathrm{Zr}$ ). This phase was first reported by Ellinger and Land [78]. Taylor [80] observed it in samples that had been heat treated at $200^{\circ} \mathrm{C}$ for 6 weeks and determined that it decomposes peritectoidally to $\gamma$-Pu and $\delta$-Pu at $275^{\circ} \mathrm{C}$.

$\mathrm{Pu}-\mathrm{Zr}$ alloys commonly have $\mathrm{Pu}-$ bearing high-Zr inclusions in alloys that phase diagrams indicate have too little $\mathrm{Zr}$ to form $\alpha-\mathrm{Zr}$ or $\beta-\mathrm{Zr}$ (e.g., [81]). These inclusions are commonly referred to as "oxygen-stabilized $\alpha-Z r$." Little is known about them, and further research is needed to determine why they form and whether they are stable. 


\subsubsection{Phase Diagrams}

Early experimental Pu-Zr phase diagrams were proposed by Bochvar et al. [73] and Marples [70]. Later research led to the removal of $\kappa-\mathrm{PuZr}_{2}$ as a result of data suggesting that it was oxygen-stabilized. Maeda et al. [82] resolved discrepancies in solidus and liquidus temperatures. Suzuki et al. [76] explored compositions with 50-100 at\% Zr, and Taylor [80] explored high-Pu compositions. All of the experimental data were synthesized by Okamoto $[68,69]$ to produce a single phase diagram, which has been simplified in Figure 3. Despite numerous areas of uncertainty, this remains the best available phase diagram for the $\mathrm{Pu}-\mathrm{Zr}$ binary.

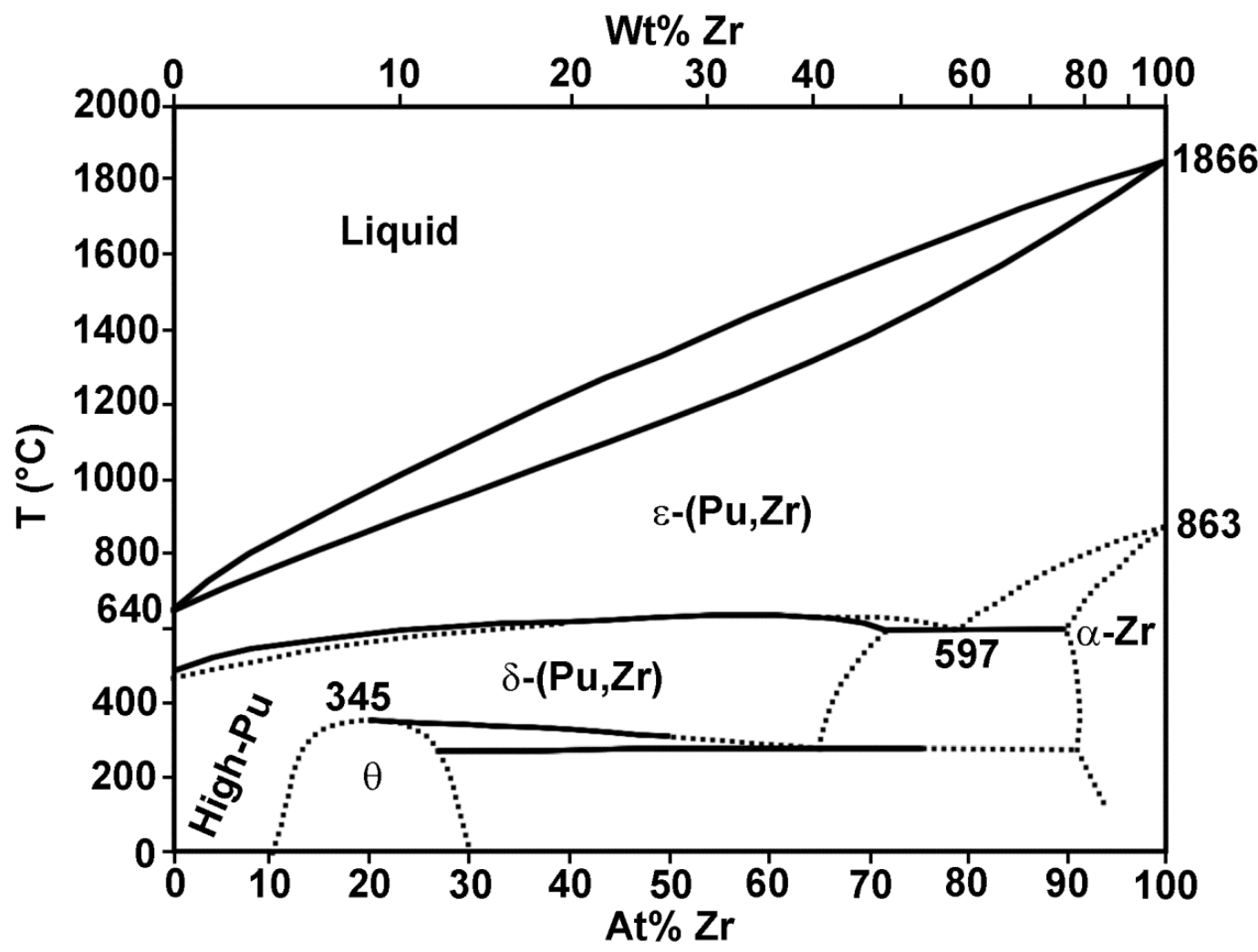

Figure 3. $\mathrm{Pu}-\mathrm{Zr}$ phase diagram simplified from Okamoto [69]. High-Pu phases (allotropes of $\alpha-\mathrm{Pu}, \beta-\mathrm{Pu}$, $\gamma-\mathrm{Pu}$, and $\left.\delta^{\prime}-\mathrm{Pu}\right)$ are not shown.

\subsection{U-Pu Alloys}

\subsubsection{Introduction}

The U-Pu system has the unusual feature that solidus and liquidus both have minima at the same intermediate composition and temperature $\left(\sim 12\right.$ at $\% \mathrm{U}$ and $\left.610^{\circ} \mathrm{C}\right)$ [83]. There are two intermediate U-Pu phases: $\zeta-(\mathrm{U}, \mathrm{Pu})$, which can have $\sim 25-72$ at $\% \mathrm{U}$ and is stable at room temperature, and $\eta-(\mathrm{Pu}-\mathrm{Zr})$, which can have between $\sim 3$ and 70 at $\% \mathrm{U}$ and is stable at temperatures between 278 and $705^{\circ} \mathrm{C}$. With the exception of a continuous solid solution between $\gamma-\mathrm{U}$ and $\varepsilon-\mathrm{Pu}$, no $\mathrm{Pu}$ phase can dissolve more than $\sim 2$ at $\% \mathrm{U}$, and no $\mathrm{U}$ phase can dissolve more than $\sim 20 \mathrm{at} \% \mathrm{Pu}$.

The 1989 U-Pu phase diagram proposed by Peterson and Foltyn [83] (Figure 4) is generally accepted, although more recent measurements suggest that the solidus may be slightly higher than shown by this phase diagram and the liquidus may be lower by at least $30^{\circ} \mathrm{C}$ for some compositions [84]. 
Kinetics of phase transformations are sluggish, and experimental results are likely to vary between samples with different thermal histories (e.g., [74, 85]).

Models of the U-Pu phase diagram based on thermodynamic properties include those of Leibowitz et al.[86], Ogawa [87], and Y. Okamoto et al. [84]. Kurata [44, 47, 49] developed an internally consistent database of thermodynamic properties and used the CALPHAD approach to calculate a phase diagram that agrees well with the experimental data. Landa and colleagues modeled U-Pu alloys using ab initio and density functional theory approaches [88-90].

\subsubsection{Phases and Phase Transformations}

The U-Pu phases include a continuous solid solution between $\gamma-\mathrm{U}$ and $\varepsilon-\mathrm{Pu}$, allotropic modifications of other $\mathrm{U}$ and $\mathrm{Pu}$ phases, and the intermediate phases $\zeta-(\mathrm{U}, \mathrm{Pu})$ and $\eta-(\mathrm{U}, \mathrm{Pu})$. With the exception of a continuous solid solution between $\gamma-\mathrm{U}$ and $\varepsilon$ - $\mathrm{Pu}$, no Pu phase can dissolve more than $\sim 2$ at $\% \mathrm{U}$, and no $\mathrm{U}$ phase can dissolve more than $\sim 20$ at $\% \mathrm{Pu}$. Therefore, it seems reasonable to use crystallographic data for $\mathrm{U}$ and $\mathrm{Pu}$ (Sections 3.1 and 3.2 of this document) for allotropic modifications of $\mathrm{U}$ and Pu phases unless other information is given below.

The U-Pu phases are:

- $\quad(\alpha-\mathrm{Pu})$ : Allotropic modification of $\alpha-\mathrm{Pu}$. Peterson and Foltyn report a maximum solubility of $\sim 0.2$ at $\% \mathrm{U}$ [83]; however, Kittel et al. [91] report that incorporation of 2 at $\% \mathrm{U}$ shrinks the lattice parameters by $\sim 0.1$ to $0.3 \%$ without significantly changing the lattice angle $\beta$.

- $\quad(\beta-\mathrm{Pu})$ : Allotropic modification of $\beta-\mathrm{Pu}$ with a maximum solubility of $2 \mathrm{at} \% \mathrm{U}$ [83]

- $\quad(\gamma-\mathrm{Pu})$ : Allotropic modification of $\gamma-\mathrm{Pu}$ with a maximum solubility of 0.7 at $\% \mathrm{U}$ [83]

- $\quad(\delta-\mathrm{Pu}):$ Allotropic modification of $\delta$-Pu with a maximum solubility of 0.3 at $\% \mathrm{U}$ [83]

- $\quad\left(\delta^{\prime}-\mathrm{Pu}\right)$ : Allotropic modification of $\delta^{\prime}-\mathrm{Pu}$ with a maximum solubility of 1.5 at\% $\mathrm{U}$ [83]

- $\quad(\alpha-U)$ : Allotropic modification of $\alpha-\mathrm{U}$ with a maximum solubility of 15 at $\% \mathrm{Pu}$ [74, 83, 92]. Incorporation of $\mathrm{Pu}$ increases $a$ and $c$ lattice parameters and decreases $b$. Room-temperature lattice parameters of an alloy with $15 \mathrm{wt} \%$ Pu are $a=2.8625 \AA, b=5.8562 \AA$, and $c=4.9631 \AA$ [92].

- $\quad(\beta-\mathrm{U})$ : Allotropic modification of $\beta-\mathrm{U}$ with a maximum solubility of 20 at $\% \mathrm{Pu}$ [83]

- $\quad \gamma-(\mathrm{U}, \mathrm{Pu})$ : A continuous solid solution between $\gamma-\mathrm{U}$ and $\varepsilon-\mathrm{Pu}$, with a body-centered cubic structure [83]

- $\quad \zeta-(\mathrm{U}, \mathrm{Pu})$ : This phase has $25-74$ at $\% \mathrm{U}$ and is stable at room temperature [83]. Although some early structure determinations indicated that it might be cubic, neutron diffraction data indicate that it has a large rhombohedral unit cell with a lattice angle close to 90 degrees (space group $R-3 m, a=10.6583$ $\AA, \alpha=89.736^{\circ}$ at $29^{\circ} \mathrm{C}$ for a sample with $60 \mathrm{at} \% \mathrm{Pu}$ ) [93].

- $\quad \eta-(\mathrm{U}, \mathrm{Pu})$, a high-temperature phase with 4 to $70 \mathrm{at} \% \mathrm{U}$ [83]. The crystal structure of this phase has not been determined, although Ellinger et al. [85] suggested that it might be tetragonal with $a=10.57$ and $c=10.76 \AA$ for a sample with 25 at $\% \mathrm{U}$ that had been quenched from $500^{\circ} \mathrm{C}$.

The only published measurements of phase-transition temperatures are based on isothermal drop-calorimetry data from a U-10 $\mathrm{wt} \%(10 \mathrm{at} \%)$ alloy [94]. The original reference does not explicitly tabulate phase-transformation temperatures; however, they can be inferred from polynomial representations of the data by other authors $[64,83]$. These temperatures are:

- $\quad(\alpha-U)$ to $(\beta-U): 865-875 \mathrm{~K}$ 
- $\quad(\beta-\mathrm{U})$ to $(\gamma-\mathrm{U}): 1000-1020 \mathrm{~K}$

- $\quad(\gamma-\mathrm{U})$ to liquid: $1310-1365 \mathrm{~K}$.

Direct measurements of phase-transition enthalpies are lacking. However, differences between incremental enthalpies for a sample with $10 \mathrm{wt} \%(\sim 10 \mathrm{at} \%) \mathrm{Pu}$ and those for pure $\mathrm{U}$ are negligible [64], suggesting that phase-transition enthalpies for this alloy are similar to those for pure $U$.

Savage [94] reported that the heat of fusion of a U-10Pu alloy is $2.4 \mathrm{kcal} / \mathrm{g}$-atom $(\sim 10 \mathrm{~kJ} / \mathrm{mol})$ (as compared to his measurement of $2.9 \mathrm{kcal} / \mathrm{g}$-atom $(\sim 12.1 \mathrm{~kJ} / \mathrm{mol})$ for pure $\mathrm{U})$. This value for the heat of fusion of pure $U$ is at the maximum of the range of experimental values (Section 3.6.2), and it seems likely that the heat of fusion of $\mathrm{U}-10 \mathrm{Pu}$ in the same publication is also high. However, in the absence of new experimental data, it seems reasonable to assume that the difference between the heats of fusion of $U$ and $\mathrm{U}-10 \mathrm{Pu}$ (a decrease of $\sim 2 \mathrm{~kJ} / \mathrm{mol}$ ) is accurate.

\subsubsection{Phase Diagrams}

Numerous researchers have investigated the U-Pu phase diagram, beginning in the 1950s (e.g., [84, 85, 94-96]. In 1989, Peterson and Foltyn [83] combined an experimental phase diagram proposed by Ellinger et al. [85] with other data to produce a phase diagram that is still widely accepted (Figure 4). More recent measurements by Y. Okamoto et al. [84] are consistent with sub-solidus phase-transition temperatures in the Peterson and Foltyn phase diagram, but suggest that the solidus may be slightly higher and the liquidus may be lower by $\sim 30^{\circ} \mathrm{C}$ or more. It has been suggested that Peterson and Foltyn phase diagram should be modified as a result of these measurements [84,97]; however, recent reviews and experimental publications (e.g., $[12,49,95])$ continue to use the phase diagram of Peterson and Foltyn.

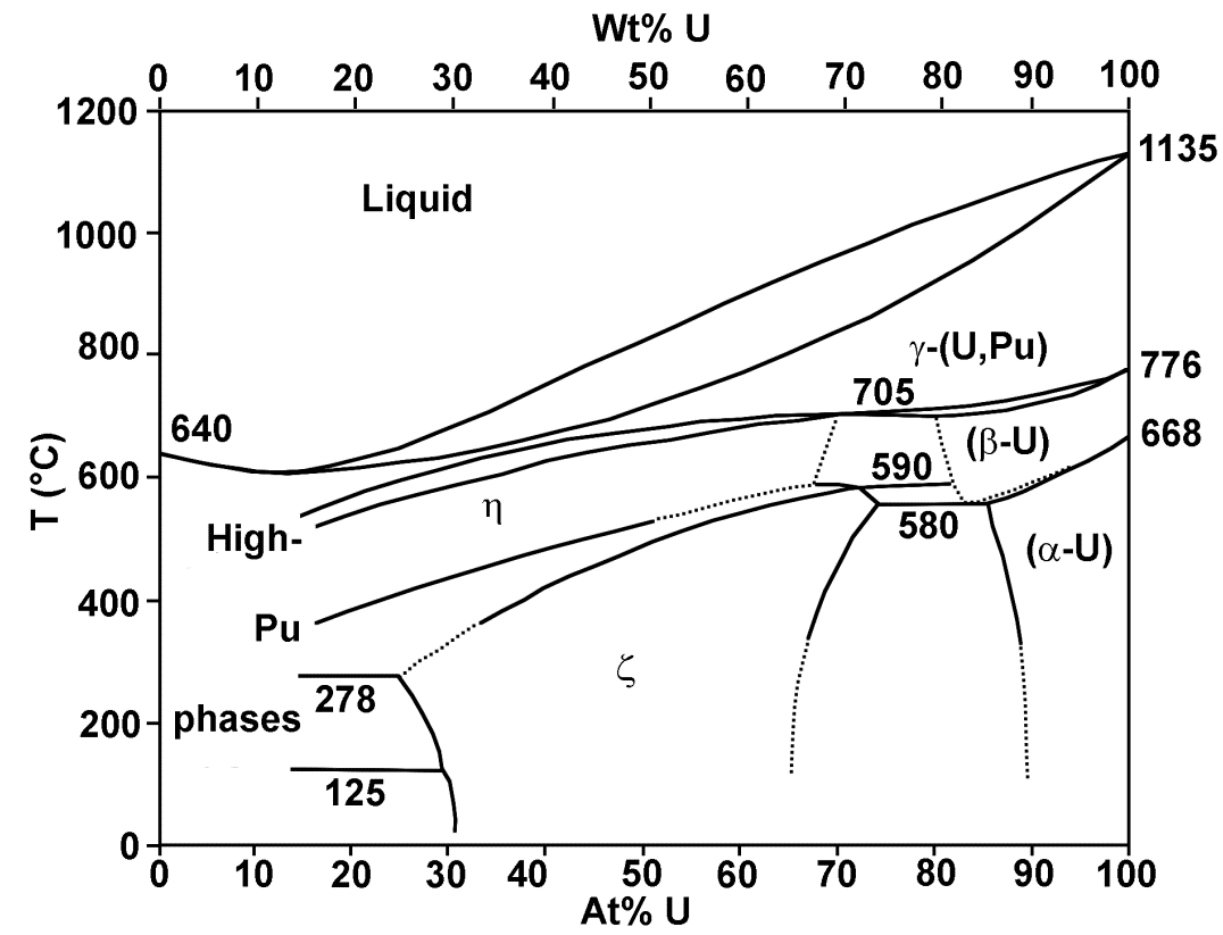

Figure 4. U-Pu phase diagram simplified from Peterson and Foltyn [83]. High-Pu phases (allotropes of $\alpha-\mathrm{Pu}, \beta-\mathrm{Pu}, \gamma-\mathrm{Pu}, \delta-\mathrm{Pu}$, and $\left.\delta^{\prime}-\mathrm{Pu}\right)$ are not shown for simplicity, but have at most a few at $\% \mathrm{U}$. 


\subsection{U-Pu-Zr alloys}

\subsubsection{Introduction}

Although U-Pu-Zr alloys have been investigated for more than 50 years, the only experimentally determined ternary phase diagram was published by O'Boyle and Dwight in 1970 [98]. This phase diagram is represented by a series of isothermal sections at temperatures between 500 and $700^{\circ} \mathrm{C}$ and a table of possible phase-transformation reactions.

There is general agreement that all of the phases in the U-Pu-Zr system at temperatures above $\sim 500^{\circ} \mathrm{C}$ are allotropic modifications of phases in the $\mathrm{U}-\mathrm{Pu}, \mathrm{U}-\mathrm{Zr}$, and $\mathrm{Pu}-\mathrm{Zr}$ systems. The first phase to crystallize for all $\mathrm{U}-\mathrm{Pu}-\mathrm{Zr}$ ternary compositions is a body-centered cubic solid solution between $\gamma-\mathrm{U}, \varepsilon-\mathrm{Pu}$, and $\beta-\mathrm{Zr}$, which transforms to a number of lower-temperature phases by solid-state reactions. These reactions are characteristically slow, and annealing times of 25 days at $700^{\circ} \mathrm{C}$ and five months at $590^{\circ} \mathrm{C}$ were required to obtain grains large enough for microprobe analyses [98]. Thus, it is likely that characterization results are influenced by thermal histories of the specific samples analyzed.

All of the experimental measurements of liquidus and solidus temperatures are from samples with high concentrations of $\mathrm{U}$ or $\mathrm{Pu}$. Three approaches to estimating solidus and liquidus temperatures for other compositions have been suggested [4, 44, 49, 53, 58]. Although the three approaches produce results that differ by $\sim 100^{\circ} \mathrm{C}$ for some compositions, currently available data are not adequate to determine which model is best.

Data on phase-transformation enthalpies are generally lacking. However, researchers at Idaho National Laboratory (INL) recently obtained data for six U-Pu-Zr alloys.

Other recent research has emphasized modeling. Landa and colleagues developed density functional theory models for the U-Pu-Zr system [99], Wenzhong and Unal [100] addressed ways to incorporate $\mathrm{U}-\mathrm{Pu}-\mathrm{Zr}$ phase diagrams into the Moose-Bison fuel performance code, and Kurata [44, 47] compiled a thermodynamic database and used it to calculate isothermal diagrams that are in reasonably good agreement with the isothermal sections of O'Boyle and Dwight.

\subsubsection{Phases and Phase Transformations}

$\mathrm{U}-\mathrm{Pu}-\mathrm{Zr}$ alloys have been investigated extensively. At least 50 measurements of sub-solidus phase transformation temperatures $[75,96,101-103]$ and 75 determinations of phases in annealed samples [98, 104-106] have been previously reported, although much of the data is described as "preliminary."

All of the known phases in the U-Pu-Zr ternary system are allotropic modifications of phases in the $\mathrm{U}-\mathrm{Pu}, \mathrm{U}-\mathrm{Zr}$, or Pu-Zr system. These phases include:

- $\quad(\alpha-\mathrm{U})$ : Allotropic modification of $\alpha$-U that can incorporate up to $\sim 15$ at $\% \mathrm{Pu}$ and $0.5 \mathrm{at} \% \mathrm{Zr}$ ([98] and sections 3.4 and 3.6 of this handbook).

- $\quad(\beta-\mathrm{U})$ : Allotropic modification of $\beta$-U that can incorporate up to $\sim 20$ at $\% \mathrm{Pu}$ and $1.1 \mathrm{at} \% \mathrm{Zr}$ (reference [98] and sections 3.4 and 3.6 of this handbook).

- $(\alpha-Z r)$ : Allotropic modification of $\alpha-Z r$ that can incorporate up to $1 \mathrm{at} \% \mathrm{U}$ and also has a low solubility for $\mathrm{Pu}$ (sections 3.4 and 3.5 of this handbook).

- $\quad(\eta)$ : Modification of $\eta-(\mathrm{U}, \mathrm{Pu})$, with a limited solubility for $\mathrm{Zr}$ [98].

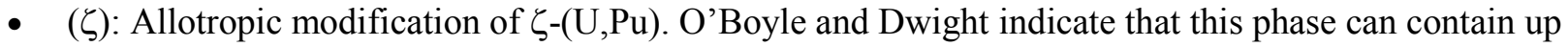
to $\sim 5$ at $\% \mathrm{Zr}$, and that the solubility of $\mathrm{Zr}$ decreases at lower temperatures. In contrast, researchers from Mound Laboratory [75, 107] found that this phase can contain up to 9 at $\% \mathrm{Zr}$ at $675^{\circ} \mathrm{C}$, and that the solubility of $\mathrm{Zr}$ increases at lower temperatures to a maximum of $\sim 20$ at $\%$ at $640^{\circ} \mathrm{C}$. The unit cell size increases by $\sim 0.02 \%$ as a result of the incorporation of $\mathrm{Zr}$ [98]. 
- $\left(\delta-\mathrm{UZr}_{2}\right)$ : Allotropic modification of $\delta-\mathrm{UZr}_{2}$ with extensive solubility for Pu. O'Boyle and Dwight [98] suggest a possible continuous solid solution with $\kappa-\mathrm{PuZr}_{2}$; however, $\kappa-\mathrm{PuZr}_{2}$ does not appear in recent $\mathrm{Pu}-\mathrm{Zr}$ phase diagrams because of research suggesting that it is oxygen-stabilized. O'Boyle and Dwight [98] report that the lattice parameter of $\delta-\mathrm{UZr}_{2}$ increases with Pu concentrations in alloys with 0,10 , or 20 at $\% \mathrm{Pu}$.

- $\quad(\delta-\mathrm{Pu})$ :Allotropic modification of $\delta$-Pu, which has extensive solubility with $\mathrm{Zr}$ but can dissolve at most $\sim 0.3$ at $\%$ U (sections 3.5 and 3.6 of this handbook).

- $\quad(\alpha-\mathrm{Pu}),(\beta-\mathrm{Pu}),(\gamma-\mathrm{Pu})$, and $\left(\delta^{\prime}-\mathrm{Pu}\right)$ : Allotropic modifications of $\mathrm{Pu}$ phases with low solubilities for both $\mathrm{U}$ and $\mathrm{Zr}$.

- $\quad\left(\zeta-\mathrm{Pu}_{28} \mathrm{Zr}\right)$ and $(\theta)$ : Allotropic modifications of $\zeta-\mathrm{Pu}_{28} \mathrm{Zr}$ and $\theta-(\mathrm{Pu}, \mathrm{Zr})$. These phases are poorly known even in binary alloys, where they occur only at temperatures below the isothermal sections of O’Boyle and Dwight [98].

- $(\gamma)$ : A body-centered cubic solid solution between $\gamma-\mathrm{U}, \beta-\mathrm{Zr}$, and $\varepsilon-\mathrm{Pu}$, commonly referred to as $(\gamma-\mathrm{U})$.

$\mathrm{U}-\mathrm{Pu}-\mathrm{Zr}$ alloys commonly have high-Zr inclusions that contain up to $4.0 \mathrm{wt} \% \mathrm{U}$ and $2.5 \mathrm{wt} \% \mathrm{Pu}$ in alloys that phase diagrams indicate have too little $Z r$ to form $\alpha-Z r$ or $\beta-Z r$ (e.g., $[53,98,108-110]$ ). These inclusions are commonly referred to as "oxygen-stabilized $\alpha$-Zr." Little is known about them, and further research is needed to determine why they form and whether they are stable.

Researchers at INL recently measured phase-transition temperatures and enthalpies for six U-Pu-Zr alloys (Figure 5, Figure 6) by DSC (Table 2). Many of the peaks were broad or asymmetrical, suggesting that individual peaks in the DSC data probably represent multiple phase transformations occurring at similar temperatures. Peak shapes and phase-transformation temperatures in the INL data are comparable to previously published data from samples with similar compositions [75, 96, 101-103].

The INL data were collected in an air-atmosphere glovebox. Despite a flowing cover gas with oxygen concentration below the parts per billion range, the samples developed visible oxide layers during data collection.

Because of peak overlaps in the DSC curves, it was not possible to separate peaks from individual transformations. However, total enthalpies were calculated from the areas under all of the peaks corresponding to temperatures between 400 and $800^{\circ} \mathrm{C}$ (Table 3). There are no previously published quantitative enthalpy values to which the INL data can be compared. 


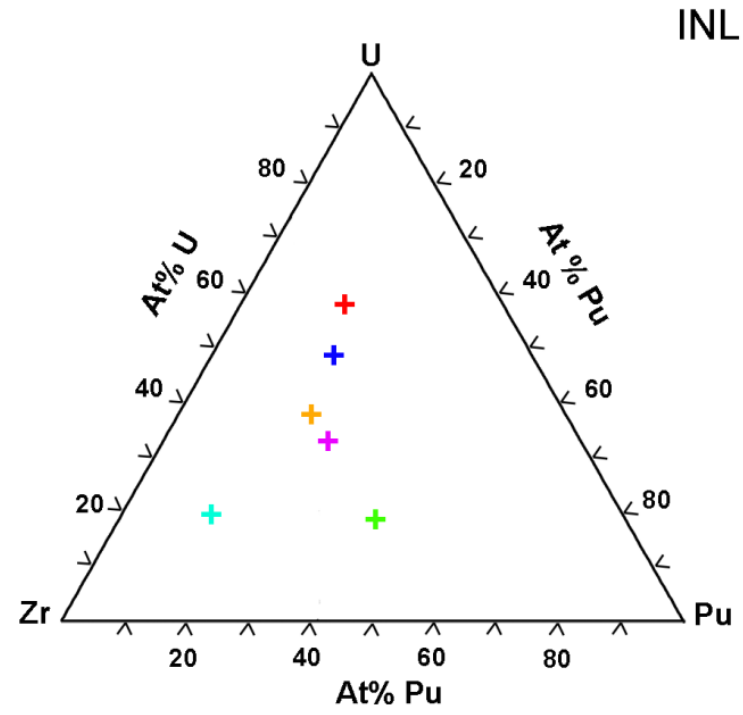

NL sample compositions, at \%

$+\mathrm{U}-17 \mathrm{Pu}-23 \mathrm{Zr}$

$+\mathrm{U}-27 \mathrm{Pu}-40 \mathrm{Zr}$

$+\mathrm{U}-19 \mathrm{Pu}-32 \mathrm{Zr}$

$+\mathrm{U}-12 \mathrm{Pu}-68 \mathrm{Zr}$

$+\mathrm{U}-41 \mathrm{Pu}-40 \mathrm{Zr}$

$+\mathrm{U}-22 \mathrm{Pu}-40 \mathrm{Zr}$

Figure 5. Compositions (in at $\%$ ) of alloys whose phase-transition temperatures and enthalpies were recently measured at INL

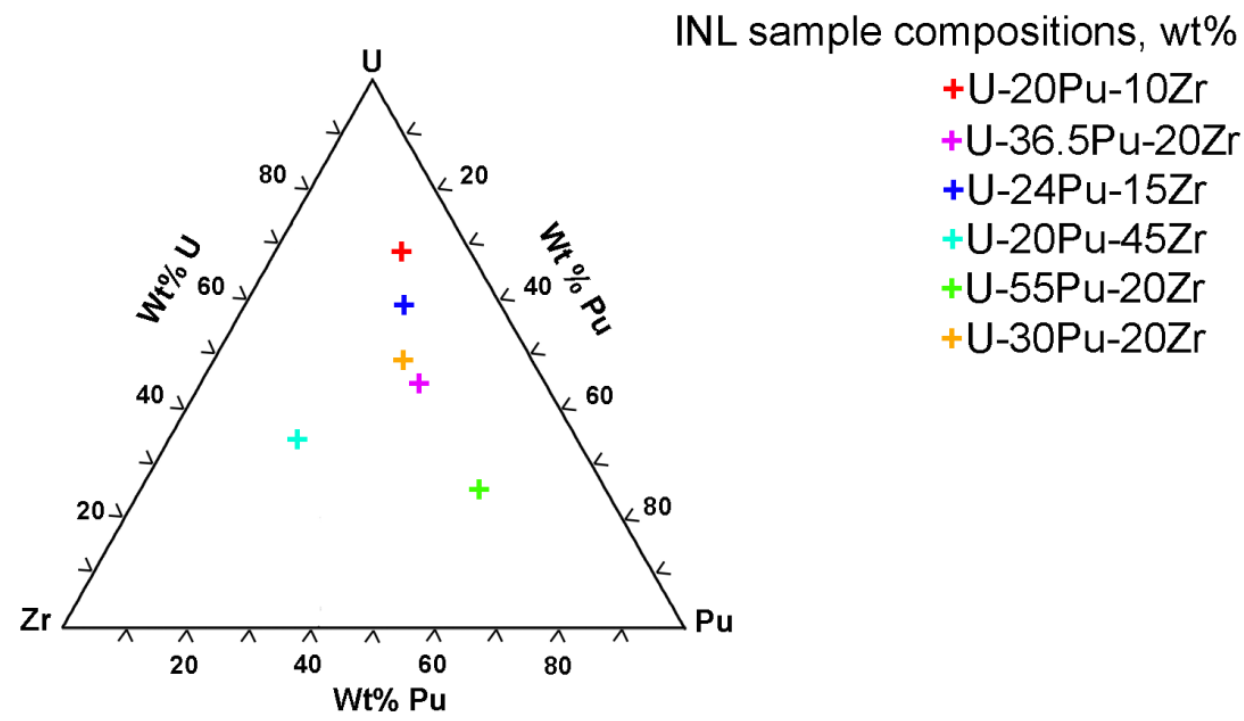

Figure 6. Compositions (in wt $\%$ ) of alloys whose phase-transition temperatures and enthalpies were recently measured at INL 
Table 2. Onset temperatures for peaks at temperatures above $400^{\circ} \mathrm{C}$ in recent INL data, measured during heating

\begin{tabular}{cccc}
\hline $\begin{array}{c}\text { Composition } \\
(\mathrm{wt} \%)\end{array}$ & $\begin{array}{c}\text { Composition } \\
(\mathrm{at} \%)\end{array}$ & $\begin{array}{c}\text { First } \\
\text { transition } \\
\left({ }^{\circ} \mathrm{C}\right)\end{array}$ & $\begin{array}{c}\text { Second } \\
\text { transition } \\
\left({ }^{\circ} \mathrm{C}\right)\end{array}$ \\
\hline $\mathrm{U}-55 \mathrm{Pu}-20 \mathrm{Zr}$ & $\mathrm{U}-41 \mathrm{Pu}-40 \mathrm{Zr}$ & 502 & 518 \\
$\mathrm{U}-20 \mathrm{Pu}-45 \mathrm{Zr}$ & $\mathrm{U}-12 \mathrm{Pu}-68 \mathrm{Zr}$ & 591 & \\
$\mathrm{U}-36.5 \mathrm{Pu}-20 \mathrm{Zr}$ & $\mathrm{U}-27 \mathrm{Pu}-40 \mathrm{Zr}$ & 551 & 570 \\
$\mathrm{U}-30 \mathrm{Pu}-20 \mathrm{Zr}$ & $\mathrm{U}-22 \mathrm{Pu}-40 \mathrm{Zr}$ & 570 & 598 \\
$\mathrm{U}-24 \mathrm{Pu}-15 \mathrm{Zr}$ & $\mathrm{U}-19 \mathrm{Pu}-32 \mathrm{Zr}$ & 574 & 637 \\
$\mathrm{U}-20 \mathrm{Pu}-10 \mathrm{Zr}$ & $\mathrm{U}-17 \mathrm{Pu}-23 \mathrm{Zr}$ & 580 & 654 \\
\hline
\end{tabular}

Table 3. Combined enthalpies for all transformations at temperatures between 400 and $800^{\circ} \mathrm{C}$ corresponding to data summarized in Table 2

\begin{tabular}{ccc}
\hline $\begin{array}{c}\text { Composition } \\
(\mathrm{wt} \%)\end{array}$ & $\begin{array}{c}\text { Composition } \\
(\text { at } \%)\end{array}$ & $\Delta \mathrm{H}_{\mathrm{Tr}}(\mathrm{J} / \mathrm{g})$ \\
\hline $\mathrm{U}-55 \mathrm{Pu}-20 \mathrm{Zr}$ & $\mathrm{U}-41 \mathrm{Pu}-40 \mathrm{Zr}$ & $35.75 \pm 0.57$ \\
$\mathrm{U}-20 \mathrm{Pu}-45 \mathrm{Zr}$ & $\mathrm{U}-12 \mathrm{Pu}-68 \mathrm{Zr}$ & $32.37 \pm 0.07$ \\
$\mathrm{U}-36.5 \mathrm{Pu}-20 \mathrm{Zr}$ & $\mathrm{U}-27 \mathrm{Pu}-40 \mathrm{Zr}$ & $27.76 \pm 0.1$ \\
$\mathrm{U}-30 \mathrm{Pu}-20 \mathrm{Zr}$ & $\mathrm{U}-22 \mathrm{Pu}-40 \mathrm{Zr}$ & $32.28 \pm 0.71$ \\
$\mathrm{U}-24 \mathrm{Pu}-15 \mathrm{Zr}$ & $\mathrm{U}-19 \mathrm{Pu}-32 \mathrm{Zr}$ & $29.07 \pm 0.36$ \\
$\mathrm{U}-20 \mathrm{Pu}-10 \mathrm{Zr}$ & $\mathrm{U}-17 \mathrm{Pu}-23 \mathrm{Zr}$ & $30.54 \pm 0.3$ \\
\hline
\end{tabular}

\subsubsection{Phase Diagrams}

\subsubsection{Liquidus and Solidus}

Several research groups have measured the solidus and liquidus temperatures of U-Pu-Zr alloys, as summarized in Figure 7 and Figure 8. A cursory examination shows that drawing smooth temperature contours requires either assuming very large error bars for individual measurements or discounting some of the data. Leibowitz et al. [53] suggested that data from reference [96] (which includes all of the high-Pu data) should be discounted because its liquidus temperature for a $\mathrm{Pu}-15 \mathrm{at} \% \mathrm{Zr}$ alloy is $\sim 200^{\circ} \mathrm{C}$ higher than the values accepted by other researchers (e.g., $[69,80])$. However, determining the liquidus temperature for this alloy from reference [96] requires extrapolating temperatures beyond the isothermal contours suggested by the authors. Solidus temperatures for $\mathrm{Pu}-\mathrm{Zr}$ alloys and both solidus and liquidus temperatures for U-Pu alloys in reference [96] are within $\sim 30^{\circ} \mathrm{C}$ of those accepted by other researchers $[69,80,111]$. Given the relatively poor knowledge of all of the systems involved, it seems reasonable to accept the data from ternary U-Pu-Zr alloys in reference [96] pending further investigation. However, it must be remembered that measured liquidus temperatures from reference [96] may be anomalously high. 


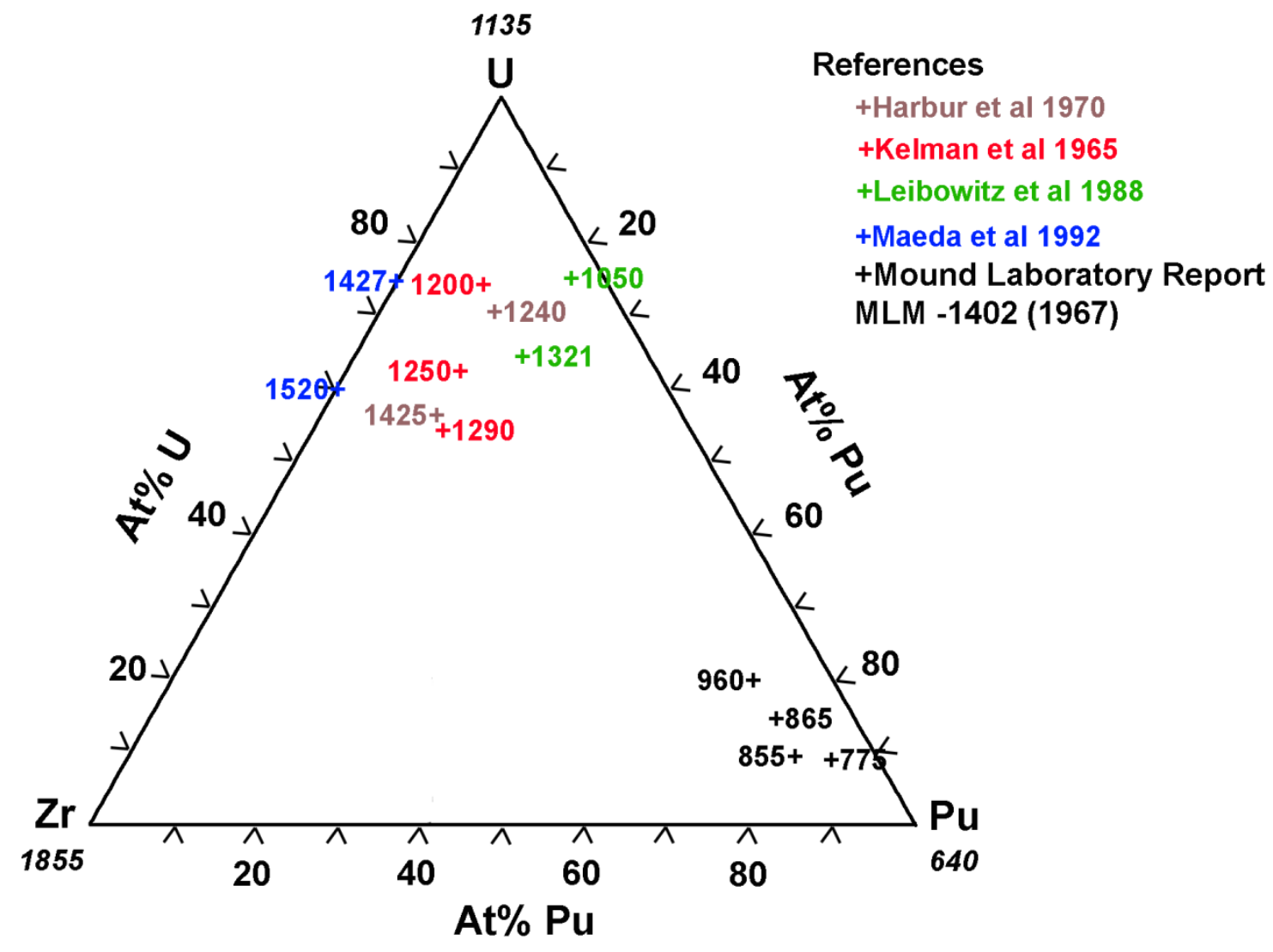

Figure 7. Experimentally determined liquidus temperatures in ${ }^{\circ} \mathrm{C}$, with melting temperatures of $\mathrm{U}, \mathrm{Pu}$, and $\mathrm{Zr}$ for comparison $[53,67,96,101,112]$. 


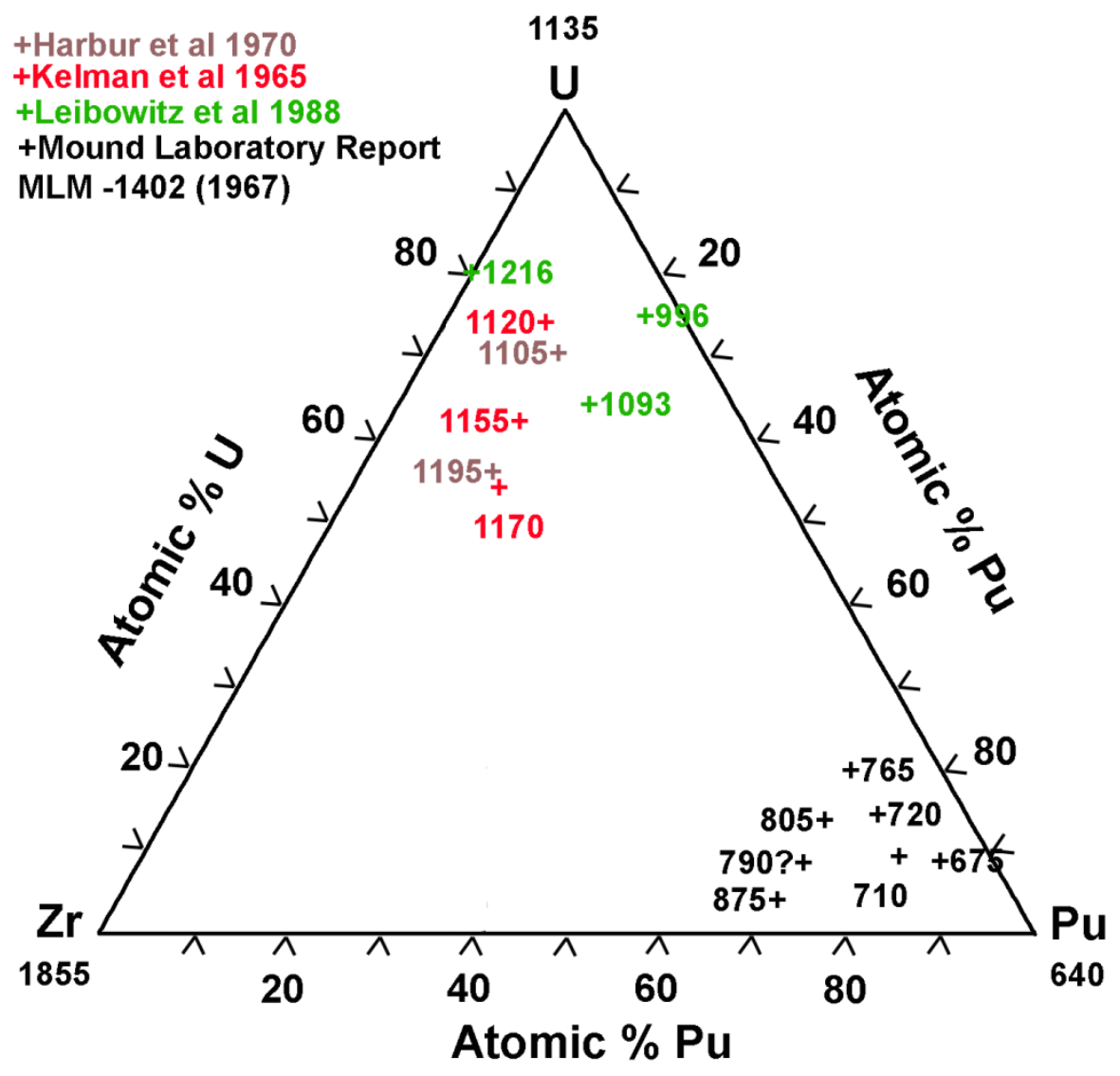

Figure 8. Experimentally determined solidus temperatures in ${ }^{\circ} \mathrm{C}$, with melting temperatures of $\mathrm{U}, \mathrm{Pu}$, and $\mathrm{Zr}$ for comparison $[53,96,101,112]$.

Based on these measurements, Leibowitz et al. [53] developed thermodynamic models for the liquidus and solidus. Later analyses by Kurata [47] made it possible to for Ogata $[4,58]$ to derive empirical expressions for liquidus and solidus temperatures for compositions with less than $80 \mathrm{at} \% \mathrm{Zr}$ and more $\mathrm{U}$ than $\mathrm{Pu}$. These expressions match experimental data on the $\mathrm{U}-\mathrm{Zr}$ and $\mathrm{U}-\mathrm{Pu}-\mathrm{Zr}$ systems [53, 67, $101,112]$ to within $60^{\circ} \mathrm{C}$ for the solidus and $130^{\circ} \mathrm{C}$ for the liquidus. Somewhat later, Kurata $[44,49]$ calculated liquid and solidus temperatures using CALPHAD, and obtained agreement with the data in references [101] and [53] to within $\pm 20^{\circ} \mathrm{C}$.

Figure 9, Figure 10, Table 4, and Table 5 compare liquidus and solidus temperatures calculated using the three models. (Data from the Ogata model are selected points calculated after algebraic manipulation to obtain a quadratic equation for the concentration of $\mathrm{Pu}$ corresponding to a given temperature and concentration of $\mathrm{Zr}$.) Solidus and liquidus temperatures from the three models generally agree with each other better than they do with the data for compositions with more than $\sim 50$ at $\% \mathrm{U}$, but commonly differ by several tens of degrees. 


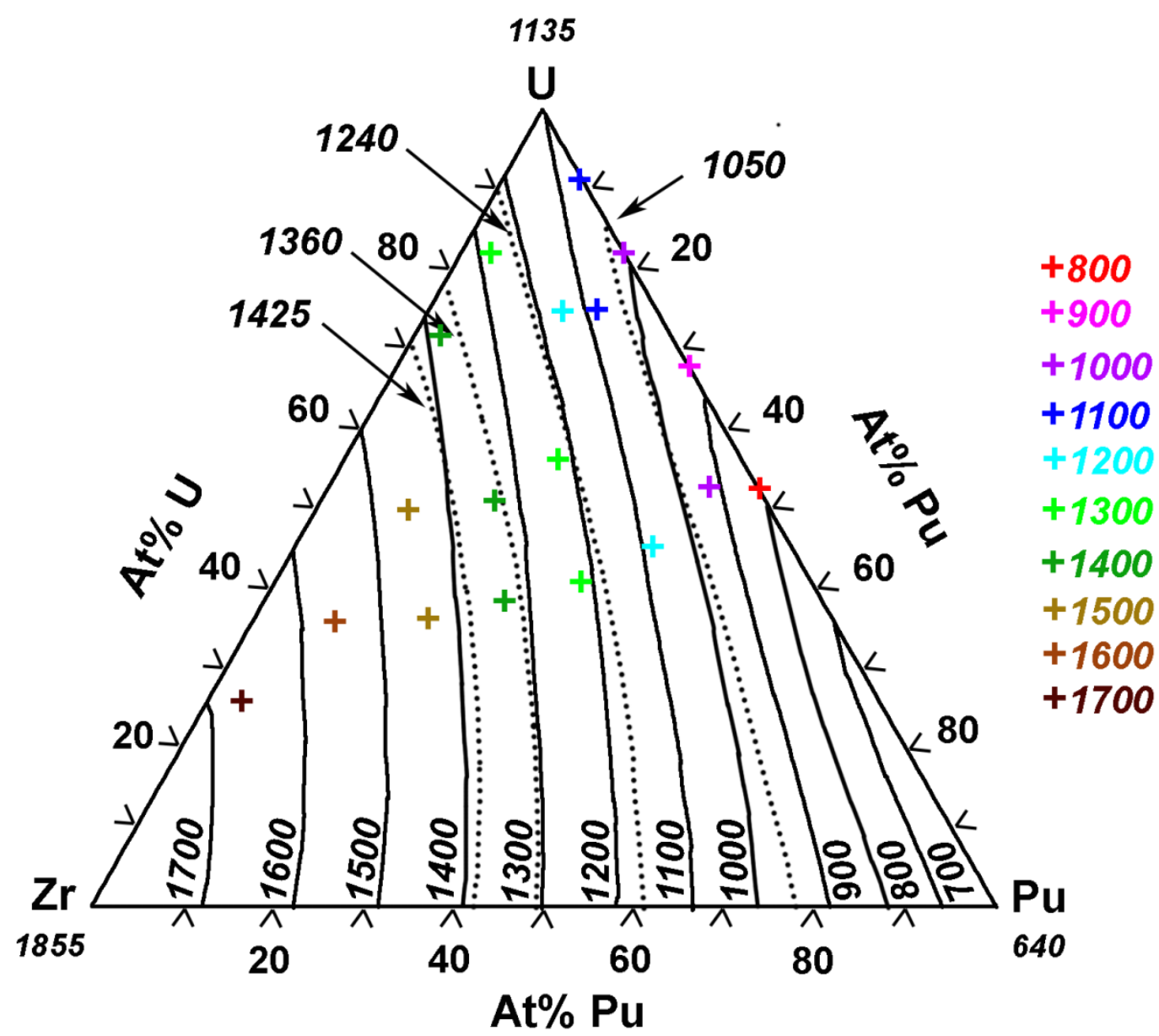

Figure 9. Liquidus temperatures $\left({ }^{\circ} \mathrm{C}\right)$ from models of Leibowitz et al. [53] (solid lines), Kurata [49] (dotted lines), and Ogata [4] (colored symbols showing examples of calculated points, with each color indicating a different temperature). Melting temperatures of $\mathrm{U}, \mathrm{Pu}$, and $\mathrm{Zr}$ are shown for comparison. 


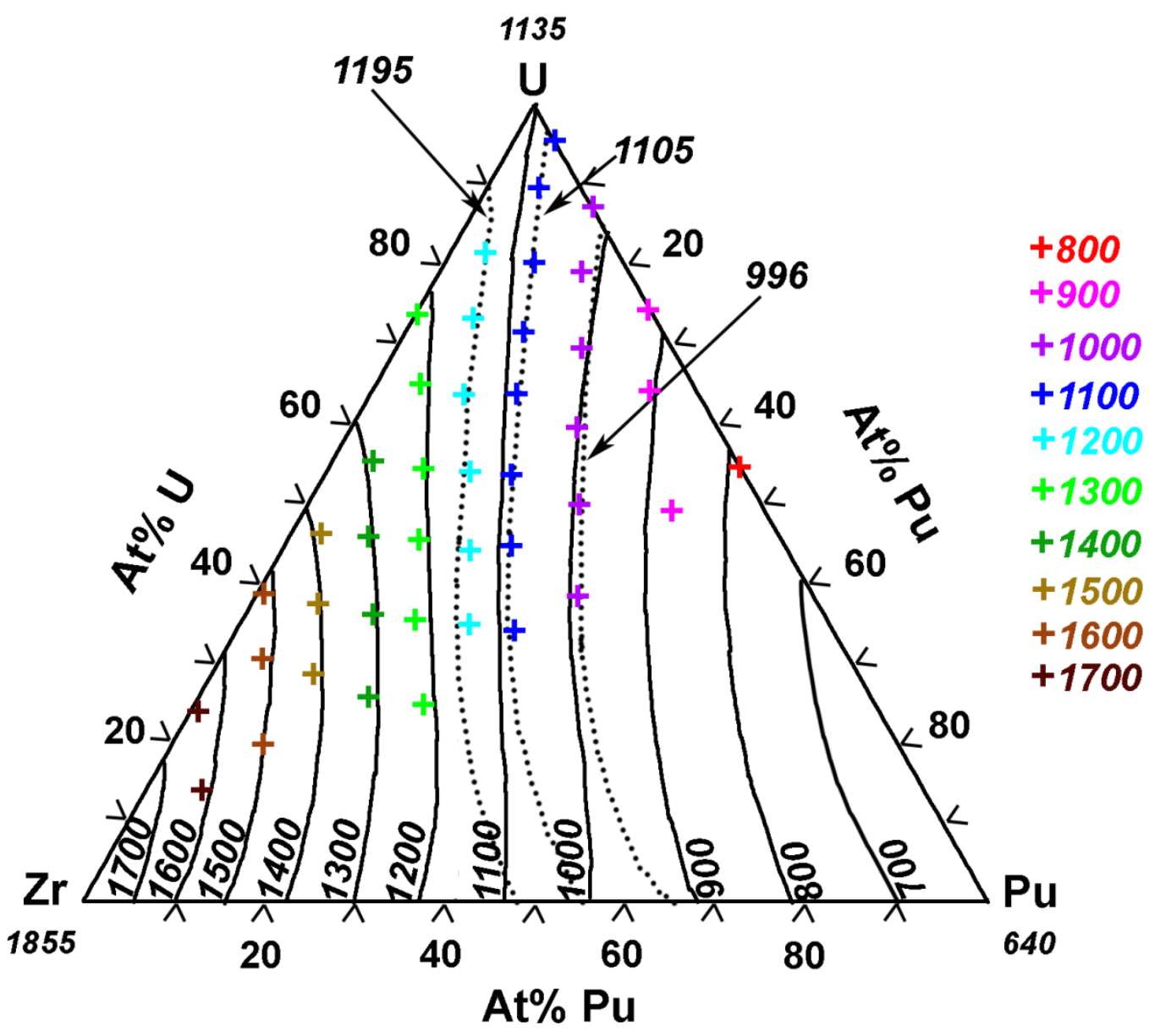

Figure 10. Solidus temperatures $\left({ }^{\circ} \mathrm{C}\right)$ from models of Leibowitz et al. [53] (solid lines), Kurata [49] (dotted lines), and Ogata [4] (colored symbols showing examples of calculated points).

Table 4. Experimental and calculated liquidus temperatures $\left({ }^{\circ} \mathrm{C}\right)$ for $\mathrm{U}-\mathrm{Zr}$ and $\mathrm{U}-\mathrm{Pu}-\mathrm{Zr}$ alloys.

\begin{tabular}{|l|l|l|l|l|l|}
\hline \multicolumn{1}{|c|}{$\begin{array}{c}\text { Composition } \\
(\mathrm{wt} \%)\end{array}$} & \multicolumn{1}{|c|}{$\begin{array}{c}\text { Composition } \\
(\mathrm{at} \%)\end{array}$} & \multicolumn{4}{|c|}{ Liquidus temperature $\left({ }^{\circ} \mathrm{C}\right)$} \\
\hline & \multicolumn{1}{|c|}{$\begin{array}{c}\text { Experimental } \\
\text { [reference] }\end{array}$} & $\begin{array}{c}\text { Ogata } \\
{[4]}\end{array}$ & $\begin{array}{c}\text { Kurata } \\
{[49]}\end{array}$ & $\begin{array}{c}\text { Leibowitz et al. } \\
{[53]}\end{array}$ \\
\hline $\mathrm{U}-15 \mathrm{Pu}-7 \mathrm{Zr}$ & $\mathrm{U}-13 \mathrm{Pu}-16 \mathrm{Zr}$ & $1240[101]$ & 1281 & $\sim 1250$ & 1268 \\
\hline $\mathrm{U}-15 \mathrm{Pu}-13.5 \mathrm{Zr}$ & $\mathrm{U}-12 \mathrm{Pu}-29 \mathrm{Zr}$ & $1425[101]$ & 1413 & $\sim 1390$ & 1394 \\
\hline $\mathrm{U}-8.4 \mathrm{Zr}$ & $\mathrm{U}-19.3 \mathrm{Zr}$ & $1358[53]$ & 1353 & $\sim 1350$ & 1371 \\
\hline $\mathrm{U}-20 \mathrm{Pu}-1 \mathrm{Zr}$ & $\mathrm{U}-19.5 \mathrm{Pu}-3.3 \mathrm{Zr}$ & $1050[53]$ & 1063 & $\sim 1060$ & 1060 \\
\hline $\mathrm{U}-22 \mathrm{Pu}-6 \mathrm{Zr}$ & $\mathrm{U}-19.3 \mathrm{Pu}-14.5 \mathrm{Zr}$ & $1321[53]$ & 1246 & $\sim 1230$ & 1216 \\
\hline $\mathrm{U}-11.1 \mathrm{Pu}-6.3 \mathrm{Zr}$ & $\mathrm{U}-10 \mathrm{Pu}-15 \mathrm{Zr}$ & $1200[112]$ & 1280 & $\sim 1250$ & $\sim 1225$ \\
\hline $\mathrm{U}-15 \mathrm{Pu}-10 \mathrm{Zr}$ & $\mathrm{U}-12.9 \mathrm{Pu}-22.5 \mathrm{Zr}$ & $1250[112]$ & 1353 & $\sim 1330$ & $\sim 1310$ \\
\hline $\mathrm{U}-18.5 \mathrm{Pu}-14.1 \mathrm{Zr}$ & $\mathrm{U}-15 \mathrm{Pu}-30 \mathrm{Zr}$ & $1290[112]$ & 1413 & $\sim 1380$ & $\sim 1350$ \\
\hline $\mathrm{U}-11 \mathrm{Zr}$ & $\mathrm{U}-24.4 \mathrm{Zr}$ & $1427[67]$ & 1400 & $\sim 1400$ & $\sim 1390$ \\
\hline $\mathrm{U}-20 \mathrm{Zr}$ & $\mathrm{U}-39.3 \mathrm{Zr}$ & $1520[67]$ & 1520 & $>1425$ & $\sim 1500$ \\
\hline
\end{tabular}


Table 5. Experimental and calculated solidus temperatures $\left({ }^{\circ} \mathrm{C}\right)$ for $\mathrm{U}-\mathrm{Zr}$ and $\mathrm{U}-\mathrm{Pu}-\mathrm{Zr}$ alloys.

\begin{tabular}{|l|l|c|c|c|c|}
\hline \multicolumn{1}{|c|}{$\begin{array}{c}\text { Composition } \\
(\mathrm{wt} \%)\end{array}$} & \multicolumn{1}{|c|}{$\begin{array}{c}\text { Composition } \\
(\mathrm{at} \%)\end{array}$} & \multicolumn{4}{|c|}{ Solidus Temperature $\left({ }^{\circ} \mathrm{C}\right)$} \\
\hline & & $\begin{array}{c}\text { Experimental } \\
\text { [reference] }\end{array}$ & $\begin{array}{c}\text { Ogata } \\
{[4]}\end{array}$ & $\begin{array}{c}\text { Kurata } \\
{[49]}\end{array}$ & $\begin{array}{c}\text { Leibowitz et al. } \\
{[53]}\end{array}$ \\
\hline $\mathrm{U}-15 \mathrm{Pu}-7 \mathrm{Zr}$ & $\mathrm{U}-13 \mathrm{Pu}-16 \mathrm{Zr}$ & $1105[101]$ & 1098 & $\sim 1105$ & 1121 \\
\hline $\mathrm{U}-15 \mathrm{Pu}-13.5 \mathrm{Zr}$ & $\mathrm{U}-12 \mathrm{Pu}-29 \mathrm{Zr}$ & $1195[101]$ & 1213 & $\sim 1195$ & 1187 \\
\hline $\mathrm{U}-8.4 \mathrm{Zr}$ & $\mathrm{U}-19.3 \mathrm{Zr}$ & $1216[53]$ & 1268 & $>1195$ & 1221 \\
\hline $\mathrm{U}-20 \mathrm{Pu}-1 \mathrm{Zr}$ & $\mathrm{U}-19.5 \mathrm{Pu}-3.3 \mathrm{Zr}$ & $996[53]$ & 961 & $<996$ & 1012 \\
\hline $\mathrm{U}-22 \mathrm{Pu}-6 \mathrm{Zr}$ & $\mathrm{U}-19.3 \mathrm{Pu}-14.5 \mathrm{Zr}$ & $1093[53]$ & 1038 & $\sim 1040$ & 1071 \\
\hline $\mathrm{U}-11.1 \mathrm{Pu}-6.3 \mathrm{Zr}$ & $\mathrm{U}-10 \mathrm{Pu}-15 \mathrm{Zr}$ & $1120[112]$ & 1124 & $\sim 1110$ & $\sim 1095$ \\
\hline $\mathrm{U}-15 \mathrm{Pu}-10 \mathrm{Zr}$ & $\mathrm{U}-12.9 \mathrm{Pu}-22.5 \mathrm{Zr}$ & $1155[112]$ & 1154 & $\sim 1150$ & $\sim 1115$ \\
\hline $\mathrm{U}-18.5 \mathrm{Pu}-14.1 \mathrm{Zr}$ & $\mathrm{U}-15 \mathrm{Pu}-30 \mathrm{Zr}$ & $1170[112]$ & 1195 & $\sim 1190$ & $\sim 1140$ \\
\hline
\end{tabular}

\subsubsection{Sub-solidus Reactions}

In the 1960s, several groups of researchers attempted to determine the U-Pu-Zr phase diagram by combining data on phase-transition temperatures with phases in annealed samples. Researchers at Mound Laboratory identified possible sub-solidus reactions and constructed a diagram showing the temperatures at which the $(\gamma-U)$ solid solution transforms to lower-temperature phases $[75,107]$. The Mound Laboratory researchers also compiled a tentative table of reactions [75], but did not use their results to suggest phase diagrams or isothermal sections.

In 1970, O'Boyle and Dwight considered all of the available data (including the data used by Mound Laboratory and their own new measurements of the lower temperature boundary of the $(\gamma-\mathrm{U})$ solid solution) and published a series of isothermal sections at temperatures between 500 and $700{ }^{\circ} \mathrm{C}$ [98]. These diagrams remain the only experimentally determined phase diagrams for the U-Pu-Zr system.

Figure 11 compares the temperatures of the highest sub-solidus reactions according to O'Boyle and Dwight and researchers from Mound Laboratory. The two sources used much of the same data and, therefore, should not be considered independent. However, both suggest that compositions of interest for fuels are likely to transform between the $(\gamma-U)$ solid solution and some combination of $(\beta-U), \eta$, and $\zeta$ at temperatures between 650 and $700^{\circ} \mathrm{C}$. 


\section{Temperature $\left({ }^{\circ} \mathrm{C}\right)$}

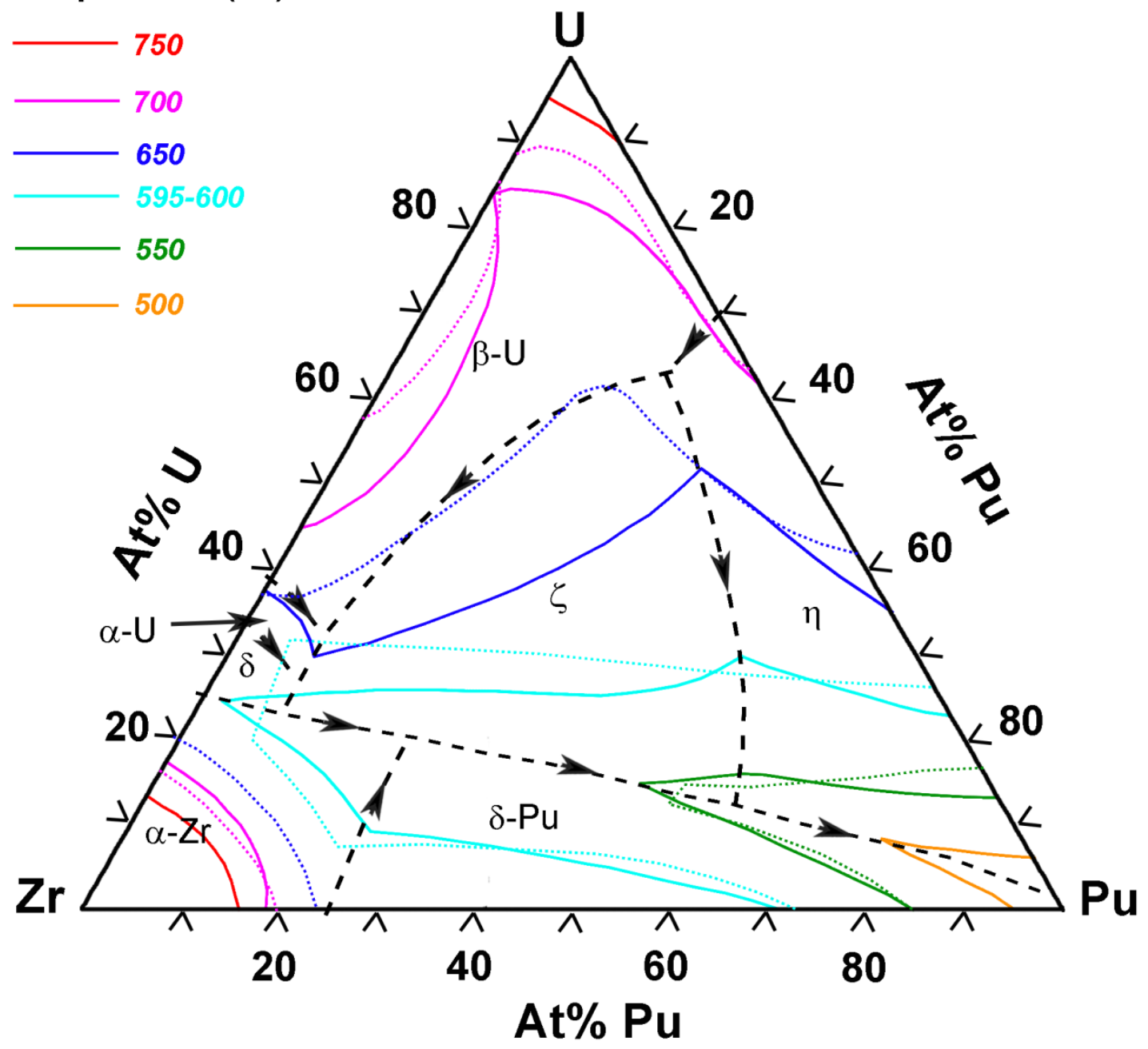

Figure 11. Ternary projection of low-temperature limit of $(\gamma-U)$ solid solution from Mound Laboratory $[75,107]$ (solid lines) with corresponding temperature contours from O'Boyle and Dwight [98] (dotted lines).

Figure 12 through Figure 20 show the isothermal sections of O'Boyle and Dwight [98] with compositions of the newly measured INL samples shown in colors corresponding to those in Figure 5. The diagrams show numerous phases with narrow composition ranges, which are probably not known to the accuracy implied by the diagrams. There are also several areas where four-phase reactions are indicated. Further research on the U-Pu-Zr phase diagram is clearly needed. 


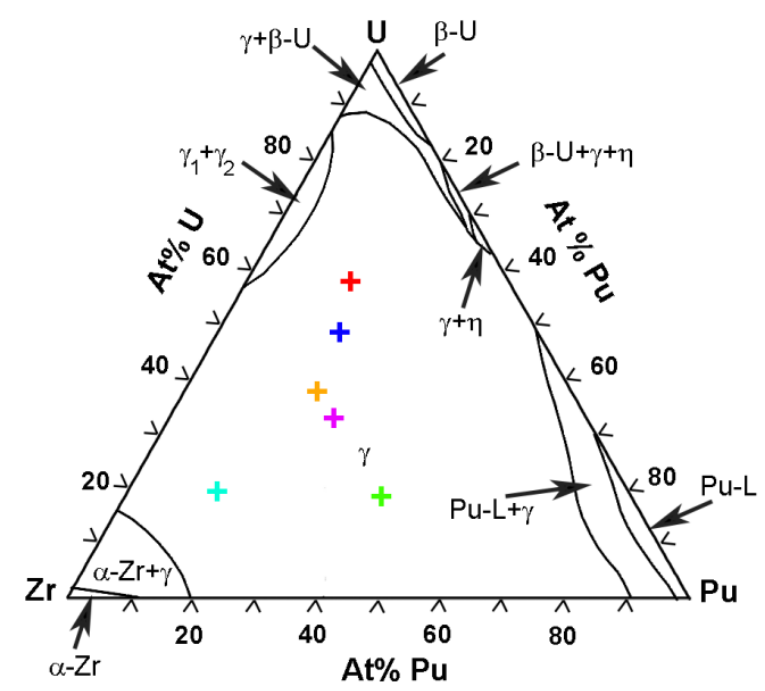

Figure 12. Isothermal section of the U-Pu- $\mathrm{Zr}$ phase diagram at $700^{\circ} \mathrm{C}$ [98].

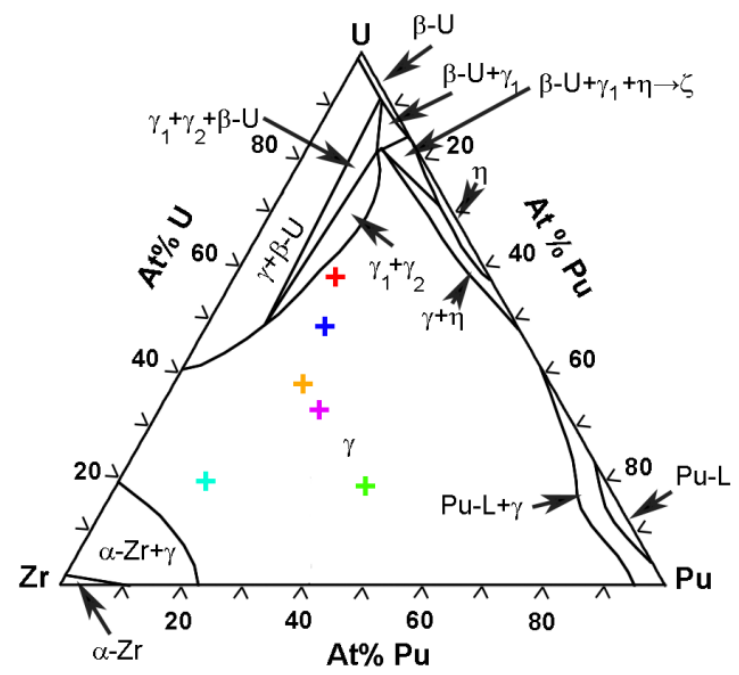

Figure 13. Isothermal section of the U-Pu-Zr phase diagram at $670^{\circ} \mathrm{C}$ [98]. 


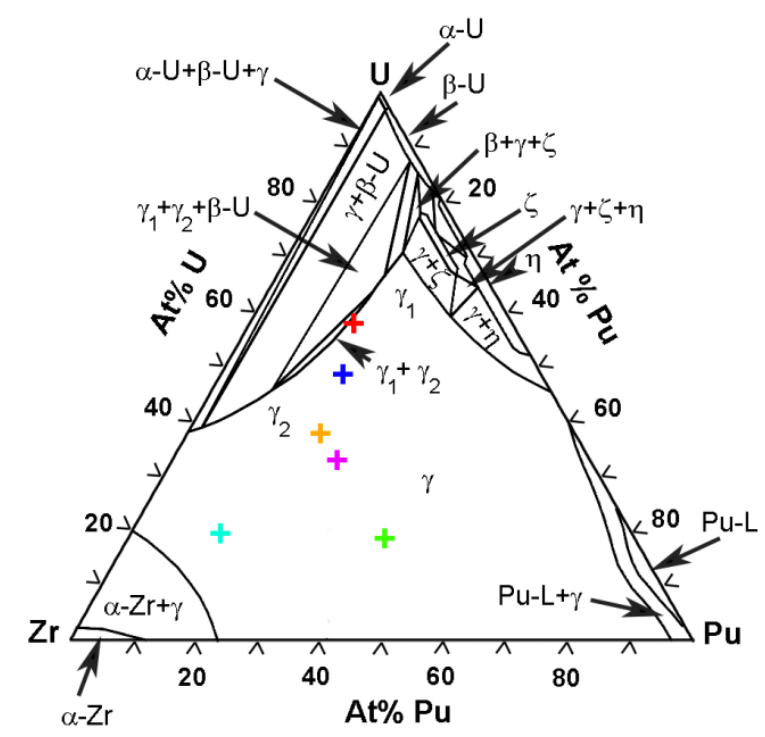

Figure 14. Isothermal section of the U-Pu-Zr phase diagram at $660^{\circ} \mathrm{C}$ [98].

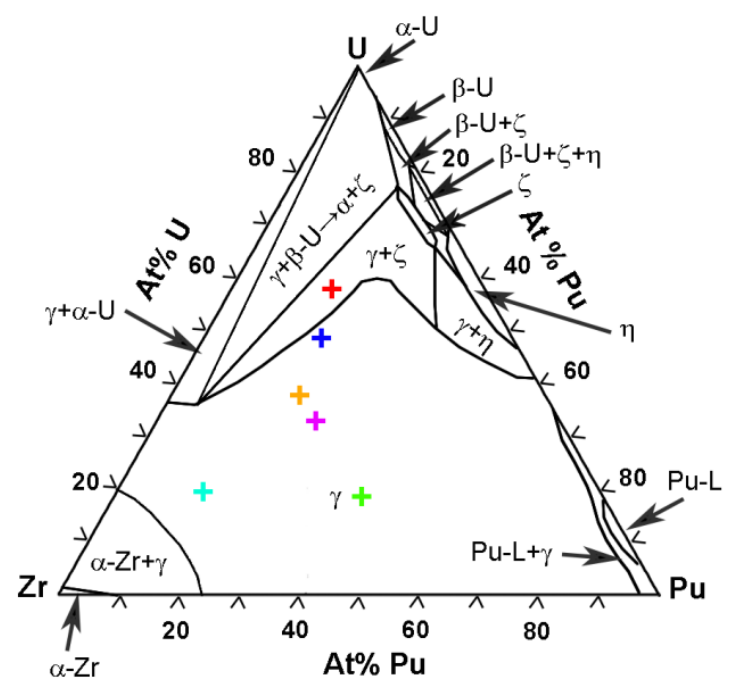

Figure 15. Isothermal section of the $\mathrm{U}-\mathrm{Pu}-\mathrm{Zr}$ phase diagram at $650^{\circ} \mathrm{C}$ [98]. 


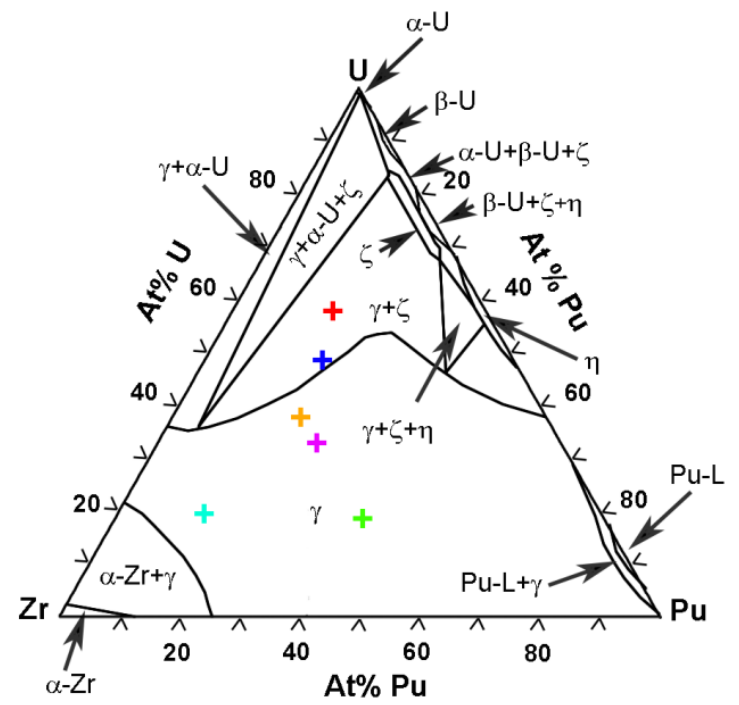

Figure 16. Isothermal section of the $\mathrm{U}-\mathrm{Pu}-\mathrm{Zr}$ phase diagram at $640^{\circ} \mathrm{C}$ [98].

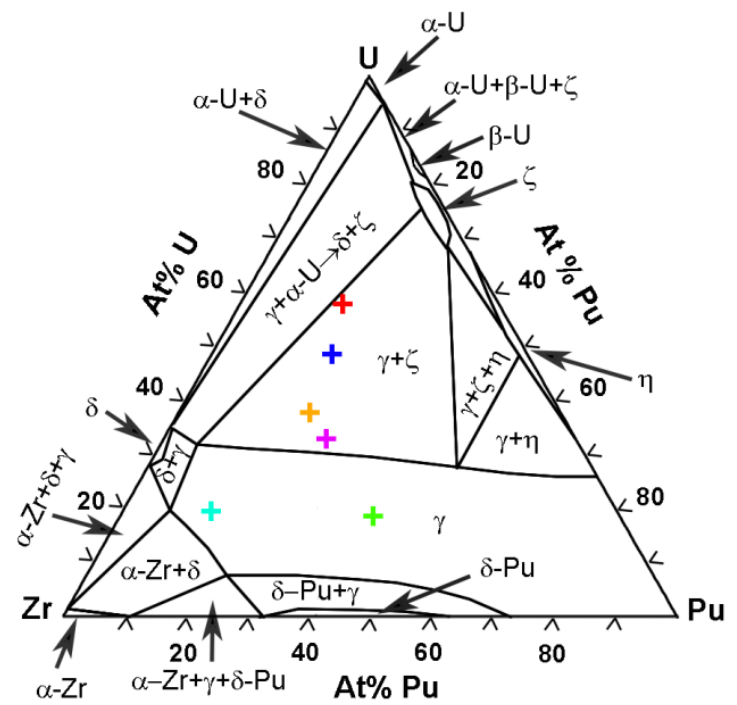

Figure 17. Isothermal section of the U-Pu-Zr phase diagram at $595^{\circ} \mathrm{C}$ [98]. 


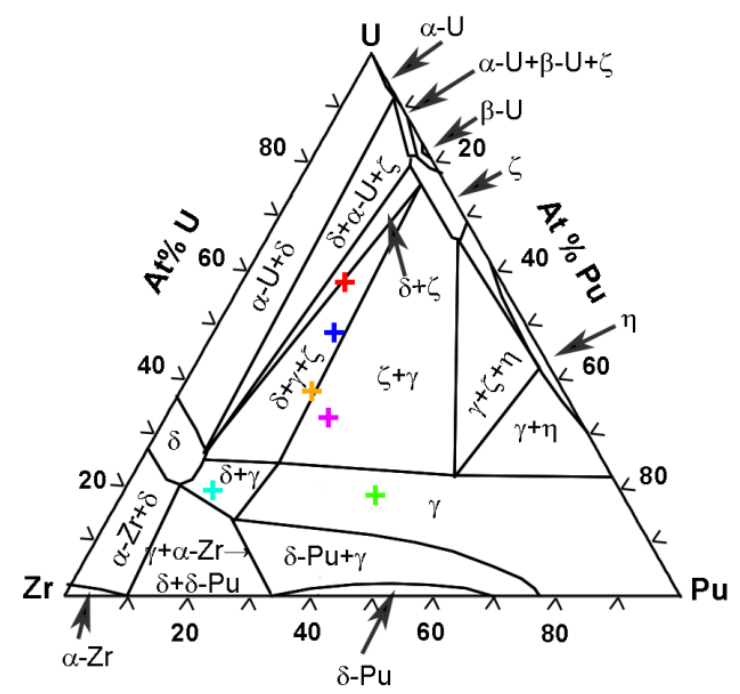

Figure 18. Isothermal section of the U-Pu- $\mathrm{Zr}$ phase diagram at $580^{\circ} \mathrm{C}$ [98].

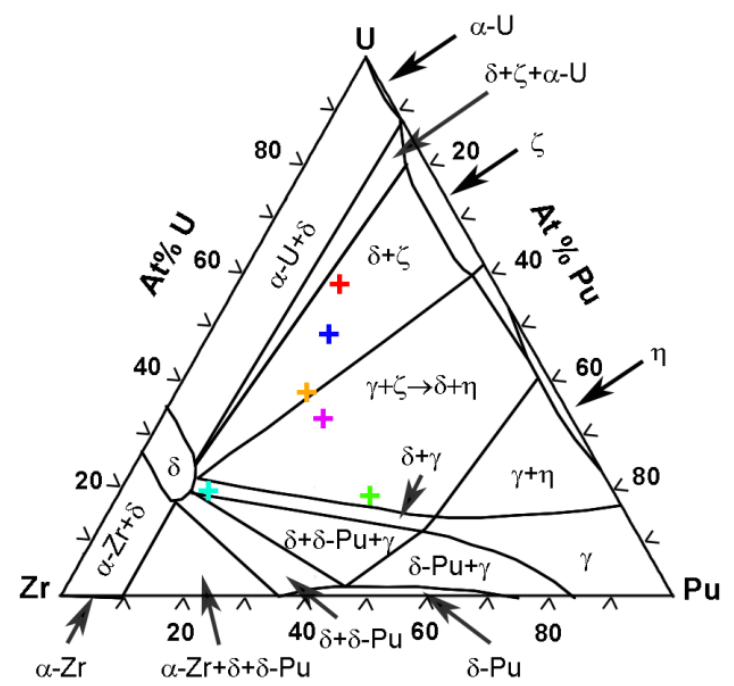

Figure 19. Isothermal section of the U-Pu-Zr phase diagram at $550^{\circ} \mathrm{C}$ [98]. 


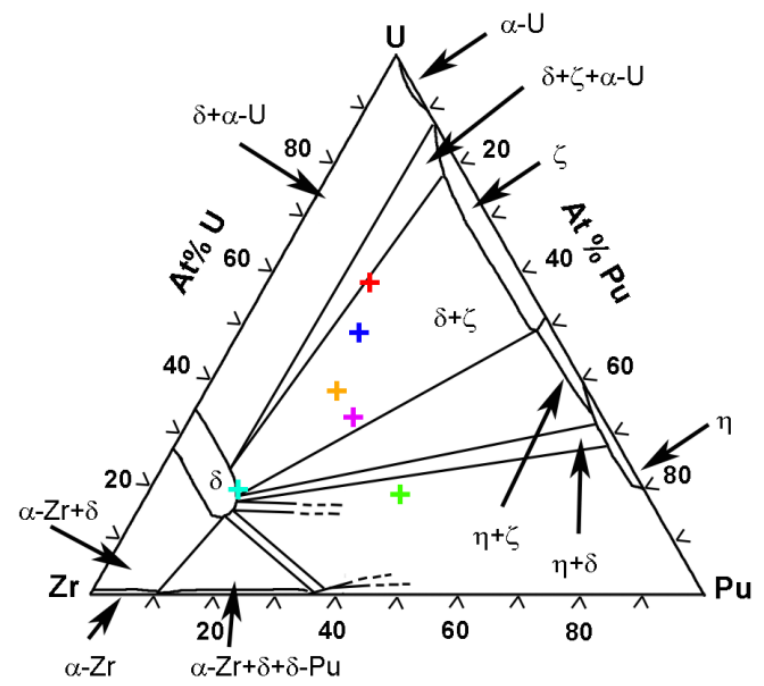

Figure 20. Isothermal section of the $\mathrm{U}-\mathrm{Pu}-\mathrm{Zr}$ phase diagram at $500^{\circ} \mathrm{C}$ [98]. 


\title{
4. HEAT CAPACITY AND RELATED PROPERTIES (ENTROPY, ENTHALPY, SPECIFIC HEAT CAPACITY)
}

\author{
$4.1 \mathrm{U}$
}

\subsubsection{Introduction}

The heat capacity of $U$ has been extensively studied, with most measurements originally published between 1947 and 1980 and independent critical reviews of the available data in 1976 and 2010 [1, 3]. Recommended values for the heat capacity of $\alpha-U$ are similar in both reviews. Although both agree that the heat capacities of $\beta-U$ and liquid $U$ are independent of temperature, their recommended values differ by $5-10 \%$. The reviews also disagree about the possible temperature dependence of the heat capacity of $\gamma$-U. The major reason for the differences between the reviews is that the 1976 review [3] used primarily measurements of heat capacity, while the 2010 review [1] also considered measurements of incremental enthalpy. The recommendations of the 2010 review are presented here and were reprinted in reference [2]; recommendations from the 1976 review can be found in a number of sources (e.g., [3, 11, 113]).

The standard enthalpy of solid U, standard entropy of uranium gas, and enthalpy of formation of uranium gas are generally accepted values (e.g., [1]). They are:

- $\mathrm{S}^{0}(298.15 \mathrm{~K})=50.20 \pm 0.20 \mathrm{~J} / \mathrm{mol} \cdot \mathrm{K}$ for $\alpha-\mathrm{U}$

- $\mathrm{S}^{0}(298.15 \mathrm{~K})=199.79 \pm 0.10 \mathrm{~J} / \mathrm{mol} \cdot \mathrm{K}$ for $\mathrm{U}$ gas

- $\Delta_{\mathrm{f}} H^{0}(298.15 \mathrm{~K})=533 \pm 8 \mathrm{~kJ} / \mathrm{mol}$ for $\mathrm{U}$ gas

\subsubsection{Heat Capacities of Solid and Liquid Phases}

Major reviews and assessments of data on the heat capacity of U include those by Oetting et al. [3] as part of an IAEA series on the chemical thermodynamics of actinide elements and compounds and Konings and Beneš [1] as part of a recent critical review of thermodynamic properties of lanthanide and actinide metals. Grenthe et al. [11] fitted a new polynomial to the $\alpha-U$ data of Oetting et al. in their review of chemical thermodynamics for NEA/OECD, and Konings et al. [2] followed Konings and Beneš in a recent review of nuclear materials.

Figure 21 shows the heat capacities for solid and liquid $U$ recommended by Oetting et al. [3] and by Konings and Beneš [1]. As shown in the figure, both reviews recommend similar values for the heat capacity of $\alpha-\mathrm{U}$ at temperatures above $\sim 300 \mathrm{~K}$. The heat capacity of $\beta$-U in reference [1] is almost $10 \%$ larger than that in reference [3] $(47.12 \mathrm{vs} 42.3 \mathrm{~J} / \mathrm{mol} \cdot \mathrm{K})$, and the heat capacity of liquid $\mathrm{U}$ is almost $5 \%$ smaller $(46.45 \mathrm{vs} 48.69 \mathrm{~J} / \mathrm{mol} \cdot \mathrm{K})$. The average values for the heat capacity of $\gamma$-U are similar in both reviews $(38.31 \mathrm{~J} / \mathrm{mol} \cdot \mathrm{K}$ in reference [3] and $39.05 \mathrm{~J} / \mathrm{mol} \cdot \mathrm{K}$ in reference [1]), although reference [3] suggests that the heat capacity of this phase is independent of temperature and reference [1] indicates that it is not.

Almost all of the original data on heat capacities and incremental enthalpies of solid and liquid $U$ were originally published between about 1947 and 1980. However, Oetting et al. [3] considered primarily measurements of heat capacity, while Konings and Beneš [1] also considered measurements of incremental enthalpy. In the absence of further experimental data, it seems reasonable to consider the recommendations of Konings and Beneš (Equation 3, Equation 4, Equation 5, and Equation 6) to be a more accurate representation of the heat capacities of solid and liquid $U$ phases than the recommendations of Oetting et al. because Konings and Beneš considered a larger amount of data collected using a wider variety of measurement techniques, including some that are well-suited to collecting high-temperature data. 


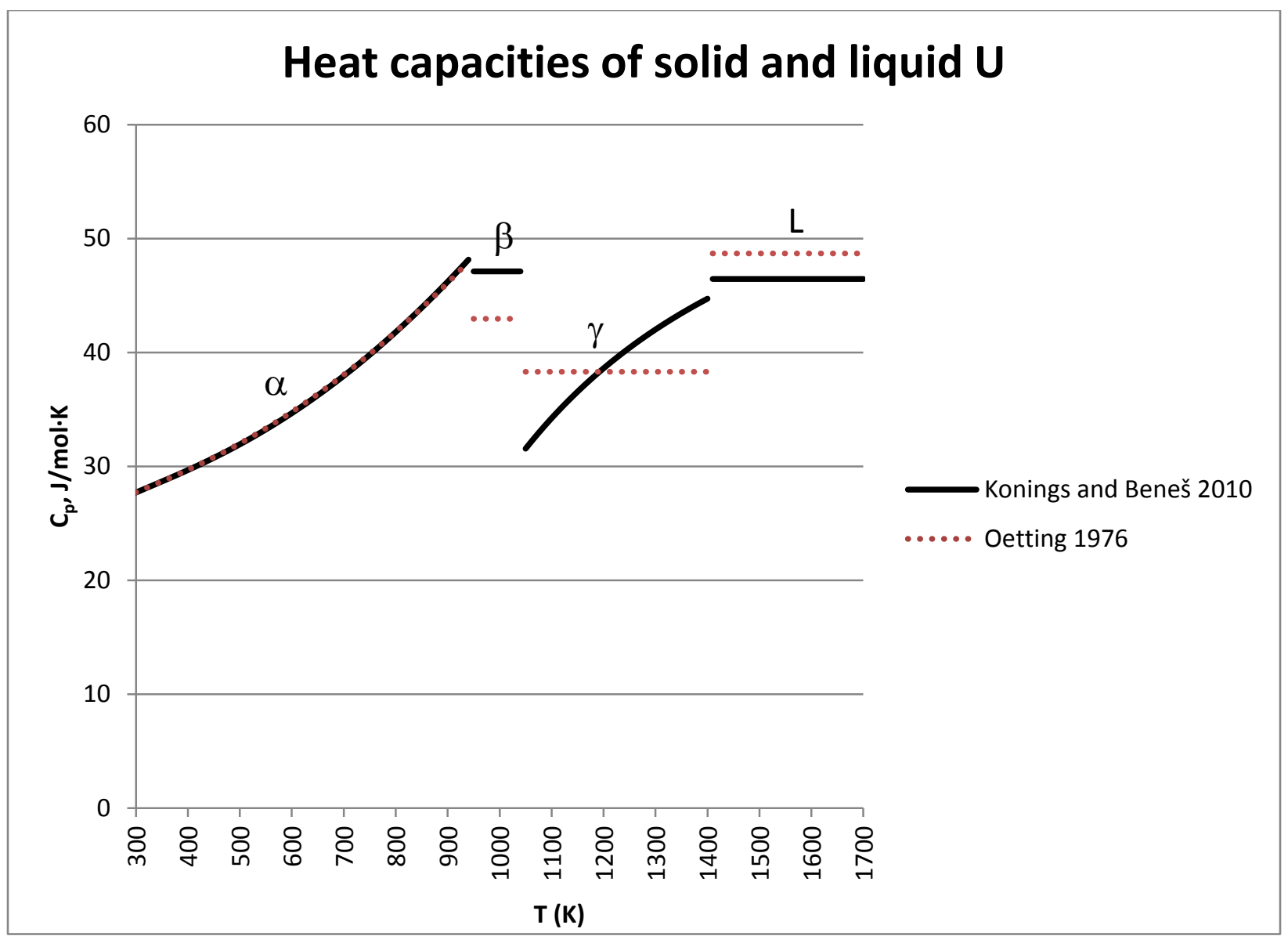

Figure 21. Heat capacities of solid and liquid U. Values from Konings and Beneš [1] (Equation 3, Equation 4, and Equation 5) are preferred

Equation 3. $C_{p}$ of $\alpha-U\left(C_{p}\right.$ in $\mathrm{J} / \mathrm{mol} \cdot \mathrm{K}, \mathrm{T}$ in $\left.\mathrm{K}\right)[1]$

$$
\mathrm{C}_{\mathrm{p}}(\alpha-\mathrm{U})=28.4264-6.9587 \times 10^{-3} \times \mathrm{T}+29.8744 \times 10^{-6} \times \mathrm{T}^{2}-0.11888 \times 10^{6} \times \mathrm{T}^{-2}
$$

Equation 4. $\mathrm{C}_{\mathrm{p}}$ of $\beta-\mathrm{U}\left(\mathrm{C}_{\mathrm{p}}\right.$ in $\mathrm{J} / \mathrm{mol} \cdot \mathrm{K}$, $\mathrm{T}$ in $\left.\mathrm{K}\right)[1]$

$$
\mathrm{C}_{\mathrm{p}}(\beta-\mathrm{U})=47.12
$$

Equation 5. $C_{p}$ of $\gamma-U\left(C_{p}\right.$ in $\mathrm{J} / \mathrm{mol} \cdot \mathrm{K}, \mathrm{T}$ in $\left.\mathrm{K}\right)[1]$

$$
C_{p}(\gamma-U)=61.6420-33.1644 \times 10^{6} \times T^{-2}
$$

Equation 6. $C_{p}$ of liquid $U\left(C_{p}\right.$ in $J / m o l \cdot K$, $T$ in $\left.K\right)$ [1]

$$
\mathrm{C}_{\mathrm{p}}(\text { liquid } \mathrm{U})=46.45
$$




\subsubsection{Heat Capacity of the Ideal Gas}

Oetting et al. [3] calculated the heat capacity of uranium as an ideal gas from information on electronic levels available before 1975. They tabulated values at temperatures from 0 to $6000 \mathrm{~K}$, although they described their values above $2000 \mathrm{~K}$ as "interim." Grenthe et al. [11] fitted a polynomial to Oetting's values for temperatures from 298.15 to $2500 \mathrm{~K}$. More recently, Konings and Beneš [1] re-calculated the heat capacity of uranium gas, using newer data and a larger number of electronic energy levels, and fitted it with two polynomials.

As shown in Figure 22, the two sets of data agree to within $\sim 1 \%$ for temperatures between $\sim 300$ and $2000 \mathrm{~K}$. If heat capacities above $4000 \mathrm{~K}$ are required, the "interim" values of Oetting et al. [3 Table A1.6] are the only available values.

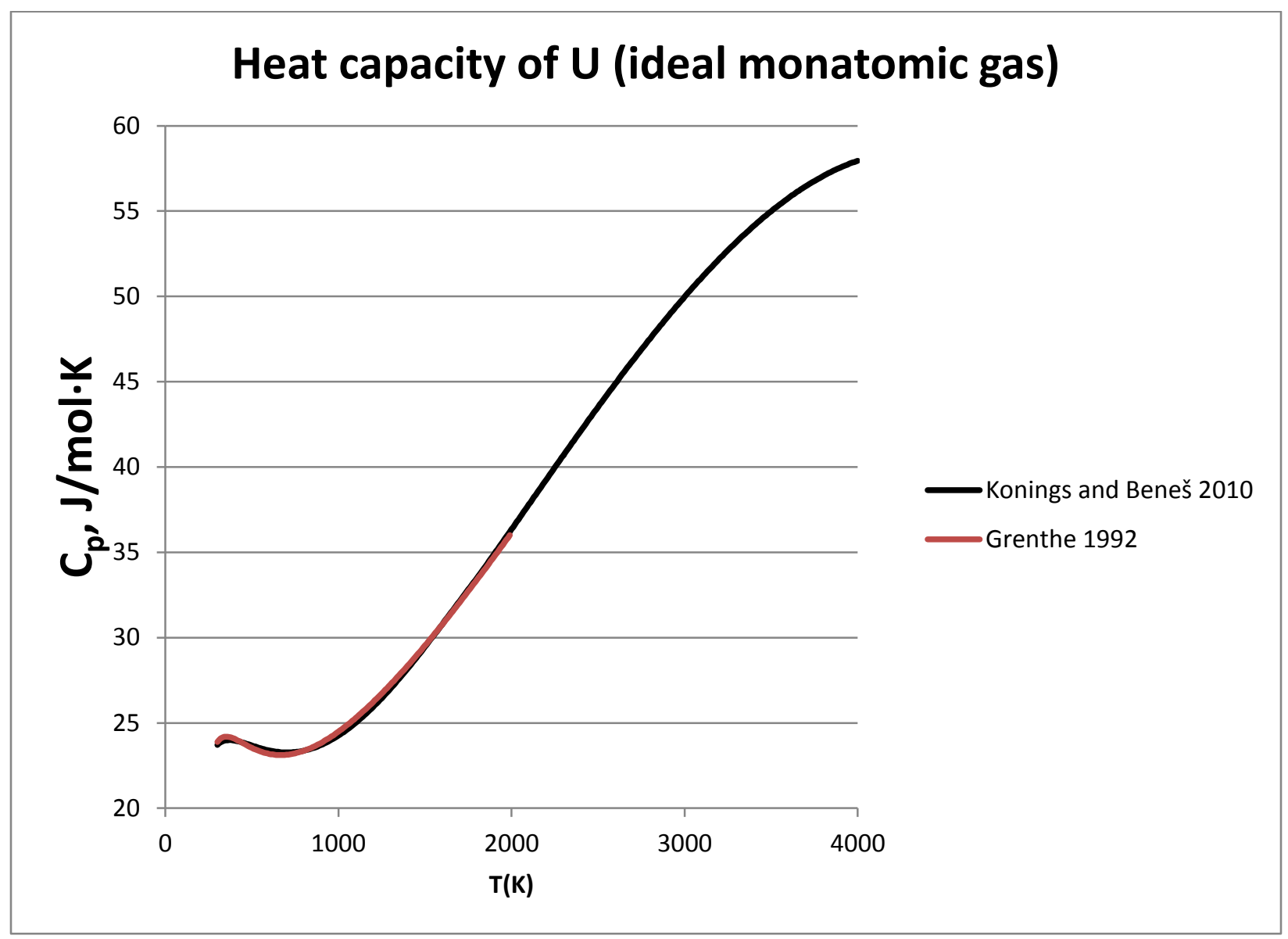

Figure 22. Heat capacity of $U$ as an ideal gas. Values from Konings and Beneš were calculated from Equation 7and Equation 8.

Equation 7. $\mathrm{C}_{\mathrm{p}}$ of $\mathrm{U}$ gas $\left(\mathrm{C}_{\mathrm{p}}\right.$ in $\mathrm{J} / \mathrm{mol} \cdot \mathrm{K}$, $\mathrm{T}$ in $\mathrm{K}$, $\mathrm{T}$ from 298.15 to $\left.1800 \mathrm{~K}\right)$ [1]

$$
\mathrm{C}_{\mathrm{p}}=35.1688-32.2466 \times 10^{-3} \times \mathrm{T}+27.0474 \times 10^{-6} \times \mathrm{T}^{2}-5.3433 \times 10^{-9} \times \mathrm{T}^{3}-3.6652 \times 10^{5} \times \mathrm{T}^{-2}
$$

Equation 8. $\mathrm{C}_{\mathrm{p}}$ of $\mathrm{U}$ gas from 1800 to $4000 \mathrm{~K}\left(\mathrm{C}_{\mathrm{p}}\right.$ in $\mathrm{J} / \mathrm{mol} \cdot \mathrm{K}$, $\mathrm{T}$ in $\mathrm{K}$, $\mathrm{T}$ from 1800 to $\left.4000 \mathrm{~K}\right)$ [1]

$$
\mathrm{C}_{\mathrm{p}}=4.9298+10.4892 \times 10^{-3} \times \mathrm{T}+3.7043 \times 10^{-6} \times \mathrm{T}^{2}-0.7598 \times 10^{-9} \times \mathrm{T}^{3}+6.8108 \times 10^{6} \times \mathrm{T}^{-2}
$$




\section{$4.2 \mathrm{Pu}$}

\subsubsection{Introduction}

Numerous researchers have studied the heat capacity of $\mathrm{Pu}$, with most results originally published by 1983. Major reviews were published by Oetting et al. [3] as part of an IAEA series on the chemical thermodynamics of actinide elements and compounds and Konings and Beneš [1] as part of a recent critical review of thermodynamic properties of lanthanide and actinide metals. The data of Oetting et al. [3] are no longer commonly used because of later experimental results obtained by Oetting and Adams [114], which are quoted by later reviews including those of Lemire et al. [20] for NEA/OECD and Konings and Beneš [1]. Key results from Konings and Beneš [1] were repeated in a recent review of nuclear materials by Konings et al. [2].

The standard enthalpy of solid $\mathrm{Pu}$ at 298.15 K, standard entropy of Pu gas, and enthalpy of formation of $\mathrm{Pu}$ gas are:

- $\mathrm{S}^{0}(298.15 \mathrm{~K})=54.46 \pm 0.80 \mathrm{~J} / \mathrm{mol} \cdot \mathrm{K}$ for $\alpha-\mathrm{Pu}[1,20]$

- $\mathrm{S}^{0}(298.15 \mathrm{~K})=177.19 \pm 0.10 \mathrm{~J} / \mathrm{mol} \cdot \mathrm{K}$ for $\mathrm{Pu}$ gas [1]

- $\Delta_{\mathrm{f}} H^{0}(298.15 \mathrm{~K})=348.9 \pm 3.0 \mathrm{~kJ} / \mathrm{mol}$ for Pu gas [1].

\subsubsection{Heat Capacities of Solid and Liquid Phases}

Figure 23 shows the heat capacities for solid and liquid Pu recommended by Lemire et al. [20] and by Konings and Beneš [1]. These reviews have identical heat capacities for $\beta-, \gamma-$, and $\delta$-Pu because both are quoting equations from Oetting and Adams [114]. The heat capacity for $\alpha-\mathrm{Pu}$ is also based on reference [114], except that Konings and Beneš adjusted it slightly upward to match their preferred values for lower-temperature measurements. Heat capacities for $\delta^{\prime}$ and $\varepsilon$-Pu are identical in both reviews because they are originally from reference [115]. The heat capacity for liquid $\mathrm{Pu}$ recommended by Konings and Beneš is also from reference [115], and the source of the heat capacity for liquid Pu recommended by Lemire et al. is not specified.

Measurement of low-temperature heat capacities in $\alpha-\mathrm{Pu}$ is complicated by radioactive self-heating. This effect does not affect the data presented here because defects are sufficiently mobile at room temperature and above to heal the damage rapidly enough that it does not affect measurements [13].

Equation 9. $\mathrm{C}_{\mathrm{p}}$ of $\alpha-\mathrm{Pu}\left(\mathrm{C}_{\mathrm{p}}\right.$ in $\mathrm{J} / \mathrm{mol} \cdot \mathrm{K}, \mathrm{T}$ in $\mathrm{K}$, T between 330 and $\left.390 \mathrm{~K}\right)$ [1] with temperature range from [114]

$$
\mathrm{C}_{\mathrm{p}}(\alpha-\mathrm{Pu})=17.6186+45.5523 \times 10^{-3} \times \mathrm{T}
$$

Equation 10. $\mathrm{C}_{\mathrm{p}}$ of $\beta-\mathrm{Pu}\left(\mathrm{C}_{\mathrm{p}}\right.$ in $\mathrm{J} / \mathrm{mol} \cdot \mathrm{K}, \mathrm{T}$ in $\mathrm{K}$, T between 408 and $\left.476 \mathrm{~K}\right)[1,20,114]$

$$
\mathrm{C}_{\mathrm{p}}(\beta-\mathrm{Pu})=27.4160+13.060 \times 10^{-3} \times \mathrm{T}
$$

Equation 11. $C_{p}$ of $\gamma-\mathrm{Pu}\left(\mathrm{C}_{\mathrm{p}}\right.$ in $\mathrm{J} / \mathrm{mol} \cdot \mathrm{K}$, $\mathrm{T}$ in $\mathrm{K}$, T between 493 and $\left.586 \mathrm{~K}\right)[1,20,114]$

$$
\mathrm{C}_{\mathrm{p}}(\gamma-\mathrm{Pu})=22.0233+22.959 \times 10^{-3} \times \mathrm{T}
$$

Equation 12. $\mathrm{C}_{\mathrm{p}}$ of $\delta$ - $\mathrm{Pu}\left(\mathrm{C}_{\mathrm{p}}\right.$ in $\mathrm{J} / \mathrm{mol} \cdot \mathrm{K}, \mathrm{T}$ in $\mathrm{K}$, T between 602 and $\left.680 \mathrm{~K}\right)[1,20,114]$

$$
\mathrm{C}_{\mathrm{p}}(\delta-\mathrm{Pu})=28.4781+10.807 \times 10^{-3} \times \mathrm{T}
$$

Equation 13. $\mathrm{C}_{\mathrm{p}}$ of $\delta^{\prime}-\mathrm{Pu}\left(\mathrm{C}_{\mathrm{p}}\right.$ in $\mathrm{J} / \mathrm{mol} \cdot \mathrm{K}, \mathrm{T}$ in $\left.\mathrm{K}\right)[1,20]$

$$
\mathrm{C}_{\mathrm{p}}\left(\delta^{\prime}-\mathrm{Pu}\right)=35.56
$$


Equation 14. $\mathrm{C}_{\mathrm{p}}$ of $\varepsilon-\mathrm{Pu}\left(\mathrm{C}_{\mathrm{p}}\right.$ in $\mathrm{J} / \mathrm{mol} \cdot \mathrm{K}, \mathrm{T}$ in $\left.\mathrm{K}\right)[1,20]$

$\mathrm{C}_{\mathrm{p}}(\varepsilon-\mathrm{Pu})=33.72$

Equation 15. $\mathrm{C}_{\mathrm{p}}$ of liquid $\mathrm{Pu}\left(\mathrm{C}_{\mathrm{p}}\right.$ in $\mathrm{J} / \mathrm{mol} \cdot \mathrm{K}$, $\mathrm{T}$ in $\left.\mathrm{K}\right)[1]$

$\mathrm{C}_{\mathrm{p}}($ liquid $\mathrm{Pu})=42.80$

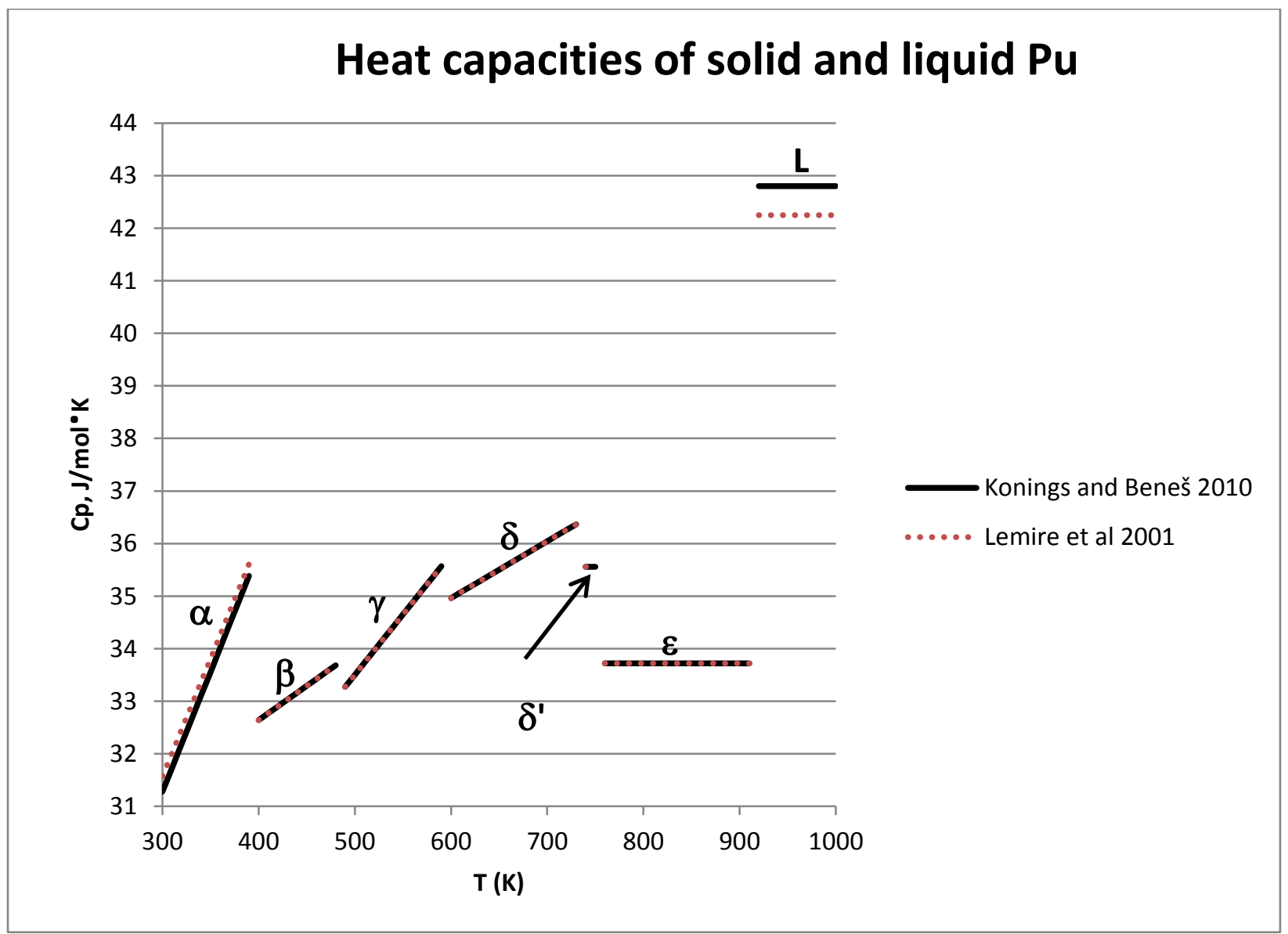

Figure 23. Heat capacities of solid and liquid Pu. Values from Konings and Beneš [1] (solid black lines, Equation 9 through Equation 15) are preferred

\subsubsection{Heat Capacity of the Ideal Gas}

Konings and Beneš [1] calculated the heat capacity of ${ }^{239} \mathrm{Pu}$ as an ideal gas and fitted the heat capacity by two polynomials (Figure 24). These polynomials match those calculated from a similar database at temperatures up to $2000 \mathrm{~K}$ by Lemire et al. [20] to within a few hundredths of a $\mathrm{J} / \mathrm{mol} \cdot \mathrm{K}$. 


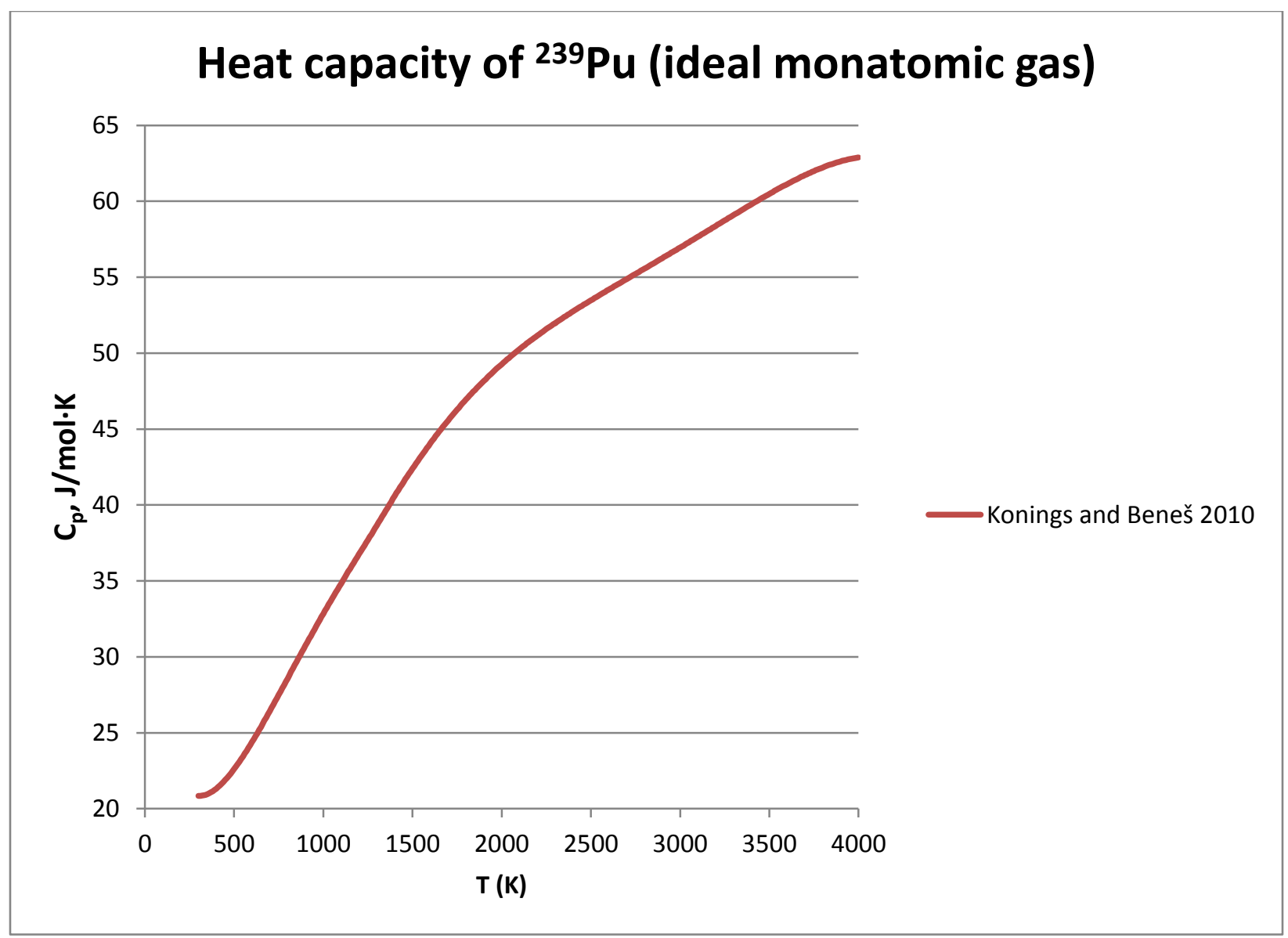

Figure 24. Heat capacity of ${ }^{239} \mathrm{Pu}$ as an ideal gas, calculated using Equation 16 and Equation 17

Equation 16. $\mathrm{C}_{\mathrm{p}}$ of $\mathrm{Pu}$ gas from 298.15 to $1400 \mathrm{~K}\left(\mathrm{C}_{\mathrm{p}}\right.$ in $\mathrm{J} / \mathrm{mol} \cdot \mathrm{K}$, $\mathrm{T}$ in $\left.\mathrm{K}\right)$ [1]

$$
\begin{gathered}
\mathrm{C}_{\mathrm{p}}=24.2954-37.0413 \times 10^{-3} \times \mathrm{T}+95.1224 \times 10^{-6} \times \mathrm{T} 2-65.8404 \times 10^{-9} \times \mathrm{T}^{3}+ \\
16.2344 \times 10^{-12} \times \mathrm{T}^{4}+6.7865 \times 10^{4} \times \mathrm{T}^{-2}
\end{gathered}
$$

Equation 17. $\mathrm{C}_{\mathrm{p}}$ of $\mathrm{Pu}$ gas from 1400 to $4000 \mathrm{~K}\left(\mathrm{C}_{\mathrm{p}}\right.$ in $\mathrm{J} / \mathrm{mol} \cdot \mathrm{K}$, $\mathrm{T}$ in $\left.\mathrm{K}\right)$ [1]

$$
\begin{gathered}
\mathrm{C}_{\mathrm{p}}=-112.0172+187.5714 \times 10^{-3} \times \mathrm{T}-86.6780 \times 10^{-6} \times \mathrm{T}^{2}+18.8245 \times 10^{-9} \times \mathrm{T}^{3}- \\
1.5431 \times 10^{-12} \times \mathrm{T}^{4}+2.7817 \times 10^{7} \mathrm{~T}^{-2}
\end{gathered}
$$

\section{3 $\mathrm{Zr}$}

\subsubsection{Introduction}

Many measurements of the heat capacities of $\alpha$ - and $\beta$ - $\mathrm{Zr}$ have been made. Recommended values in the NIST-JANAF tables and recent IAEA publications $[116,117]$ differ by a few $\mathrm{J} /(\mathrm{mol} \cdot \mathrm{K})$ for $\alpha-\mathrm{Zr}$, with much smaller differences for $\beta-Z r$.

The heat capacity of liquid $\mathrm{Zr}$ has been measured at temperatures as high as $2200 \mathrm{~K}$, and the heat capacity of the ideal monatomic gas has been calculated $[28,116]$. These values are not presented here because of their limited relevance for FCRD fuels. 


\subsubsection{Heat Capacities of Solid Phases}

Measurements of the heat capacity of solid Zr were recently reviewed by Milošević \& Maglić [118], and show generally good agreement with other publications. Values recommended by the IAEA [117] for $\alpha-\mathrm{Zr}$ are slightly higher than those in the NIST-JANAF tables [116] (Figure 25). As it was not possible to access the website from which the values in the IAEA publication were obtained, it is not possible to tell why the IAEA and NIST have different values.

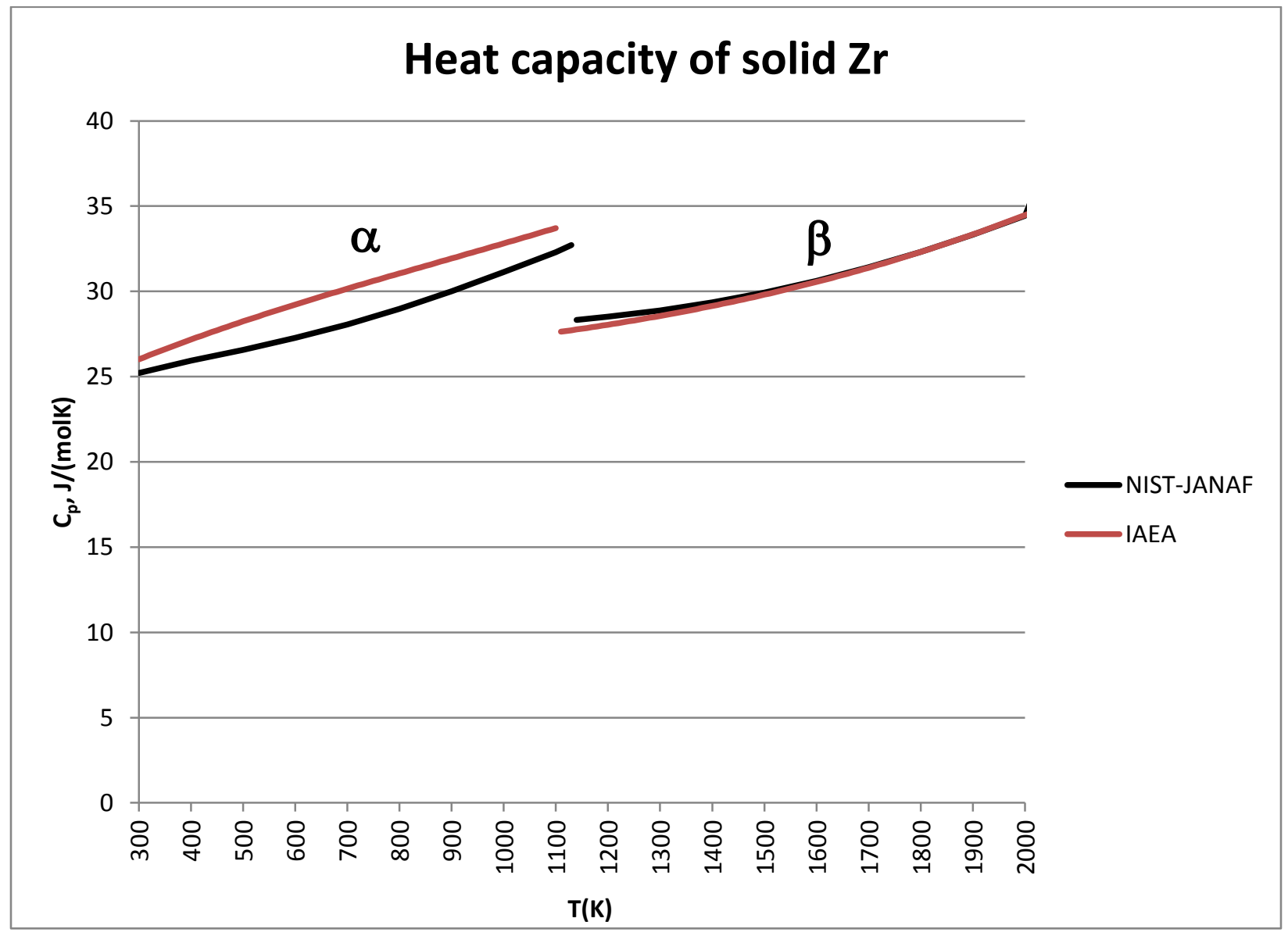

Figure 25. Heat capacities of solid Zr phases (IAEA data calculated using Equation 18 and Equation 19)

The IAEA heat-capacity values can be calculated using Equation 18 and Equation 19. These equations express heat capacity in $\mathrm{J} /(\mathrm{kg} \cdot \mathrm{K})$, which can be converted to $\mathrm{J} /(\mathrm{mol} \cdot \mathrm{K})$ by multiplying by 0.09122 (the molar weight of $\mathrm{Zr}$, expressed in $\mathrm{kg}$ ). Corresponding equations for the NIST-JANAF heat-capacity values have not been published.

Equation 18. $\mathrm{C}_{\mathrm{p}}$ of $\alpha-\mathrm{Zr}$ from 298 to $1100 \mathrm{~K}\left(\mathrm{C}_{\mathrm{p}}\right.$ in $\mathrm{J} / \mathrm{kg} \cdot \mathrm{K}$, $\mathrm{T}$ in $\left.\mathrm{K}\right)$ [117]

$$
\mathrm{C}_{\mathrm{p}}=238.596+0.181 \times \mathrm{T}-96.1 \times 10^{-6} \times \mathrm{T}^{2}+36.2 \times 10^{-9} \times \mathrm{T}^{3}
$$

Equation 19. $\mathrm{C}_{\mathrm{p}}$ of $\alpha-\mathrm{Zr}$ from $1100-2128 \mathrm{~K}\left(\mathrm{C}_{\mathrm{p}}\right.$ in $\mathrm{J} / \mathrm{kg} \cdot \mathrm{K}$, $\mathrm{T}$ in $\left.\mathrm{K}\right)$ [117]

$$
\mathrm{C}_{\mathrm{p}}=276.462+0.0141 \times \mathrm{T}-3.08 \times 10^{-6} \times \mathrm{T}^{2}+10.7 \times 10^{-9} \times \mathrm{T}^{3}
$$




\subsection{U-Zr Alloys}

\subsubsection{Introduction}

Although a number of researchers have measured heat capacities of U-Zr alloys at temperatures between $\sim 300$ and $850 \mathrm{~K}$, measured heat capacities of alloys with similar compositions made by different research groups may differ by $20-30 \%$. When measurements of different compositions made by a single research group are compared, heat capacities decrease with increasing concentration of $\mathrm{Zr}$.

Heat capacities between $\sim 850$ and $1000 \mathrm{~K}$ ( $~ 850$ and $900 \mathrm{~K}$ for high-Zr compositions) are highly dependent on composition because of phase transformations, and cannot be represented by smoothed values.

Heat capacities of $(\gamma-\mathrm{U}, \beta-\mathrm{Zr})$ solid solutions are only slightly dependent on temperature.

\subsubsection{Heat Capacities Below $850 \mathrm{~K}$}

Heat capacities of U-Zr alloys reported by Fedorov and Smirnov [119] were generally accepted until the late 1980s (e.g., [30, 64]). Later experimental work by Matsui et al. [61] and Takahashi et al. [63] suggested that these heat capacities were too high. More recent heat-capacity measurements of alloys with 6 and $7 \mathrm{wt} \% \mathrm{Zr}(\sim 14$ and 16.4 at\% Zr) $[62,120]$ are higher than those from Matsui et al. and Takahashi et al. [61, 63], and are higher than those of Federov and Smirnov [119] for alloys with similar compositions at some temperatures. Comparisons of heat capacity values from different compositions measured by the same research groups $[63,119]$ both indicate that heat capacities of U-Zr alloys decrease with increases in the concentration of $\mathrm{Zr}$.

Figure 26 shows measured heat capacities for U-Zr alloys with 13-41 at $\% \mathrm{Zr}$ at temperatures between 300 and $850 \mathrm{~K}$. Values for alloys with similar compositions measured by different research groups (e.g., 14 at $\% \operatorname{Zr}$ [63], 14.28 at\% Zr [62], and 16.4 at\% Zr [120]) differ by 20 - 30\%. Further data are clearly needed to obtain reliable heat-capacity values.

A recent review by Ogata [4] reported that the data of Matsui et al. [61] are in good agreement with a thermodynamic analysis by Kurata et al. [48] for temperatures below $850 \mathrm{~K}$. In the absence of further high-quality measurements, it seems appropriate to use the data of Matsui et al. for U-Zr alloys with less than $\sim 40$ at $\%(\sim 20 \mathrm{wt} \%) \mathrm{Zr}$.

Tabulated data values for the data from Matsui et al. can be found in reference [61]. However, a more convenient approach may be to use a polynomial that Kaity et al. [62] fitted to these data (Equation 20), noting that heat capacity is expressed in $\mathrm{J} / \mathrm{gram} \cdot \mathrm{K}$. 


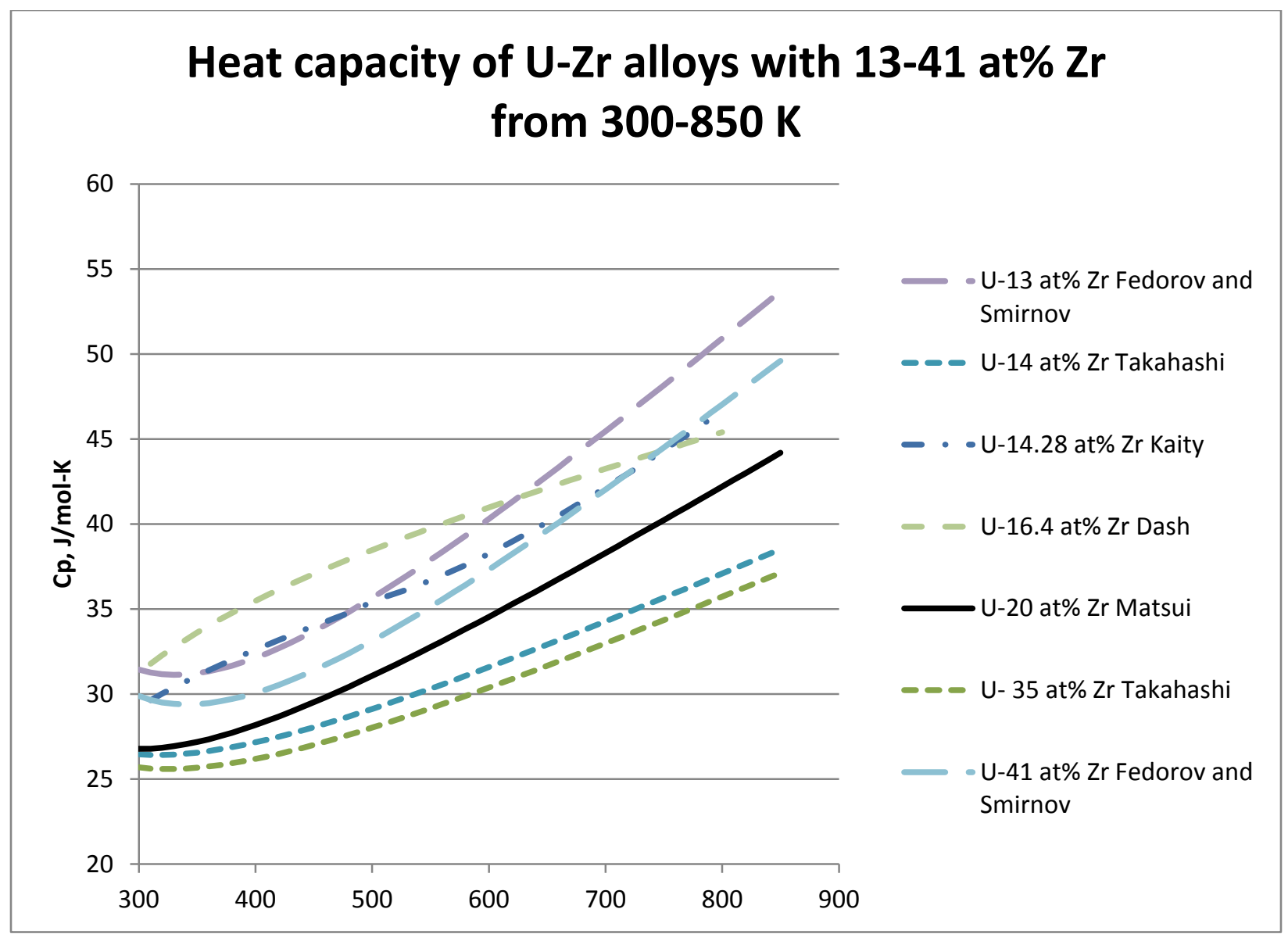

Figure 26. Measured heat capacities for $\mathrm{U}-\mathrm{Zr}$ alloys with $13-41 \mathrm{at} \% \mathrm{Zr}(\sim 5.5-21 \mathrm{wt} \% \mathrm{Zr})$ at temperatures from 300-850 K [61-63, 119, 120]. Different line types indicate different references.

Equation 20. $\mathrm{C}_{\mathrm{p}} \mathrm{U}$ of $\mathrm{U}-20$ at $\% \mathrm{Zr}(\mathrm{U}-9 \mathrm{wt} \% \mathrm{Zr})$ alloy from 289 to $852 \mathrm{~K}\left(\mathrm{C}_{\mathrm{p}}\right.$ in $\mathrm{J} / \mathrm{gram} \cdot \mathrm{K}, \mathrm{T}$ in $\left.\mathrm{K}\right)$ (Polynomial from [62], fitting data from [61]).

$$
\mathrm{C}_{\mathrm{p}}=37.99+0.2 \times \mathrm{T}+2.73 \times 10^{6} / \mathrm{T}^{2}
$$

\subsubsection{Heat Capacities between 850 and $1000 \mathrm{~K}$}

Heat capacities are highly dependent on composition and temperature between $\sim 850$ and $1000 \mathrm{~K}$ for samples with high concentrations of $\mathrm{U}$, and between $\sim 850$ and $900 \mathrm{~K}$ for samples with high concentrations of $\mathrm{Zr}$, because of phase transformations involved in the formation of $\gamma$-(U,Zr). Heat-capacity measurements for specific samples and temperatures can be found in the original references [61-63]. 


\subsubsection{Heat Capacities of $\gamma-(\mathrm{U}, \mathrm{Zr})$ Solid Solutions}

Heat capacities of $\gamma-(\mathrm{U}, \mathrm{Zr})$ solid solutions are summarized in Table 6. Experimental measurements $[61,63,119]$ and thermodynamic models [4] show only a limited dependence on temperature. Data from reference [61] appear anomalously high relative to data from reference [63]. Ogata [4] notes that the data of Takahashi et al. [63] are in good agreement with the thermodynamic analysis of Kurata et al. [48] for temperatures above $900 \mathrm{~K}$. Although further investigation is required, it seems reasonable to use the data of [63] at this point. It also seems likely that heat capacities in $\gamma-(\mathrm{U}, \mathrm{Zr})$ decrease slightly with increasing concentrations of $\mathrm{Zr}$.

Table 6. Heat capacities of $\gamma-(\mathrm{U}, \mathrm{Zr})$ solid solutions at $1000 \mathrm{~K}$.

\begin{tabular}{rrcc}
\hline $\mathrm{At} \% \mathrm{Zr}$ & $\mathrm{Wt} \% \mathrm{Zr}$ & $\mathrm{C}_{\mathrm{p}}(\mathrm{J} / \mathrm{mol} \cdot \mathrm{K})$ & Reference \\
\hline 14 & 6 & 35.8 & {$[63]$} \\
20 & 9 & 44.45 & {$[61]$} \\
35 & 17 & 34.3 & {$[63]$} \\
72 & 50 & 31.1 & {$[63]$} \\
91 & 80 & 31.0 & {$[63]$} \\
\hline
\end{tabular}

\subsection{Pu-Zr Alloys}

In the absence of published data on the heat capacity of any Pu-Zr alloy, it may be necessary to assume that properties of these alloys resemble those of $\mathrm{U}-\mathrm{Zr}$ alloys with similar concentrations of $\mathrm{Zr}$.

\subsection{U-Pu Alloys}

\subsubsection{Introduction}

Almost all of the published experimental data about the heat capacity of any of U-Pu alloy are from a single paper by Savage [94], who calculated specific heats from incremental enthalpies measured with drop-calorimetry. Savage concluded that the heat capacity of a U-10Pu alloy was similar to that of pure U. He presented quadratic equations representing heat capacities of individual phases as functions of temperature. Chiotti et al. [64] proposed an alternative set of equations to match the same data. The equations of Chiotti et al. [64] were accepted (with modifications to express heat capacity in J/mol-K rather than cal/mol-K) by Peterson and Foltyn [83] in their presentation of the currently accepted phase diagram.

It is important to note that Savage's conclusion that the heat capacities of U and U-10 Pu are similar was based on measurements of $U$ that were available at the time of his research. Savage's measurements for $\alpha-U$ and the average heat capacity of $\gamma-U$ are similar to the recommended values for pure $U$ in Section 3.1, but his values for $\beta-U$ and liquid $U$ are not. In the absence of new experimental data, it seems reasonable to qualitatively accept Savage's conclusion that heat capacities of U and U-10 Pu are similar, even when this leads to disagreement with his quantitative values. Further research is needed to test this suggestion, and to investigate thermophysical properties of other U-Pu alloys.

\subsubsection{Incremental Enthalpy of U-10Pu}

Figure 27 shows the incremental enthalpy of $\mathrm{U}-10 \mathrm{Pu}$, as represented by Peterson and Foltyn's polynomial fit to Savage's experimental results $[83,94]$. The incremental enthalpies of $(\beta-U),(\gamma-U)$, and liquid are linear functions of temperature. 


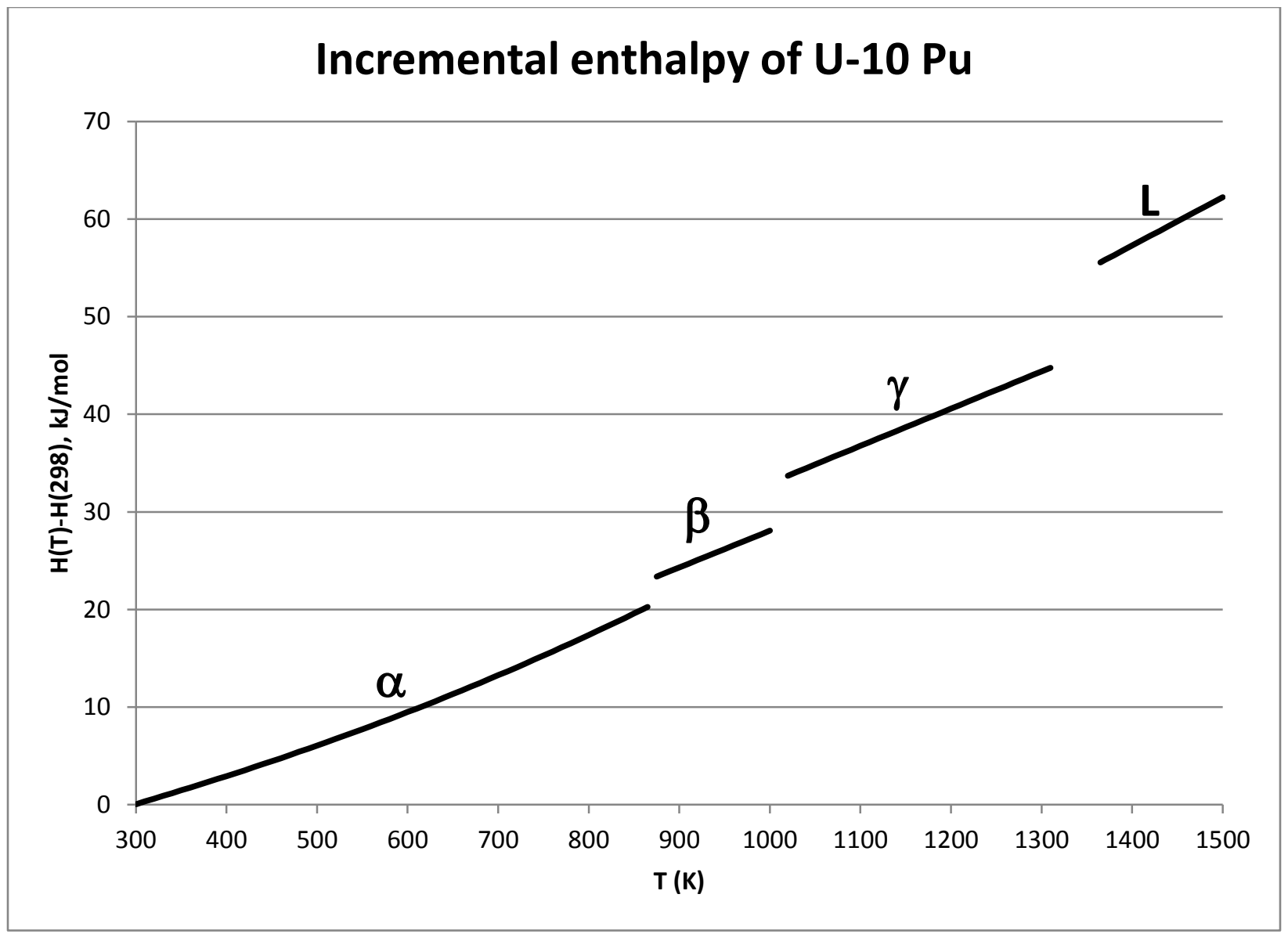

Figure 27. Incremental enthalpy $(\mathrm{H}(\mathrm{T})-\mathrm{H}(298))$ of $\mathrm{U}-10 \mathrm{Pu}$, calculated from Equation 21, Equation 22, Equation 23, and Equation 24 [83]

Equation 21. Incremental enthalpy of $(\alpha-\mathrm{U})$ phase in $\mathrm{U}-10 \mathrm{Pu}(\mathrm{H}$ in $\mathrm{J} / \mathrm{mol}$, $\mathrm{T}$ in $\mathrm{K}$, T between 298 and $865 \mathrm{~K})$ [83]

$$
\mathrm{H}(\mathrm{T})-\mathrm{H}(298)=-3948+12.196 \times \mathrm{T}+3.774 \times 10^{-2} \times \mathrm{T}^{2 / 2}-4.074 \times 10^{5} \times \mathrm{T}^{-1}
$$

Equation 22. Incremental enthalpy of $(\beta-\mathrm{U})$ phase in $\mathrm{U}-10 \mathrm{Pu}(\mathrm{H}$ in $\mathrm{J} / \mathrm{mol}, \mathrm{T}$ in $\mathrm{K}$, $\mathrm{T}$ between 875 and $1000 \mathrm{~K})[83]$

$$
\mathrm{H}(\mathrm{T})-\mathrm{H}(298)=-9517.3+37.572 \times \mathrm{T}
$$

Equation 23. Incremental enthalpy of $(\gamma-\mathrm{U})$ phase in $\mathrm{U}-10 \mathrm{Pu}(\mathrm{H}$ in $\mathrm{J} / \mathrm{mol}$, $\mathrm{T}$ in $\mathrm{K}$, $\mathrm{T}$ between 1020 and $1310 \mathrm{~K})[83]$

$$
\mathrm{H}(\mathrm{T})-\mathrm{H}(298)=-5189.4+38.116 \times \mathrm{T}
$$

Equation 24. Incremental enthalpy of U-10Pu liquid ( $\mathrm{H}$ in $\mathrm{J} / \mathrm{mol}$, $\mathrm{T}$ in $\mathrm{K}$, $\mathrm{T}$ between 1365 and $1500 \mathrm{~K})[83]$

$$
H(T)-H(298)=-11867+49.371 \times T
$$


A slightly earlier paper by Kelman et al. [112 Table VII] reported the enthalpy difference between $25^{\circ} \mathrm{C}$ and melting for a U-10Pu alloy as $46 \mathrm{cal} / \mathrm{g}(\sim 45.8 \mathrm{~kJ} / \mathrm{mol}$, consistent with the results published by Savage [94]). These data were repeated by Kittel [91]. Since Savage was an author of the Kelman et al. paper, the enthalpies in all three publications $[91,94,112]$ probably represent the same experimental results.

\subsubsection{Heat Capacity of U-10Pu}

Figure 28 shows the incremental enthalpy of $\mathrm{U}-10 \mathrm{Pu}$, as represented by Peterson and Foltyn's polynomial fit to Savage's experimental results $[83,94]$. Recommended values for the heat capacity of pure $U$ from Konings and Beneš [1] are shown for comparison. The heat capacities of $(\alpha-U)$ in $U-10 \mathrm{Pu}$ and pure $\alpha-\mathrm{U}$ are similar, and the average heat capacity for $(\gamma-\mathrm{U})$ in $\mathrm{U}-10 \mathrm{Pu}$ is slightly smaller than that for pure $\gamma-U$. Heat capacities of ( $\beta-U)$ in U-10 Pu and of liquid U-10 Pu are independent of temperature, as they are for $U$. However, the reported values of the heat capacities of $(\beta-U)$ and liquid U-10 Pu differ significantly from those for pure U. Further research is needed to understand why these differences occur, and to measure the heat capacities of other U-Pu alloys.

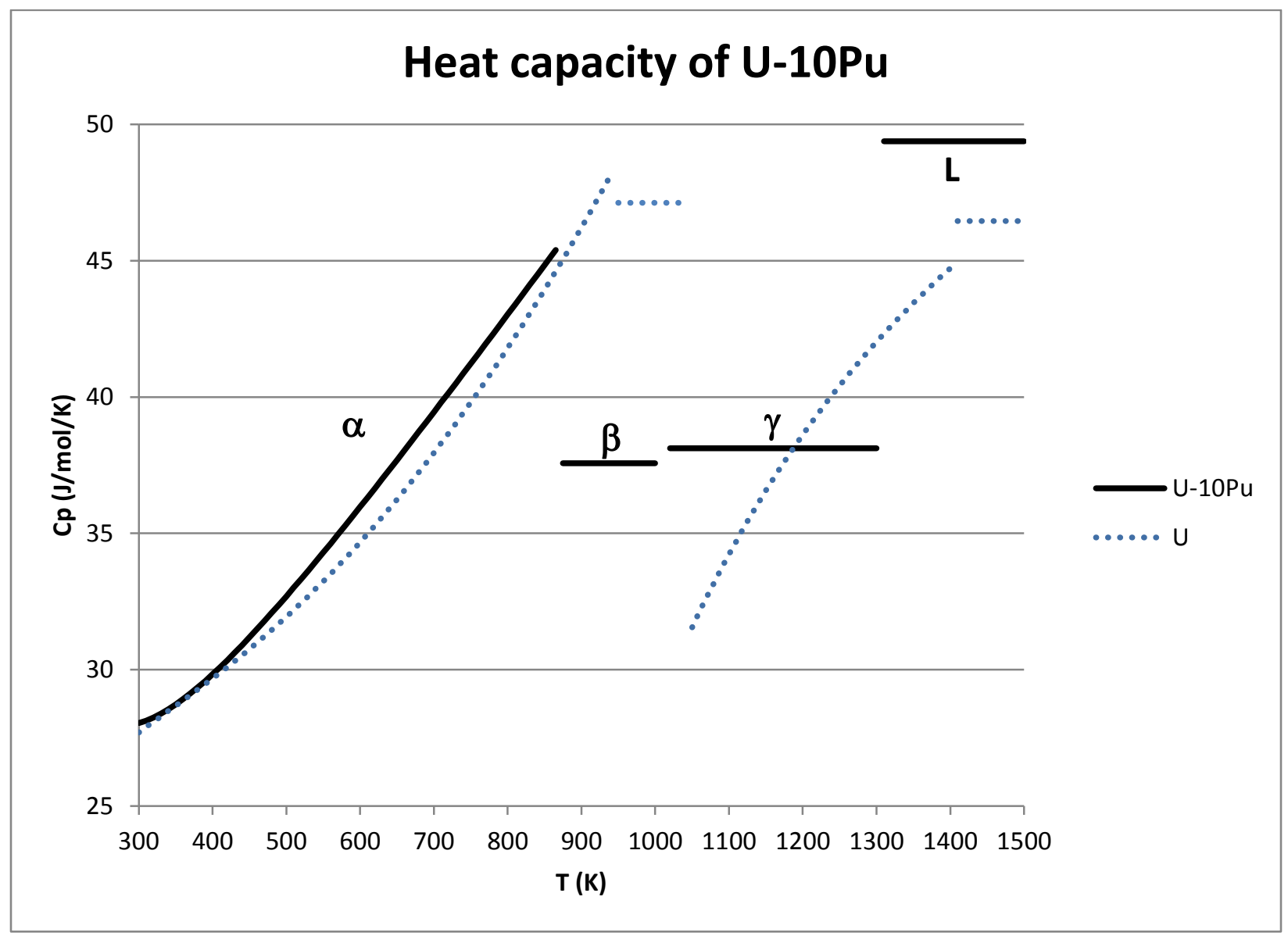

Figure 28. Heat capacity of U-10Pu (calculated from Equation 25, Equation 26, Equation 27, and Equation 28), with the heat capacity of $U$ [1] for comparison 
Equation 25. Heat capacity of $(\alpha-\mathrm{U})$ phase in $\mathrm{U}-10 \mathrm{Pu}\left(\mathrm{C}_{\mathrm{p}}\right.$ in $\mathrm{J} / \mathrm{mol} \cdot \mathrm{K}$, $\mathrm{T}$ in $\mathrm{K}$, $\mathrm{T}$ between 298 and $\left.865 \mathrm{~K}\right)$ [83]

$$
\mathrm{C}_{\mathrm{p}}=12.196+3.774 \times 10^{-2} \times \mathrm{T}+4.074 \times 10^{5} \times \mathrm{T}^{-2}
$$

Equation 26. Heat capacity of $(\beta-\mathrm{U})$ phase in $\mathrm{U}-10 \mathrm{Pu}\left(\mathrm{C}_{\mathrm{p}}\right.$ in $\mathrm{J} / \mathrm{mol} \cdot \mathrm{K}$, $\mathrm{T}$ in $\mathrm{K}$, $\mathrm{T}$ between 875 and $1000 \mathrm{~K})[83]$

$$
\mathrm{C}_{\mathrm{p}}=37.572
$$

Equation 27. Heat capacity of $(\gamma-\mathrm{U})$ phase in $\mathrm{U}-10 \mathrm{Pu}\left(\mathrm{C}_{\mathrm{p}}\right.$ in $\mathrm{J} / \mathrm{mol} \cdot \mathrm{K}, \mathrm{T}$ in $\mathrm{K}$, $\mathrm{T}$ between 1020 and $1310 \mathrm{~K})[83]$

$$
\mathrm{C}_{\mathrm{p}}=38.116
$$

Equation 28. Heat capacity of $\mathrm{U}-10 \mathrm{Pu}$ liquid $\left(\mathrm{C}_{\mathrm{p}}\right.$ in $\mathrm{J} / \mathrm{mol} \cdot \mathrm{K}, \mathrm{T}$ in $\mathrm{K}$, $\mathrm{T}$ between 1365 and $\left.1500 \mathrm{~K}\right)[83$ ]

$$
\mathrm{C}_{\mathrm{p}}=49.371
$$

\subsection{U-Pu-Zr Alloys}

\subsubsection{Introduction}

The only published experimental data about the heat capacity of any of U-Pu-Zr alloy are from a single paper by Savage [94], which includes the specific heat of U-15 wt $\% \mathrm{Pu}-10 \mathrm{wt} \% \mathrm{Zr}$ calculated from incremental enthalpies measured using drop calorimetry. Savage concluded that the heat capacity of $\mathrm{U}-15 \mathrm{Pu}-10 \mathrm{Zr}$ is similar to that of pure $\mathrm{U}$ at temperatures up to about $500^{\circ} \mathrm{C}$ and about $10 \%$ lower than that of $\mathrm{U}$ at temperatures of $800^{\circ} \mathrm{C}$ and above. However, comparison of Savage's U-Pu-Zr data with heat-capacity data from pure $U$ [1] suggests that the heat capacities of the two materials are sufficiently similar that the recommended heat-capacity values for $U$ from reference [1] can be used to represent the heat capacity of $\mathrm{U}-15 \mathrm{Pu}-10 \mathrm{Zr}$ even at temperatures above $800^{\circ} \mathrm{C}$. Recommended heat capacities from other references such as Oetting et al. and Grenthe et al. $[3,11]$ are less similar to the heat capacity of $\mathrm{U}-15 \mathrm{Pu}-10 \mathrm{Zr}$ because they treat the heat capacity of $\gamma-\mathrm{U}$ as independent of temperature.

Further work on other $\mathrm{U}-\mathrm{Pu}-\mathrm{Zr}$ alloys is clearly required, including research at higher temperatures.

\subsubsection{Incremental Enthalpy of U-15 wt\% Pu-10 wt\% Zr}

Figure 29 shows Savage's measurements of the incremental enthalpy of U-15Pu-10Zr. Symbols indicate measured data, and curves represent Savage's fit to the measured data. Savage attributes the abrupt rise in the incremental enthalpy between 600 and $650{ }^{\circ} \mathrm{C}$ to the transformation from $(\alpha-\mathrm{U})$ to $(\gamma-\mathrm{U})$ and disappearance of $\left(\delta-\mathrm{UZr}_{2}\right)$. Although Savage does not give a minimum temperature, the non-zero incremental enthalpy at $0^{\circ} \mathrm{C}$ suggests that in practice this equation should not be extrapolated to temperatures below the measured range. 


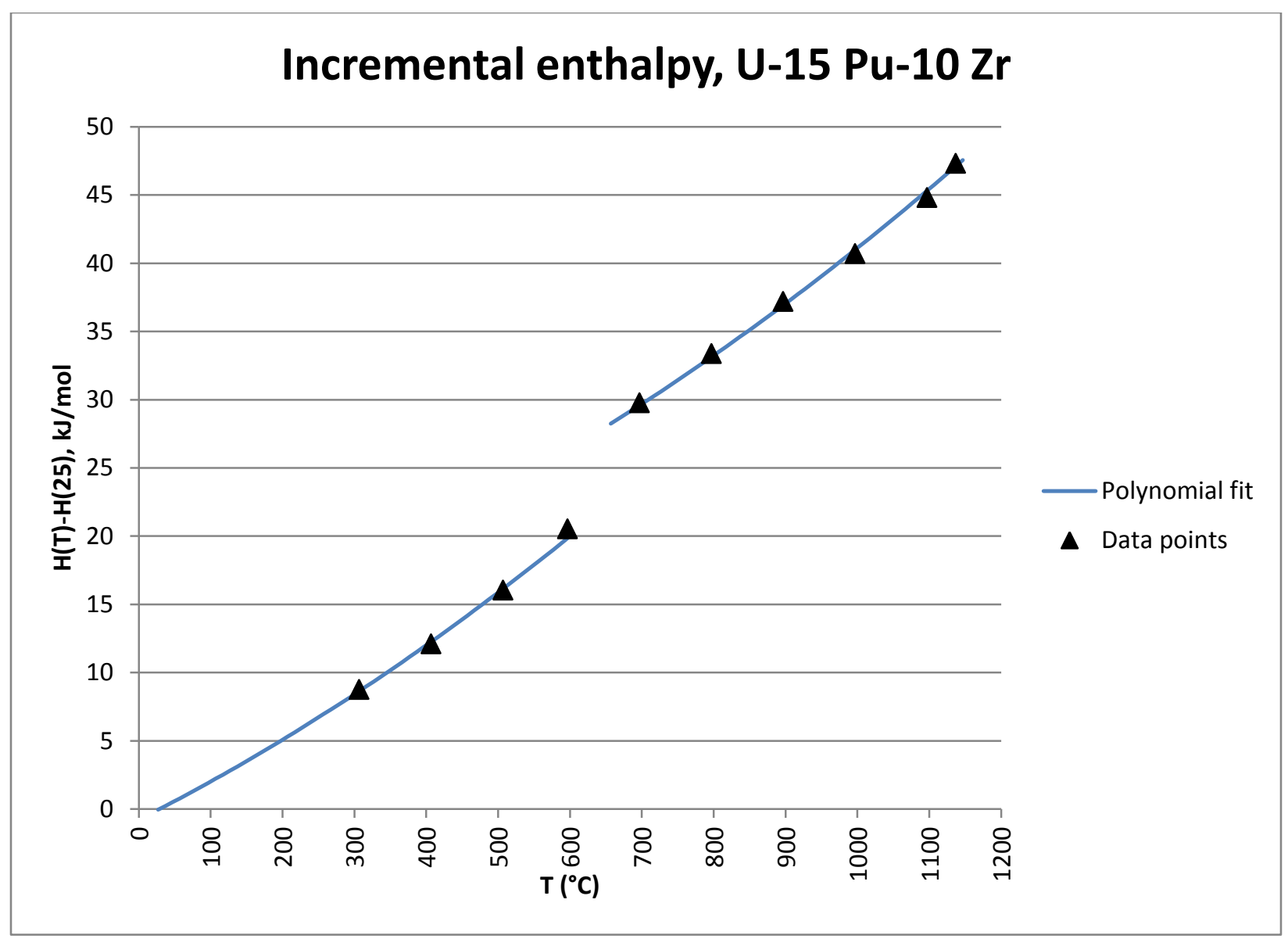

Figure 29. Incremental enthalpy $(\mathrm{H}(\mathrm{T})-\mathrm{H}(25))$ of $\mathrm{U}-15 \mathrm{wt} \% \mathrm{Pu}-10 \mathrm{wt} \% \mathrm{Zr}$ [94]. Note that temperature is in ${ }^{\circ} \mathrm{C}$. Triangles are measured data points, and lines are calculated from Equation 29 and Equation 30.

Equation 29. Incremental enthalpy of U-15Pu-10Zr [94] ( $\mathrm{H}$ in $\mathrm{kcal} / \mathrm{mol}$, $\mathrm{T}$ between 25 and $\left.600^{\circ} \mathrm{C}\right)$

$$
\mathrm{H}(\mathrm{T})-\mathrm{H}(25)=-0.185+0.00636 \times \mathrm{T}+0.00000318 \times \mathrm{T}^{2}
$$

Equation 30. Incremental enthalpy of $\mathrm{U}-15 \mathrm{Pu}-10 \mathrm{Zr}[94]$ ( $\mathrm{H}$ in $\mathrm{kcal} / \mathrm{mol}$, $\mathrm{T}$ between 650 and $1150^{\circ} \mathrm{C}$ )

$$
\mathrm{H}(\mathrm{T})-\mathrm{H}(25)=2.91+0.00379 \times \mathrm{T}+0.00000312 \times \mathrm{T}^{2}
$$

\subsubsection{Heat capacity of U-15 wt\% Pu-10 wt $\% \mathrm{Zr}$}

Figure 30 shows the heat capacity of $\mathrm{U}-15 \mathrm{Pu}-10 \mathrm{Zr}$ calculated from incremental enthalpy data measured with drop calorimetry (Section 4.7.2), with recommended values for the heat capacity of pure $U$ from Konings and Beneš [1] for comparison. Savage et al. represented the heat capacity of U-15Pu-10Zr by two equations, one corresponding to temperatures below the transformation of $(\alpha-U)$ to $(\gamma-U)$ and the disappearance of $\left(\delta-\mathrm{UZr}_{2}\right)$ at $\sim 600^{\circ} \mathrm{C}$, and one corresponding to $(\gamma-\mathrm{U})\left(\sim 650-1150^{\circ} \mathrm{C}\right)$. Both equations are linear functions of temperature. 


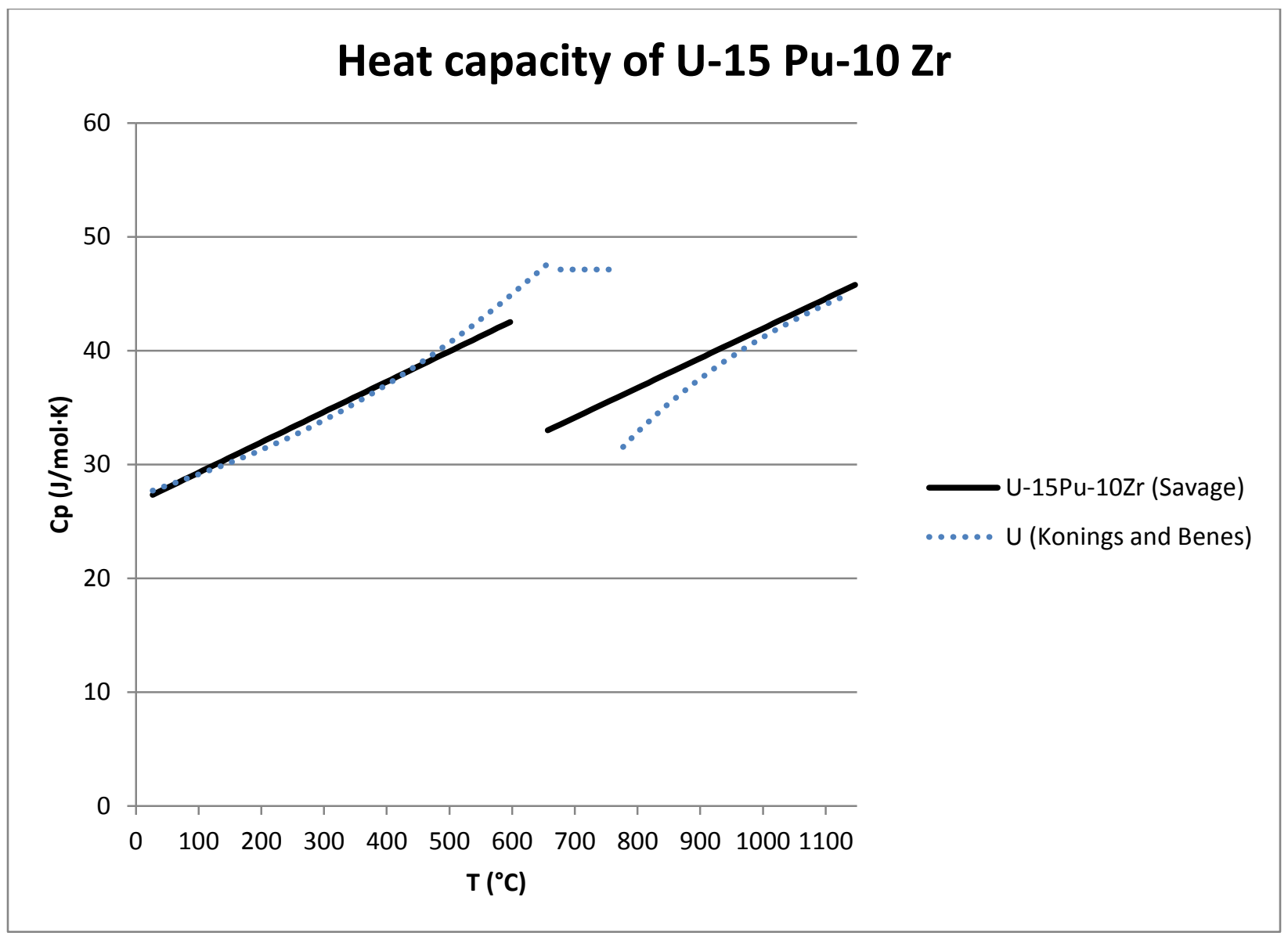

Figure 30. Heat capacity of U-15Pu-10Zr (by weight), calculated from Equation 31 and Equation 32 [94]. The heat capacity of pure $U[1]$ is provided for comparison.

Equation 31. Heat capacity of $\mathrm{U}-15 \mathrm{Pu}-10 \mathrm{Zr}[94]\left(\mathrm{C}_{\mathrm{p}}\right.$ in cal $/ \mathrm{mol} \cdot{ }^{\circ} \mathrm{C}$, $\mathrm{T}$ between 25 and $\left.600^{\circ} \mathrm{C}\right)$ $\mathrm{Cp}(\mathrm{U}-15 \mathrm{Pu}-10 \mathrm{Zr})=6.36+0.00636 \times \mathrm{T}$

Equation 32. Heat capacity of U-15Pu-10Zr $[94]\left(\mathrm{C}_{\mathrm{p}}\right.$ in $\mathrm{cal} / \mathrm{mol} \cdot{ }^{\circ} \mathrm{C}$, $\mathrm{T}$ between 650 and $\left.1150^{\circ} \mathrm{C}\right)$ $\mathrm{Cp}(\mathrm{U}-15 \mathrm{Pu}-10 \mathrm{Zr})=3.79+0.00623 \times \mathrm{T}$ 


\title{
5. THERMAL EXPANSION, THERMAL EXPANSION COEFFICIENTS, AND DENSITY-TEMPERATURE RELATIONSHIPS
}

\author{
$5.1 \mathrm{U}$
}

\subsubsection{Introduction}

Numerous measurements of the thermal expansion of $\alpha-U$ have been published, and results are generally in good agreement. Although only a few measurements of thermal expansion of $\beta$-U have been published, they are in good agreement. Data on the thermal expansion of $\gamma-\mathrm{U}$ are rare.

Thermal expansion of single crystals of $\alpha-U$ is highly anisotropic, with increases in length along two of three mutually orthogonal directions and a decrease in length along the third during heating. It is commonly assumed that the thermal expansion of a polycrystalline $U$ sample can be predicted from single-crystal data. In practice, however, polycrystalline U samples develop surface roughness, change shape, and increase in volume (and, therefore, decrease in density) as a result of thermal cycling, presumably because of internal strains from differential expansion of adjacent crystals with different orientations (e.g., [121-124]). This effect can be large, as shown by a 100\% increase in the length of one sample [124]. Consequences of thermal cycling are highly sample-dependent and may be influenced by factors such as grain size, preferred orientation, sample fabrication and processing, and thermal history.

\subsubsection{Thermal Expansion}

Touloukian et al. [5] published recommended thermal expansion values for $\alpha-U$ (single crystals and polycrystalline samples) and provisional thermal expansion values for $\beta$-, and $\gamma$-U based on a review of 48 previously published measurements (Figure 31). These measurements were obtained using a variety of techniques and samples, including a number of single crystals. More recent thermal expansion measurements of $\alpha-U$ and $\gamma-U$ from dilatometry of an as-cast sample of polycrystalline $U$ by Basak et al. [125] are significantly below the values of Touloukian et al., although the thermal expansion of $\alpha-U$ reported by Basak et al. is comparable to the lowest values reported by Touloukian et al. Further investigation is needed to determine which results are most representative of the actual behavior of polycrystalline $U$. 


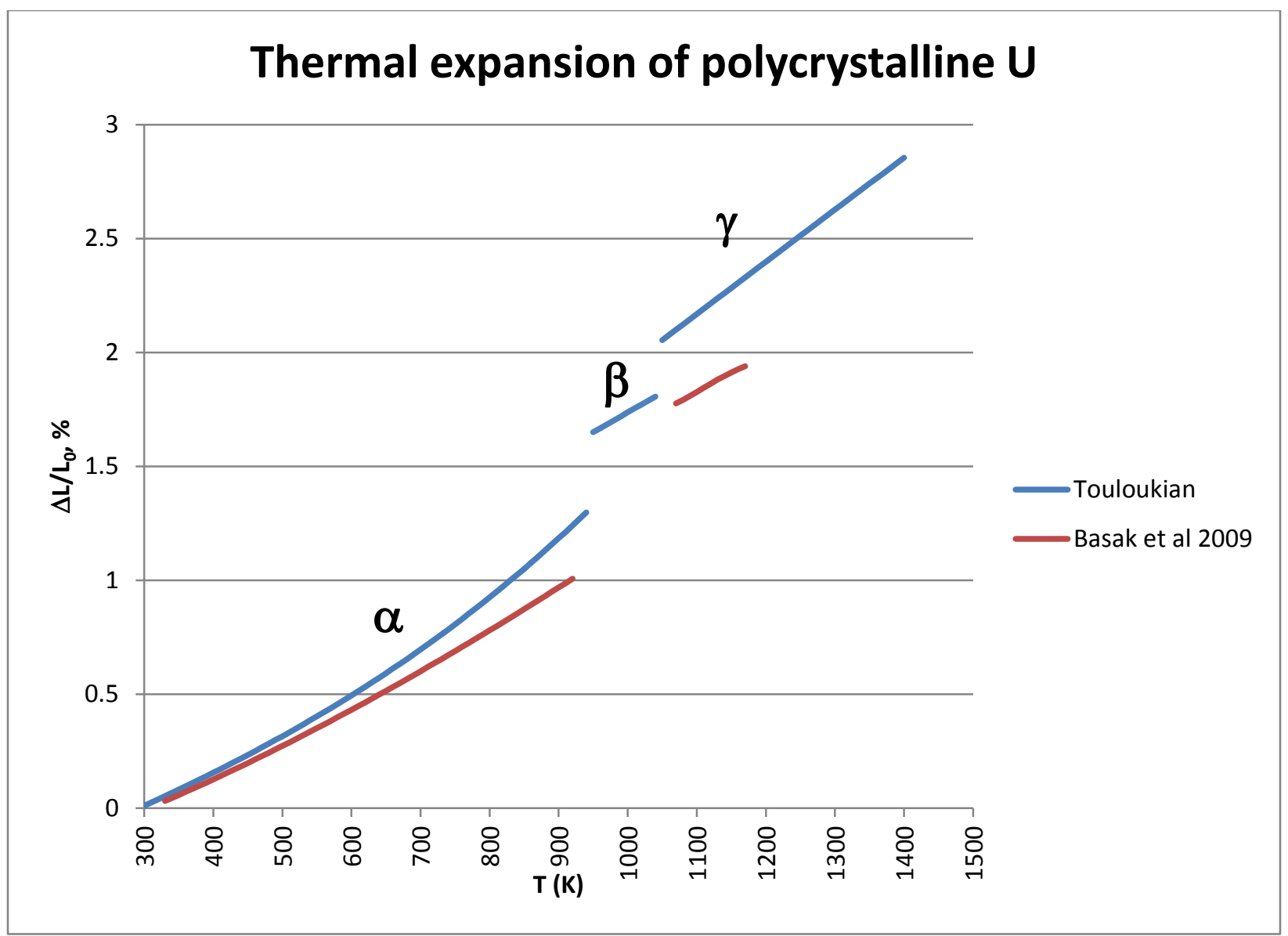

Figure 31. Thermal expansion of polycrystalline $U$ [5, 125], calculated using Equation 33 through Equation 37

Polynomials representing the thermal expansion of $\alpha-U$ are:

Equation 33. Recommended values for mean thermal expansion of polycrystalline $\alpha-U$ according to Touloukian et al. [5] (thermal expansion in \%, T in K, T from 293 to $941 \mathrm{~K}, \mathrm{~L}$ is length at temperature T, $\mathrm{L}_{0}$ is length at $293 \mathrm{~K}$ )

$$
\left(\mathrm{L}_{-} \mathrm{L}_{0}\right) / \mathrm{L}_{0}=-0.379+1.264 \times 10^{-3} \times \mathrm{T}-8.982 \times 10^{-8} \times \mathrm{T}^{2}+6.844 \times 10^{-10} \times \mathrm{T}^{3}
$$

Equation 34. Mean thermal expansion of polycrystalline $\alpha-U$ according to data of Basak et al. [125] (thermal expansion in \%, T in $\mathrm{K}, \mathrm{T}$ from 323 to $923 \mathrm{~K}, \mathrm{~L}$ is length at temperature $\mathrm{T}, \mathrm{L}_{0}$ is length at $323 \mathrm{~K}$ )

$$
\left(\mathrm{L}-\mathrm{L}_{0}\right) / \mathrm{L}_{0}=-0.326+8.338 \times 10^{-4} \times \mathrm{T}+8.038 \times 10^{-7} \times \mathrm{T}^{2}-1.465 \times 10^{-10} \times \mathrm{T}^{3}
$$

Although Touloukian et al. [5] and Basak et al. [125] did not publish equations expressing the thermal conductivity of $\beta-U$, Konings et al. [2] developed Equation 35 to represent the data used to determine the provisional values of Touloukian et al. [5].

Equation 35. Mean thermal expansion of polycrystalline $\beta-U$ according to the equation developed by Konings et al. [2] (thermal expansion in \%, T in K, T from 945 to $1045 \mathrm{~K}, \mathrm{~L}$ is length at temperature $\mathrm{T}, \mathrm{L}_{0}$ is length at $293 \mathrm{~K}$ )

$$
\left(\mathrm{L}-\mathrm{L}_{0}\right) / \mathrm{L}_{0}=8.04 \times 10^{-5}+1.729 \times 10^{-5} \times \mathrm{T}
$$


Polynomials representing the thermal expansion of $\gamma$-U are:

Equation 36. Provisional values for mean thermal expansion of polycrystalline $\gamma$-U according to Touloukian et al. [5] (thermal expansion in \%, T in K, T from 1048 to $1400 \mathrm{~K}$, L is length at temperature $\mathrm{T}, \mathrm{L}_{0}$ is length at $293 \mathrm{~K}$ )

$$
\left(\mathrm{L}-\mathrm{L}_{0}\right) / \mathrm{L}_{0}=-0.149+1.775 \times 10^{-3} \times \mathrm{T}+4.382 \times 10^{-7} \times \mathrm{T}^{2}-1.239 \times 10^{-10} \times \mathrm{T}^{3}
$$

Equation 37. Mean thermal expansion of polycrystalline $\gamma-U$ according to data of Basak et al. [125] (thermal expansion in \%, T in $\mathrm{K}, \mathrm{T}$ from 1063 to $1173 \mathrm{~K}, \mathrm{~L}$ is length at temperature $\mathrm{T}, \mathrm{L}_{0}$ is length at $323 \mathrm{~K})$

$$
\left(\mathrm{L}-\mathrm{L}_{0}\right) / \mathrm{L}_{0}=81.794-21.986 \times 10^{-2} \times \mathrm{T}+19.985 \times 10^{-5} \times \mathrm{T}^{2}-6.006 \times 10^{-8} \times \mathrm{T}^{3}
$$

\subsubsection{Thermal Expansion Coefficients}

Average values for linear thermal expansion coefficients of $\alpha-\mathrm{U}$ parallel to the $a, b$, and $c$ crystallographic directions are $26.5 \times 10^{-6} \mathrm{~K}^{-1},-2.4 \times 10^{-6} \mathrm{~K}^{-1}$, and $23.9 \times 10^{-6} \mathrm{~K}^{-1}$ over temperature ranges from $25-325^{\circ} \mathrm{C}$ [113]. Touloukian et al. [5] provide an extensive tabulation of older data from individual samples, and Lawson et al. [9] published high-resolution neutron-diffraction data.

The linear thermal expansion coefficients for $\beta$-U are $\sim 23 \times 10^{-6} \mathrm{~K}^{-1}$ parallel to $a$ and $\sim 5 \times 10^{-6} \mathrm{~K}^{-1}$ parallel to $c[9,124,126]$, corresponding to an average thermal expansion coefficient of $\sim 17 \times 10^{-6} \mathrm{~K}^{-1}$.

The linear thermal expansion coefficient for $\gamma$ - $\mathrm{U}$ is $(22.5 \pm 1.3) \times 10^{-6} \mathrm{~K}^{-1}$ [124].

\subsubsection{Density}

Room-temperature densities of $U$ phases are [127]:

- $\alpha-U, 19.04 \mathrm{~g} / \mathrm{cm}^{3}$

- $\beta-\mathrm{U}, 18.11 \mathrm{~g} / \mathrm{cm}^{3}$

- $\gamma-\mathrm{U}, 18.06 \mathrm{~g} / \mathrm{cm}^{3}$.

The high-temperature density of solid $U$ can calculated from the room-temperature volume and thermal expansion (Equation 38) or from high-temperature diffraction data. The high-temperature density of liquid U can be calculated using Equation 39.

Equation 38. Density of solid $U$ as a function of thermal expansion [2]

$$
\rho(T)=\frac{238}{12.50\left(1+3 \frac{\Delta L}{L_{0}(T)}\right)}
$$

where $\rho(T)$ is the density at temperature T, M is the atomic mass ( 238 for $U), V_{0}$ is the molar volume at the reference temperature $\left(12.50 \mathrm{~cm}^{3} / \mathrm{mol}\right.$ near room temperature for $\left.\alpha-\mathrm{U}\right)$, and $\Delta \mathrm{L} / \mathrm{L}_{0}$ is the thermal expansion expressed as a fraction

The density of liquid U can be calculated using Equation 39.

Equation 39. Density of liquid $\mathrm{U}$ (density in $\mathrm{g} / \mathrm{cm}^{3}$, $\mathrm{T}$ in $\mathrm{K}$, $\mathrm{T}$ between 1405 and $2100 \mathrm{~K}$ ) [2, 117]

$$
\rho=20.332-2.146 \times \mathrm{T}
$$


Figure 32 shows the high-temperature density of U. Data labeled "Klepfer and Chiotti" and "Lawson et al." are from high-temperature X-ray and neutron diffraction data, respectively [9, 124]. Data labeled "Touloukian" were calculated from Touloukian's equations for thermal expansion (Equation 33, Equation 35, Equation 36) using Equation 38. Data labeled "Konings et al." were calculated using Equation 39. Where densities from more than one kind of information are available, they are in good agreement.

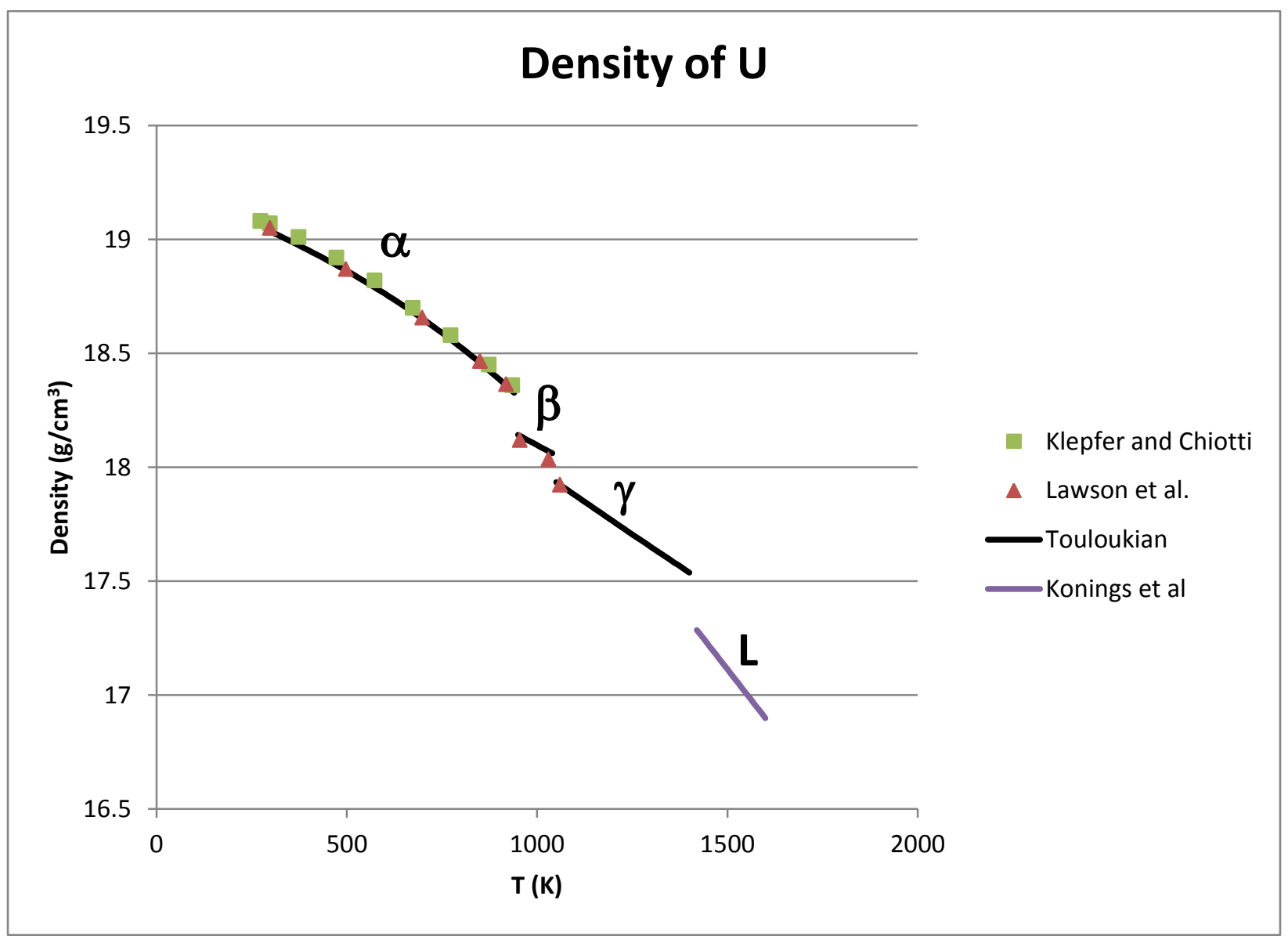

Figure 32. Density of U.

\section{$5.2 \mathrm{Pu}$}

\subsubsection{Introduction}

Measuring the thermal expansion of $\mathrm{Pu}$ is difficult, and there are wide variations between individual measurements reported in the literature. Detailed studies of phase-transformation mechanisms by Ennaceur $[21-24,128]$ show that transformations in individual samples are affected by factors such as previous thermal and phase-transformation history, and that the order in which transformations occur may be different during heating and cooling. Understanding thermal expansion is further complicated by the anisotropic thermal expansion of $\alpha-\mathrm{Pu}, \beta-\mathrm{Pu}, \gamma-\mathrm{Pu}$, and $\delta^{\prime}-\mathrm{Pu}$, and by the negative thermal expansion of $\delta$-Pu and $\delta^{\prime}-\mathrm{Pu}$. Even when phase transformations are not involved, thermal expansion of polycrystalline aggregates may be vary between individual samples. Addition of a few at $\%$ of alloying elements such as $\mathrm{Ga}$ and $\mathrm{Al}$ produces large changes in thermal expansion behavior [12]. 
Recent attempts to model the thermal expansion of $\mathrm{Pu}$ have emphasized understanding the negative expansion of $\delta$-Pu and its relationship to elastic properties [129-133].

\subsubsection{Thermal Expansion}

Reviews of experimental measurements of thermal expansion of $\mathrm{Pu}[5,12,13,134]$ generally agree about the thermal expansion of individual Pu phases (Figure 33), although expansions associated with phase transformations are less consistent.

Equations representing the thermal dependence of $\alpha$-Pu have been developed by Touloukian et al. [5] (Equation 40) and by Schonfeld and Tate [134]. Values produced by the two equations agree to within $\sim 0.1 \%$.

The thermal expansion of $\beta-, \gamma-, \delta$-, $\delta^{\prime}$, and $\varepsilon-\mathrm{Pu}$ has a very limited dependence on temperature, and can be represented using the values in Table 7.

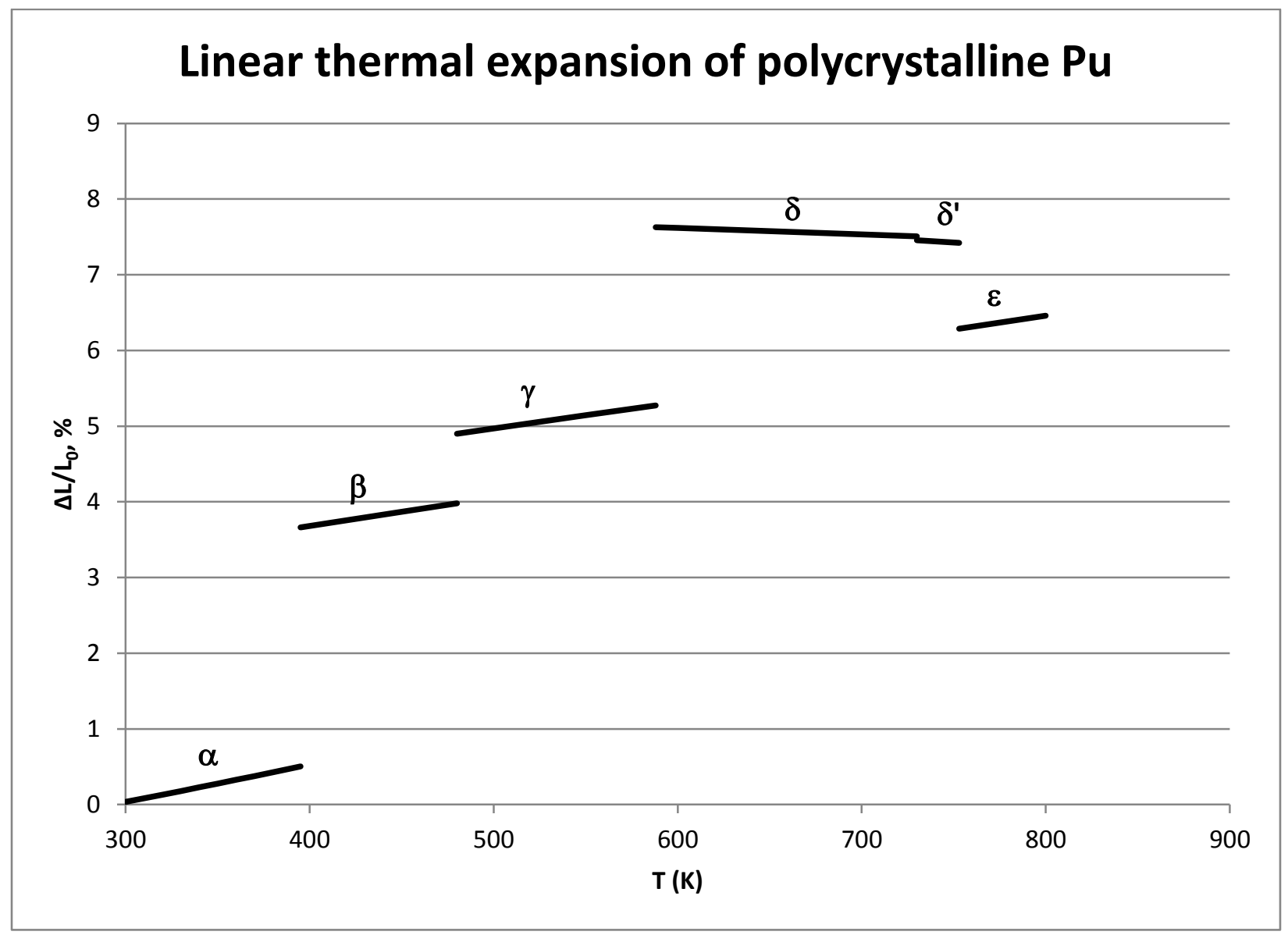

Figure 33. Linear thermal expansion of polycrystalline $\mathrm{Pu}[134]$.

Equation 40. Thermal expansion of $\alpha-\mathrm{Pu}$ [5] (thermal expansion in \%, T in $\mathrm{K}$, $\mathrm{T}$ from 200 to $395 \mathrm{~K}$, $\mathrm{L}$ is length at temperature $T, \mathrm{~L}_{0}$ is length at $293 \mathrm{~K}$ )

$$
\left(\mathrm{L}-\mathrm{L}_{0}\right) / \mathrm{L}_{0}=-0.407+4.099 \times 10^{-3} \times(\mathrm{T}-200)+3.552 \times 10^{-6} \times(\mathrm{T}-200)^{2}-3.360 \times 10^{-9} \times(\mathrm{T}-200)^{3}
$$

\subsubsection{Thermal Expansion Coefficients}

Table 7 summarizes mean coefficients of thermal expansion for $\beta-, \gamma-, \gamma^{\prime}, \delta-, \varepsilon$ - and liquid Pu from several reviews. There is generally good agreement between the reviews for all of the phases in the table. 
Values for solid phases are for ideal polycrystalline materials with no preferred orientation. The thermal expansion of these phases is largely independent of temperature, and the mean coefficients can be used throughout the stability fields of the individual phases [135]. (The thermal expansion coefficient of $\alpha-\mathrm{Pu}$ is not included in the table because the thermal expansion of $\alpha-\mathrm{Pu}$ is a non-linear function of temperature, so its thermal expansion is not a constant.) Values for liquid $\mathrm{Pu}$ are volumetric thermal expansion coefficients, each of which is approximately three times the corresponding linear coefficient, and are independent of temperature.

Table 7. Thermal expansion coefficients $\left(10^{-6} / \mathrm{K}\right)$ of solid and liquid $\mathrm{Pu}[5,13,134]$.

\begin{tabular}{cccc}
\hline Phase & Reference [13] & Reference [5] & Reference [134] \\
\hline$\beta$ & 42 & 37.3 & 42.3 \\
$\gamma$ & $34.6 \pm 0.7$ & 34.6 & 34.7 \\
$\delta$ & $-8.6 \pm 0.3$ & -8.6 & -9.0 \\
$\delta^{\prime}$ & $-65.6 \pm 10.1$ & -16.1 & -66 \\
$\varepsilon$ & 36.5 & 36.6 & \\
Liquid & 93 (volumetric) & 90.4 (volumetric) & \\
\hline
\end{tabular}

${ }^{1}$ Average of two values

Table 8 shows values of mean coefficients of thermal expansion along single directions for anisotropic $\mathrm{Pu}$ phases. $\delta$-Pu, $\varepsilon-\mathrm{Pu}$, and liquid are not included in the table because their thermal expansion is isotropic.

Table 8. Mean linear coefficients of thermal expansion along single directions for anisotropic $\mathrm{Pu}$ phases [13].

\begin{tabular}{|c|c|c|c|c|}
\hline Phase & Coefficient $^{\mathrm{a}}$ & Crystallographic orientation & $\begin{array}{c}\text { Temperature range } \\
\left({ }^{\circ} \mathrm{C}\right)\end{array}$ & $\begin{array}{l}\text { Value } \\
\left(10^{-6} / \mathrm{C}\right)\end{array}$ \\
\hline \multirow[t]{3}{*}{$\alpha$} & $\bar{\alpha}_{1}$ & $\perp$ c-axis & $21-104$ & 60 \\
\hline & $\bar{\alpha}_{2}$ & $\|$ b-axis & & 75 \\
\hline & $\bar{\alpha}_{3}$ & $\|$ c-axis & & 29 \\
\hline \multirow[t]{3}{*}{$\beta$} & $\bar{\alpha}_{1}$ & & $93-190$ & 94 \\
\hline & $\bar{\alpha}_{2}$ & $\|$ b-axis ${ }^{b}$ & & 14 \\
\hline & $\bar{\alpha}_{3}$ & $\perp(10 \overline{1})$ & & 19 \\
\hline \multirow[t]{3}{*}{$\gamma$} & $\bar{\alpha}_{a}$ & $\|$ a-axis & $210-310$ & $-19.7 \pm 1.0$ \\
\hline & $\bar{\alpha}_{\mathrm{b}}$ & $\|$ b-axis & & $39.5 \pm 0.6$ \\
\hline & $\bar{\alpha}_{c}$ & $\| \mathrm{c}$-axis & & $84.3 \pm 1.6$ \\
\hline \multirow[t]{2}{*}{$\delta^{\prime}$} & $\bar{\alpha}_{a}$ & $\|$ a-axis & $452-480$ & $444.8 \pm 12.1$ \\
\hline & $\bar{\alpha}_{c}$ & $\|$ c-axis & & $-1063.5 \pm 18.2$ \\
\hline
\end{tabular}

a. Overbar indicates that these are mean coefficients; subscripts identify individual coefficients. All coefficients for each phase are mutually orthogonal.

b. In space group $I 2 / \mathrm{m}$.

\subsubsection{Density}

The density of $\mathrm{Pu}$ varies by at most a few tenths of a gram per cubic centimeter within each phase. These differences are relatively small compared to differences between phases and the likely uncertainties in the density data, and can be neglected for most purposes. 
Densities of $\mathrm{Pu}$ phases (in $\mathrm{g} / \mathrm{cm}^{3}$ at listed temperatures) are [117]:

- $\quad \alpha-P u, 19.816(298 \mathrm{~K})$

- $\quad \beta-\mathrm{Pu}, 17.770(463 \mathrm{~K})$

- $\gamma-\mathrm{Pu}, 17.140(508 \mathrm{~K})$

- $\delta-\mathrm{Pu}, 15.920(593 \mathrm{~K})$

- $\quad \delta^{\prime}-\mathrm{Pu}, 16.01(723 \mathrm{~K})$

- $\quad \varepsilon-\mathrm{Pu}, 16.48(783 \mathrm{~K})$.

\section{$5.3 \mathrm{Zr}$}

\subsubsection{Introduction}

The thermal expansion of $\alpha-\mathrm{Zr}$ is anisotropic. There is generally good agreement about its thermal expansion for single-crystal and polycrystalline materials $[5,136]$. Variations in expansion as a result of thermal cycling have been reported [136]. The thermal expansion of $\beta-\mathrm{Zr}$ is less commonly studied, but there is generally good agreement about linear expansion of polycrystalline materials at temperatures up to $\sim 1800 \mathrm{~K}$. Higher-temperature measurements (to $2100 \mathrm{~K}$ for $\beta-\mathrm{Zr}$ and $2300 \mathrm{~K}$ for liquid) have been reported in a single publication [28].

Recent research has emphasized detailed investigation of changes in thermal expansion during the $\alpha-\beta$ phase transformation [137], extending measurements to higher temperatures $[28,118,136]$, and modeling [138, 139].

\subsubsection{Thermal Expansion}

Figure 34 shows recently recommended values for the thermal expansion of polycrystalline $\mathrm{Zr}$ [136]. Values for thermal expansion (in \%) differ by less than 0.05 from the earlier recommendations of Touloukian et al. [5], with the largest difference occurring immediately above the phase transformation. 


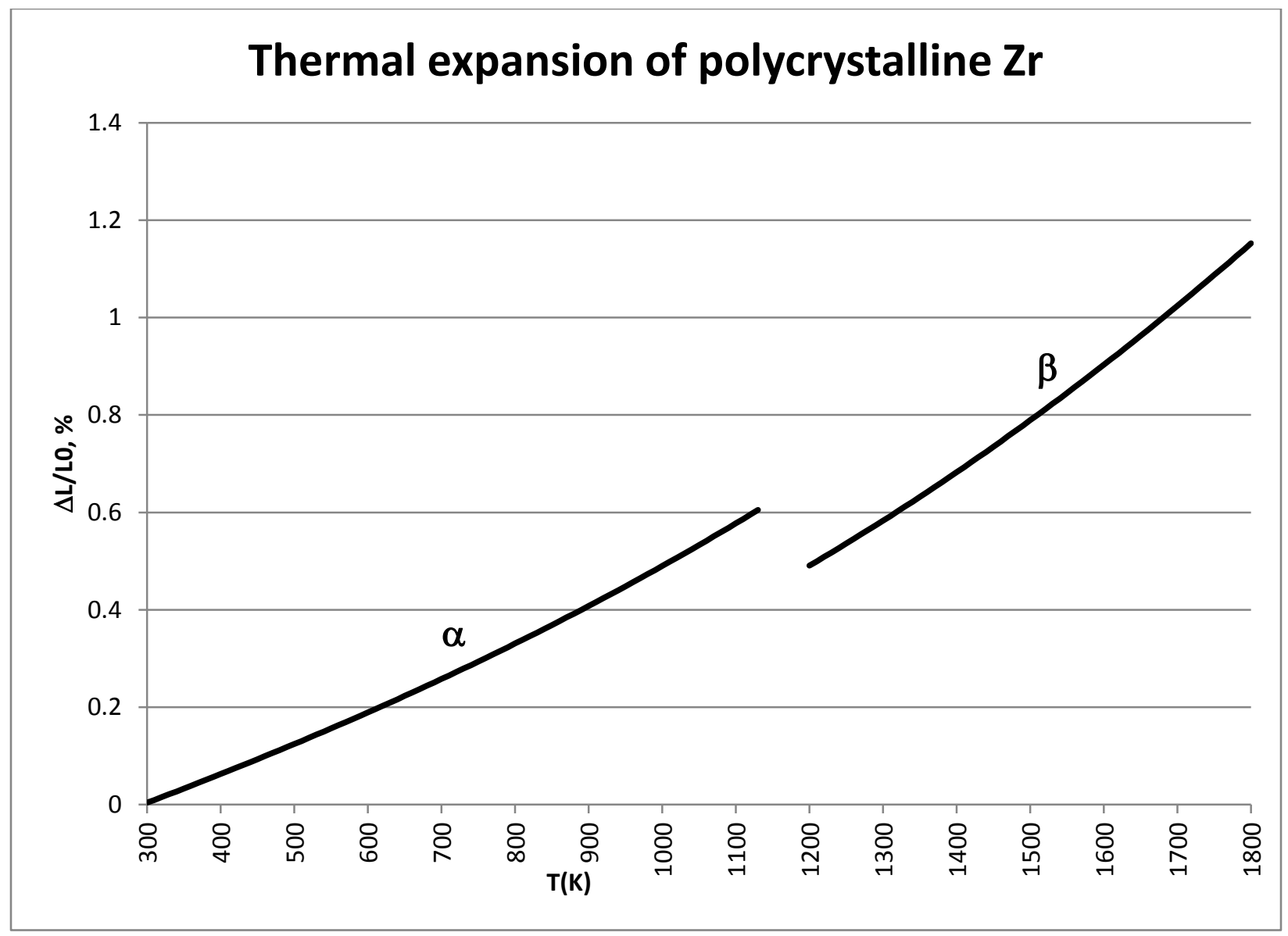

Figure 34. Thermal expansion of polycrystalline Zr, calculated from Equation 41 and Equation 42 [136]

Equation 41. Thermal expansion of $\alpha-\mathrm{Zr}$ (thermal expansion in \%, $\mathrm{T}$ in $\mathrm{K}, \mathrm{T}$ from 293 to $1130 \mathrm{~K}, \mathrm{~L}$ is length at temperature $\mathrm{T}, \mathrm{L}_{0}$ is length at $\left.293 \mathrm{~K}\right)$ [136]

$$
\left(\mathrm{L}-\mathrm{L}_{0}\right) / \mathrm{L}_{0}(\alpha-\mathrm{Zr})=5.7406 \times 10^{-4} \times(\mathrm{T}-293)+1.1888 \times 10^{-7} \times(\mathrm{T}-293)^{2}+7.0155 \times 10^{-11} \times(\mathrm{T}-293)^{3}
$$

Equation 42. Thermal expansion of $\beta-\mathrm{Zr}$ (thermal expansion in $\%, \mathrm{~T}$ in $\mathrm{K}, \mathrm{T}$ from 1200 to $1830 \mathrm{~K}, \mathrm{~L}$ is length at temperature $T, \mathrm{~L}_{0}$ is length at $293 \mathrm{~K}$ ) [136]

$$
\left(\mathrm{L}-\mathrm{L}_{0}\right) / \mathrm{L}_{0}(\beta-\mathrm{Zr})=1.894 \times 10^{-4} \times(\mathrm{T}-293)+3.9735 \times 10^{-7} \times(\mathrm{T}-293)^{2}-1.0345 \times 10^{-11} \times(\mathrm{T}-293)^{3}
$$




\subsubsection{Thermal Expansion Coefficients}

Equation 43 and Equation 44 express the mean linear thermal expansion coefficients corresponding to the curves in Figure 34.

Equation 43. Mean linear thermal expansion coefficient for polycrystalline $\alpha-\operatorname{Zr}\left(\bar{\alpha}\right.$ in units of $10^{-6} / \mathrm{K}, \mathrm{T}$ in $\mathrm{K}$, T from 293 to $1130 \mathrm{~K}$ ) [136]

$$
\bar{\alpha} \times 10^{6}(\alpha-\mathrm{Zr})=5.7406+1.1888 \times 10^{-3} \times(\mathrm{T}-293)+7.0155 \times 10^{-7} \times(\mathrm{T}-293)^{2}
$$

Equation 44. Mean linear thermal expansion coefficient for polycrystalline $\beta-\operatorname{Zr}\left(\bar{\alpha}\right.$ in units of $10^{-6} / \mathrm{K}, \mathrm{T}$ in $\mathrm{K}$, T from 1200 to $1830 \mathrm{~K}$ ) [136]

$$
\bar{\alpha} \times 10^{6}(\beta-\mathrm{Zr})=1.894+3.9735 \times 10^{-3} \times(\mathrm{T}-293)-1.0345 \times 10^{-7} \times(\mathrm{T}-293)^{2} \text { for } 1200<\mathrm{T}<1830
$$

Paradis and Rhim [28] determined that the volume expansion coefficients for $\beta$ - $\mathrm{Zr}$ and liquid $\mathrm{Zr}$ at $2128 \mathrm{~K}$ (the melting temperature) are $2.35 \times 10^{-5} \mathrm{~K}^{-1}$ and $4.6 \times 10^{-5} \mathrm{~K}^{-1}$, respectively. These are the only published experimental measurements of the thermal expansion of $\mathrm{Zr}$ at the melting temperature.

\subsubsection{Density}

Densities of $\mathrm{Zr}$ phases (in $\mathrm{g} / \mathrm{cm}^{3}$ at listed temperatures) are:

- $\quad \alpha-Z r, 6.52(298 \mathrm{~K})[140]$

- $\quad \beta-Z r, 6.47(1250 \mathrm{~K})[28]$

- $\quad$ Liquid Zr, 6.24 (2128 K) [28].

According to a recent review by the IAEA [117], the density of solid $\mathrm{Zr}$ can be approximated by Equation 45, which neglects the relatively small density difference due to the $\alpha-\beta$ phase transformation.

Equation 45. Density of solid $\mathrm{Zr}$ ( $\rho$ in $\mathrm{kg} / \mathrm{m}^{3}$, $\mathrm{T}$ in $\mathrm{K}$, $\mathrm{T}$ from 298 to $2128 \mathrm{~K}$ ) [117]

$$
\rho=6550-0.1685 \times \mathrm{T}
$$

\section{$5.4 \mathrm{U}-\mathrm{Zr}$ alloys}

\subsubsection{Introduction}

Data on the thermal expansion of polycrystalline $\mathrm{U}-\mathrm{Zr}$ alloys with up to $\sim 20 \mathrm{wt} \% \mathrm{Zr}$ are originally from one of two publications (Saller et al. [141], which was the source of all of the data from this composition range in the review of Touloukian et al. [5], and Basak et al. [125]). Both publications show similar thermal expansion behavior for all alloys in this composition range at temperatures up to $\sim 800 \mathrm{~K}$. However, there is an important qualitative difference: data reported by Saller et al. indicate that the thermal expansion of $\mathrm{U}-\mathrm{Zr}$ alloys decreases with increasing concentration of $\mathrm{Zr}$. In contrast, data reported by Basak et al. indicate that, at least for alloys with up to $10 \mathrm{wt} \% \mathrm{Zr}$, the thermal expansion increases with increasing concentration of $\mathrm{Zr}$. This qualitative difference becomes quantitatively important at higher temperatures, leading to differences in thermal expansion of up to $\sim 0.5 \%$ for similar alloys. Further work is required to resolve this disagreement. 


\subsubsection{Thermal Expansion}

Figure 35 shows linear thermal expansion for polycrystalline $\mathrm{U}-\mathrm{Zr}$ alloys with up to $\sim 15.5 \mathrm{wt} \% \mathrm{Zr}$ from reference [5], as well as Touloukian's polynomial fits for alloys with 10 and 20\% Zr (Equation 46 and Equation 47), which are considered accurate to within $\pm 7 \%$ for the entire temperature range. Thermal expansion curves for $U$ and $\mathrm{Zr}$ (Equation 33, Equation 35, Equation 36, Equation 41, and Equation 42) are shown for comparison. Although individual measurements vary slightly, these data shows a strong tendency for thermal expansion to decrease with increasing concentrations of $\mathrm{Zr}$. This tendency is consistent with the relative thermal expansion of $\mathrm{U}$ and $\mathrm{Zr}$ and the existence of a continuous solid solution between $\gamma-\mathrm{U}$ and $\beta-\mathrm{Zr}$ (Section 5.4.3).

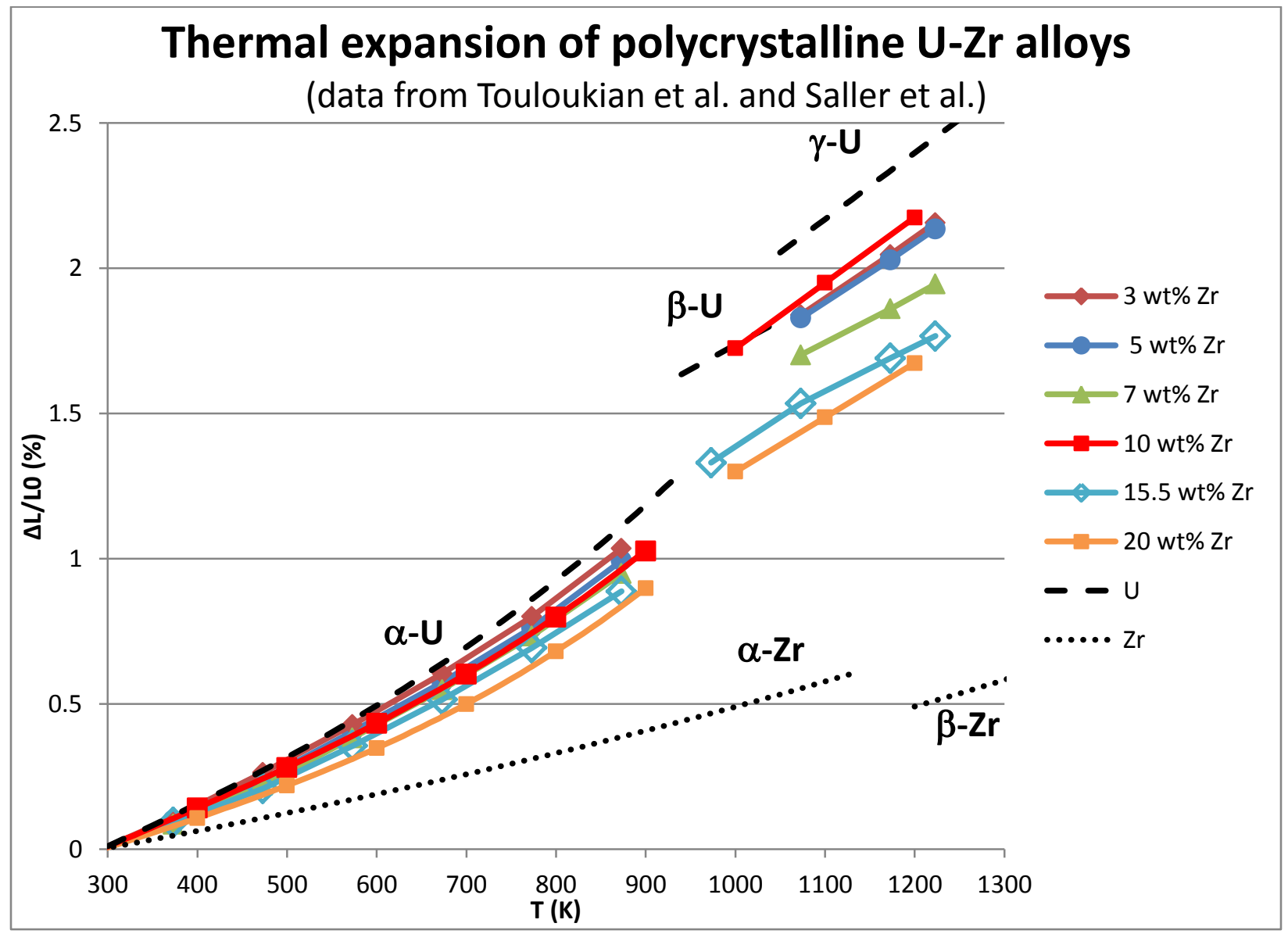

Figure 35. Thermal expansion of U-Zr alloys according to Saller et al. and Touloukian et al. [5, 141], with thermal expansion of $U$ and $\mathrm{Zr}[5,136]$ for comparison. Values for $10 \mathrm{wt} \%$ and $20 \mathrm{wt} \% \mathrm{Zr}$ are polynomial fits to tabulated data from Touloukian et al. [5]

Figure 36 shows results of recent dilatometry experiments by Basak et al. [125], which show that thermal expansion increases in alloys with up to $10 \mathrm{wt} \% \mathrm{Zr}$. The thermal conductivity of $U$ from the same publication (Equation 34 and Equation 37) is shown for comparison. As noted by Basak et al., there is a significant difference between pure $\mathrm{U}$ and an alloy with $2 \mathrm{wt} \% \mathrm{Zr}$. 


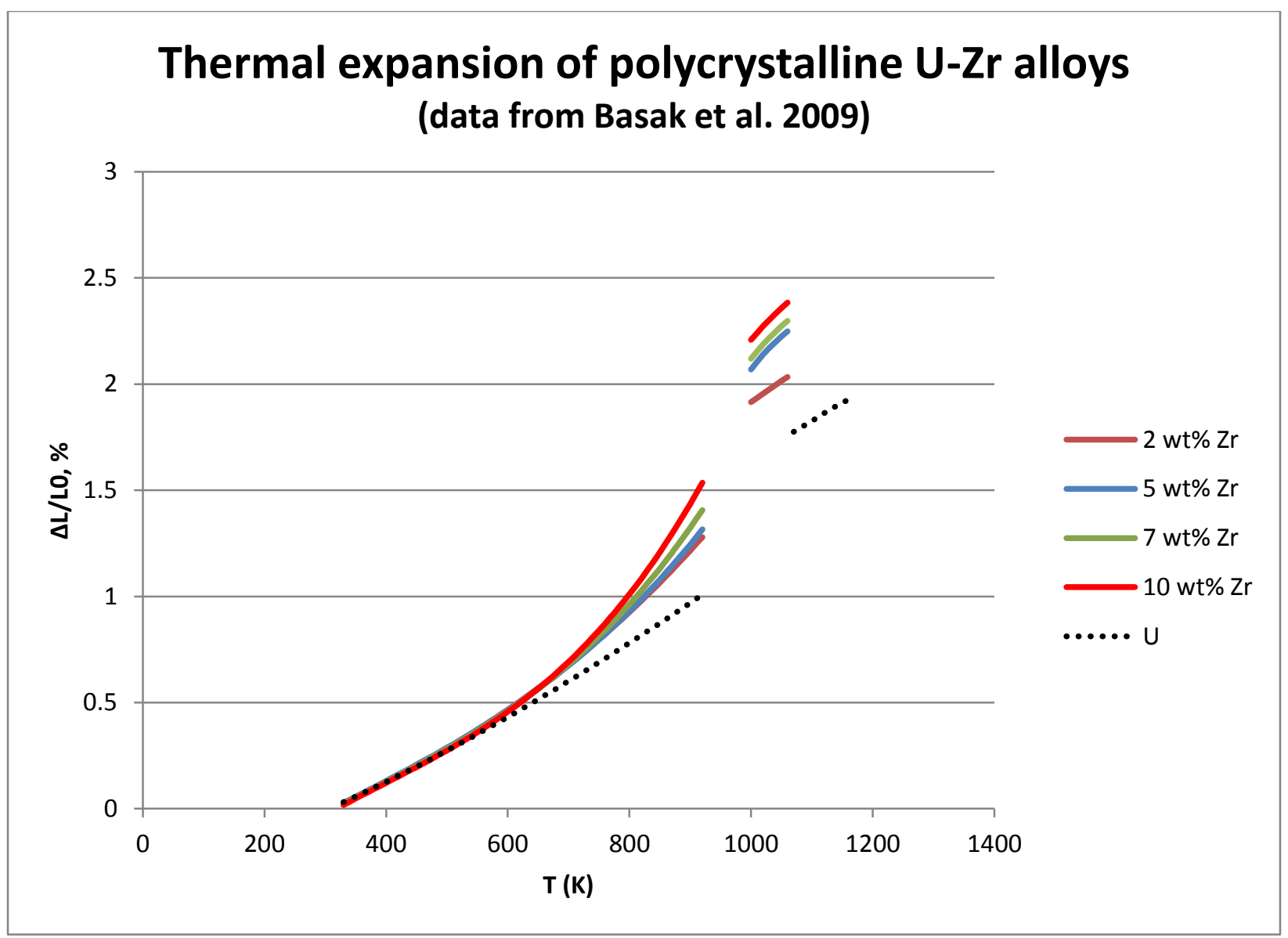

Figure 36. Thermal expansion of U and U-Zr alloys according to Basak et al. [125]

Equation 46 and Equation 47 express the recommended thermal expansion values for $(\alpha-U)$ in well-annealed alloys with 10 and $20 \mathrm{wt} \% \mathrm{Zr}$ from reference [5]. Both equations are reported as accurate to within $\pm 7 \%$ over the entire temperature range.

Equation 46. Thermal expansion of U-10 wt\%-Zr (thermal expansion in \%, T in K, $\mathrm{T}$ from 293 to $900 \mathrm{~K}$, $\mathrm{L}$ is length at temperature $\mathrm{T}, \mathrm{L}_{0}$ is length at $293 \mathrm{~K}$ ) [5]

$$
\left(\mathrm{L}-\mathrm{L}_{0}\right) / \mathrm{L}_{0}=-0.424+1.658 \times 10^{-3} \times \mathrm{T}-1.052 \times 10^{-6} \times \mathrm{T}^{2}+1.115 \times 10^{-9} \times \mathrm{T}^{3}
$$

Equation 47. Thermal expansion of U-20 wt\%-Zr (thermal expansion in \%, T in $\mathrm{K}$, $\mathrm{T}$ from 293 to $900 \mathrm{~K}$, $\mathrm{L}$ is length at temperature $\mathrm{T}, \mathrm{L}_{0}$ is length at $293 \mathrm{~K}$ ) [5]

For U-20 wt\% Zr:

$$
\left(\mathrm{L}-\mathrm{L}_{0}\right) / \mathrm{L}_{0}=-0.301+1.160 \times 10^{-3} \times \mathrm{T}-7.790 \times 10^{-7} \times \mathrm{T}^{2}+1.080 \times 10^{-9} \times \mathrm{T}^{3}
$$

Basak et al. [125] also fitted their data with polynomials (Equation 48 through Equation 55):

Equation 48. Thermal expansion of $(\alpha-\mathrm{U})$ in $\mathrm{U}-2 \mathrm{wt} \%-\mathrm{Zr}$ (thermal expansion in \%, $\mathrm{T}$ in $\mathrm{K}, \mathrm{T}$ from 323 to $923 \mathrm{~K}, \mathrm{~L}$ is length at temperature T) [125]

$$
\left(\mathrm{L}-\mathrm{L}_{0}\right) / \mathrm{L}_{0}=-0.381+12.238 \times 10^{-4} \times \mathrm{T}-2.793 \times 10^{-7} \times \mathrm{T}^{2}+9.904 \times 10^{-10} \times \mathrm{T}^{3}
$$


Equation 49. Thermal expansion of $(\gamma-\mathrm{U})$ in $\mathrm{U}-2 \mathrm{wt} \%-\mathrm{Zr}$ (thermal expansion in \%, $\mathrm{T}$ in $\mathrm{K}$, $\mathrm{T}$ from 998 to $1173 \mathrm{~K}, \mathrm{~L}$ is length at temperature T) [125]

$$
\left(\mathrm{L}-\mathrm{L}_{0}\right) / \mathrm{L}_{0}=-7.775+2.405 \times 10^{-2} \times \mathrm{T}-2.105 \times 10^{-5} \times \mathrm{T}^{2}+0.669 \times 10^{-8} \times \mathrm{T}^{3}
$$

Equation 50. Thermal expansion of $(\alpha-\mathrm{U})$ in $\mathrm{U}-5 \mathrm{wt} \%-\mathrm{Zr}$ (thermal expansion in \%, $\mathrm{T}$ in $\mathrm{K}$, $\mathrm{T}$ from 323 to $923 \mathrm{~K}, \mathrm{~L}$ is length at temperature T) [125]

$$
\left(\mathrm{L}-\mathrm{L}_{0}\right) / \mathrm{L}_{0}=-0.539+2.181 \times 10^{-3} \times \mathrm{T}-2.1 \times 10^{-6} \times \mathrm{T}^{2}+2.087 \times 10^{-9} \times \mathrm{T}^{3}
$$

Equation 51. Thermal expansion of $(\gamma-\mathrm{U})$ in $\mathrm{U}-5 \mathrm{wt} \%-\mathrm{Zr}$ (thermal expansion in \%, $\mathrm{T}$ in $\mathrm{K}$, $\mathrm{T}$ from 998 to $1173 \mathrm{~K}, \mathrm{~L}$ is length at temperature T) [125]

$$
\left(\mathrm{L}-\mathrm{L}_{0}\right) / \mathrm{L}_{0}=-55.041+14.778 \times 10^{-2} \times \mathrm{T}-12.804 \times 10^{-5} \times \mathrm{T}^{2}+3.737 \times 10^{-8} \times \mathrm{T}^{3}
$$

Equation 52. Thermal expansion of $(\alpha-\mathrm{U})$ in $\mathrm{U}-7 \mathrm{wt} \% \mathrm{Zr}$ (thermal expansion in $\%$, $\mathrm{T}$ in $\mathrm{K}, \mathrm{T}$ from 323 to $923 \mathrm{~K}, \mathrm{~L}$ is length at temperature T) [125]

$$
\left(\mathrm{L}-\mathrm{L}_{0}\right) / \mathrm{L}_{0}=-0.62+2.732 \times 10^{-3} \times \mathrm{T}-3.386 \times 10^{-6} \times \mathrm{T}^{2}+3.055 \times 10^{-9} \times \mathrm{T}^{3}
$$

Equation 53. Thermal expansion of $(\gamma-\mathrm{U})$ in $\mathrm{U}-7 \mathrm{wt} \%-\mathrm{Zr}$ (thermal expansion in \%, $\mathrm{T}$ in $\mathrm{K}$, $\mathrm{T}$ from 998 to $1173 \mathrm{~K}, \mathrm{~L}$ is length at temperature T) [125]

$$
\left(\mathrm{L}-\mathrm{L}_{0}\right) / \mathrm{L}_{0}=-42.52+11.369 \times 10^{-2} \times \mathrm{T}-9.709 \times 10^{-5} \times \mathrm{T}^{2}+2.804 \times 10^{-8} \times \mathrm{T}^{3}
$$

Equation 54. Thermal expansion of $(\alpha-\mathrm{U})$ in $\mathrm{U}-10 \mathrm{wt} \%-\mathrm{Zr}$ (thermal expansion in $\%$, $\mathrm{T}$ in $\mathrm{K}$, $\mathrm{T}$ from 323 to $923 \mathrm{~K}, \mathrm{~L}$ is length at temperature T) [125]

$$
\left(\mathrm{L}-\mathrm{L}_{0}\right) / \mathrm{L}_{0}=-0.73+3.489 \times 10^{-3} \times \mathrm{T}-5.154 \times 10^{-6} \times \mathrm{T}^{2}+4.39 \times 10^{-9} \times \mathrm{T}^{3}
$$

Equation 55. Thermal expansion of $(\gamma-\mathrm{U})$ in $\mathrm{U}-10 \mathrm{wt} \% \mathrm{-Zr}$ (thermal expansion in \%, $\mathrm{T}$ in $\mathrm{K}$, $\mathrm{T}$ from 998 to $1173 \mathrm{~K}, \mathrm{~L}$ is length at temperature T) [125]

$$
\left(\mathrm{L}-\mathrm{L}_{0}\right) / \mathrm{L}_{0}=-25.252+6.669 \times 10^{-2} \times \mathrm{T}-5.441 \times 10^{-5} \times \mathrm{T}^{2}+1.518 \times 10^{-8} \times \mathrm{T}^{3}
$$

\subsubsection{Thermal Expansion Coefficients}

Thermal expansion coefficients corresponding to the polynomial equations for alloys with 10 and 20 $\mathrm{wt} \% \mathrm{Zr}$ can be found in reference [5]. Basak et al. published thermal expansion coefficients for an alloy with $50 \mathrm{wt} \% \mathrm{Zr}$ [41], and Rough published single values expressing coefficients of thermal expansion across relatively wide temperature ranges for U-59 wt $\% \mathrm{Zr}$ and $\mathrm{U}-78 \mathrm{wt} \% \mathrm{Zr}$ [34]. In view of the inconsistencies in the thermal expansion data and the relative lack of interest in high-Zr alloys for fuels, it seems reasonable to postpone summaries of thermal expansion coefficients until further measurements are available.

\subsubsection{Introduction}

\subsection{Pu-Zr alloys}

Thermal expansion of $(\delta-\mathrm{Pu}, \mathrm{Zr})$ solid solutions varies with composition: thermal expansion is negative for alloys with less than $\sim 7.5 \mathrm{at} \% \mathrm{Zr}$ and positive for alloys with $\sim 12$ at $\% \mathrm{Zr}$. Alloys with intermediate compositions ( $\sim 8-10$ at $\% \mathrm{Zr}$ ) show relatively little thermal expansion.

The available data on $\varepsilon-(\mathrm{Pu}, \mathrm{Zr})$ solid solutions suggest that their thermal expansion is positive, like that of $\varepsilon-\mathrm{Pu}$ and $\beta-\mathrm{Zr}$. 
Solubility of $\mathrm{Zr}$ in $\alpha-, \beta-, \gamma-$, and $\delta^{\prime}$-Pu phases is limited, as is solubility of $\mathrm{Pu}$ in $\alpha-\mathrm{Zr}$. In the absence of published experimental data, it seems reasonable to assume that thermal expansion of these phases is similar to that of pure $\mathrm{Pu}$ or $\mathrm{Zr}$.

There are no published experimental data on thermal expansion of $\theta-(\mathrm{Pu}-\mathrm{Zr})$.

\subsubsection{Thermal Expansion}

Reference [142] is the primary source for experimental data on thermal expansion of $\delta$-( $\mathrm{Pu}, \mathrm{Zr})$ alloys with $\mathrm{Zr}$ concentrations from $\sim 5-12$ at $\%$ ( 2-5 wt\%). It includes measurements of thermal expansion calculated from high-temperature X-ray diffraction data and data from dilatometry. Results obtained using the two sources of data appear consistent. Reference [143] appears to be an earlier publication of results of some of the experiments in reference [142].

Figure 37 shows data from reference [142], plotted using a reference temperature of $400^{\circ} \mathrm{C}$ for convenience. The figure shows a consistent pattern in which thermal expansion of $\delta-(\mathrm{Pu}-\mathrm{Zr})$ solid solutions increases with increasing concentration of $\mathrm{Zr}$. Alloys with less than 10 at $\% \mathrm{Zr}$ show negative thermal expansion. Alloys with $\sim 8$ at $\% \mathrm{Zr}$ show relatively little expansion, and may change between negative and positive expansion depending on temperature. Alloys with 10 or 12 at $\% \mathrm{Zr}$ show positive expansion that increases with the concentration of $\mathrm{Zr}$.

Thermal expansion data from high-temperature $\mathrm{X}$-ray diffraction of nine $\mathrm{Pu}-\mathrm{Zr}$ alloys are plotted in Figure 6 of reference [71], but are not tabulated in the reference. These results appear qualitatively consistent with results from reference [142], but suggest that positive thermal expansion occurs only in alloys with at least $\sim 15$ at $\% \mathrm{Zr}$. 


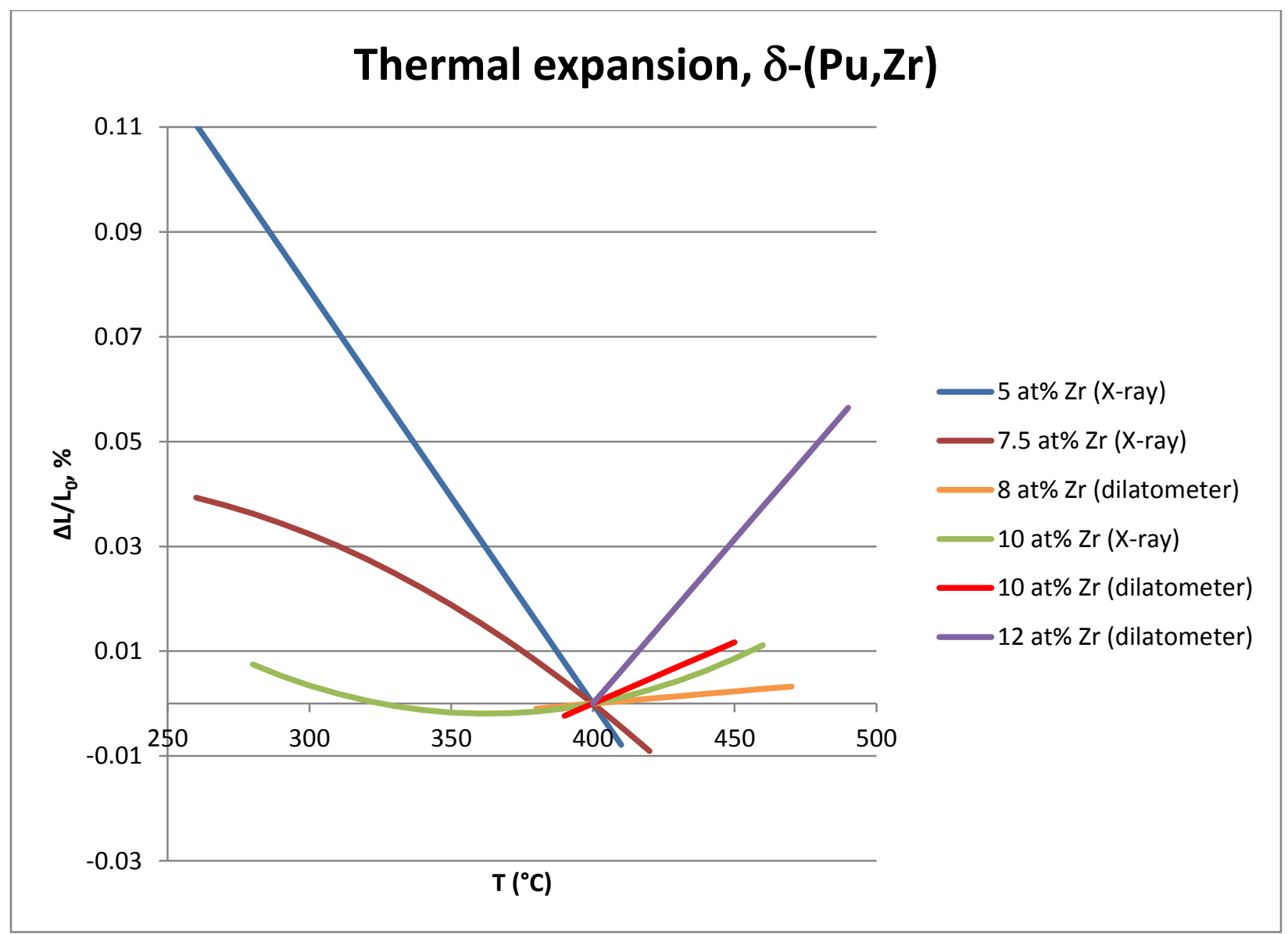

Figure 37. Thermal expansion of $\delta$-(Pu-Zr) alloys, calculated from data in reference [142] using a reference temperature of $400^{\circ} \mathrm{C}$.

The thermal expansion data in Reference [142] were published as coefficients of polynomials of the form $\mathrm{L}=\mathrm{a}+\mathrm{b} \times \mathrm{T}+\mathrm{c} \times \mathrm{T}^{2}$, where $\mathrm{L}$ is the length at temperature $\mathrm{T}$ and temperature is in ${ }^{\circ} \mathrm{C}$. These coefficients are in Table 9.

Table 9. Coefficients for equations expressing lengths of U-Pu alloys, $\mathrm{L}=\mathrm{a}+\mathrm{b} \times \mathrm{T}+\mathrm{c} \times \mathrm{T}^{2}$, where $\mathrm{L}$ is a length and $\mathrm{T}$ is a temperature in ${ }^{\circ} \mathrm{C}$ [142]. Coefficients should only be used within the stated temperature ranges.

\begin{tabular}{cllccc}
\hline $\begin{array}{c}\text { Composition } \\
(\mathrm{at} \% \mathrm{Zr})\end{array}$ & \multicolumn{1}{c}{$\begin{array}{c}\text { Measurement } \\
\text { Type }\end{array}$} & \multicolumn{1}{c}{$\mathrm{a}$} & $\mathrm{b}$ & $\mathrm{c}$ & T Range $\left({ }^{\circ} \mathrm{C}\right)$ \\
\hline 5 & X-ray & 4.6495 & $-3.656 \times 10^{-5}$ & -- & $259-410$ \\
7.5 & X-ray & 4.6379 & $1.986 \times 10^{-5}$ & $-4.98 \times 10^{-8}$ & $260-425$ \\
8.0 & Dilatometer & 0.98598 & $0.460 \times 10^{-6}$ & -- & $380-440$ \\
10.0 & X-ray & 4.6459 & $-4.634 \times 10^{-5}$ & $6.39 \times 10^{-8}$ & $275-462$ \\
10.0 & Dilatometer & 0.97372 & $2.284 \times 10^{-6}$ & -- & $391-440$ \\
12.0 & Dilatometer & 1.00776 & $2.284 \times 10^{-6}$ & -- & $401-499$ \\
\hline
\end{tabular}

The only available data on solid solutions between $\varepsilon-\mathrm{Pu}$ and $\beta-\mathrm{Zr}$ indicate that the thermal expansion of this phase is positive, like that of both $\varepsilon-\mathrm{Pu}$ and $\beta-\operatorname{Zr}[71]$. 


\subsubsection{Thermal Expansion Coefficients}

Table 10 has thermal expansion coefficients for $\delta-(\mathrm{Pu}, \mathrm{Zr})$ corresponding to the data in Figure 37 and Table 9. An average thermal expansion coefficient for $\delta$-Pu is included for comparison. Like the thermal expansion data, the thermal expansion coefficients are negative for compositions with less than $\sim 8$ at $\%$ $\mathrm{Zr}$, small for samples with $\sim 8-10 \mathrm{at} \% \mathrm{Zr}$, and positive for samples with $12 \mathrm{at} \% \mathrm{Zr}$.

Table 10. Coefficients of thermal expansion for $\delta$-(Pu, $\mathrm{Zr})$. Data for Pu are from reference [13]; other data are from reference [142]. Coefficients should not be used outside the listed temperature ranges.

\begin{tabular}{cccl}
\hline $\begin{array}{c}\text { Composition } \\
(\mathrm{at} \% \mathrm{Zr})\end{array}$ & $\bar{\alpha} \times 10^{6} /{ }^{\circ} \mathrm{C}$ & $\begin{array}{c}\text { Temperature Range } \\
\text { For } \bar{\alpha}\left({ }^{\circ} \mathrm{C}\right)\end{array}$ & Measurement Type \\
\hline $\mathrm{Pu}$ & -8.6 & $320-440$ & \\
5.0 & -7.88 & $300-401$ & X-ray diffraction \\
7.5 & -3.50 & $300-425$ & X-ray diffraction \\
8.0 & 0.47 & $380-440$ & Dilatometer \\
10.0 & 0.21 & $300-440$ & X-ray diffraction \\
10.0 & 2.34 & $391-440$ & Dilatometer \\
12.0 & 6.28 & $401-440$ & Dilatometer \\
\hline
\end{tabular}

Thermal expansion coefficients for $\varepsilon-\mathrm{Pu} / \beta-\mathrm{Zr}$ solid solutions show considerable scatter, but suggest that the thermal expansion coefficient decreases from $27 \times 10^{-6}$ per ${ }^{\circ} \mathrm{C}$ for pure $\varepsilon$-Pu to $\sim 20.5 \times 10^{-6}$ per ${ }^{\circ} \mathrm{C}$ for alloys with 20 at $\% \mathrm{Zr}$ [71]. (This value for the thermal expansion coefficient of $\varepsilon-\mathrm{Pu}$ is significantly lower than the commonly accepted value of $36.5 \times 10^{-6}$ per ${ }^{\circ} \mathrm{C}$ [13], suggesting that coefficients for $\mathrm{Pu}-\mathrm{Zr}$ alloys may also be too low.)

\subsection{U-Pu alloys}

\subsubsection{Introduction}

Published data on thermal expansion of U-Pu alloys are limited to a single report of thermal expansion of an alloy with $15 \mathrm{wt} \%(\sim 15 \mathrm{at} \%) \mathrm{Pu}$, early reports of average coefficients of thermal expansion for alloys with 10 and $20 \mathrm{at} \% \mathrm{Pu}$, and measurements of changes in lattice parameters in $\zeta-(\mathrm{U}, \mathrm{Pu})$ in an alloy with $60 \mathrm{at} \% \mathrm{Pu}$. There is no published data on thermal expansion of $\eta-(\mathrm{U}, \mathrm{Pu})$ or of any alloy with more than 60 at $\% \mathrm{Pu}$.

Samples of U-Pu alloys may exhibit marked changes as a result of thermal cycling. For example, one sample of an alloy with $10 \mathrm{wt} \% \mathrm{Pu}$ that was cycled between 450 and $700^{\circ} \mathrm{C}$ experienced a $25 \%$ increase in length and $30 \%$ decrease in density, even though the sample was held at temperature for long enough to assure completion of phase transformations between cycles [112].

\subsubsection{Thermal Expansion of U-Pu Alloys}

Kaity et al. [95] measured changes in length of a sample of a U-15wt\% Pu alloy with a high-temperature dilatometer. They divided their thermal expansion data into three temperature ranges, separated by the $(\alpha-\mathrm{U})$ to $(\beta-\mathrm{U})$ phase transformation beginning at $842 \mathrm{~K}$, and the $(\beta-\mathrm{U})$ to $(\gamma-\mathrm{U})$ transformation from 992 to $1009 \mathrm{~K}$. The $(\alpha-U)$ to $(\beta-U)$ transformation was associated with a length increase $\left(\Delta \mathrm{L} / \mathrm{L}_{0}\right)$ of $0.275 \%$, and the $(\beta-\mathrm{U})$ to $(\gamma-\mathrm{U})$ transformation was associated with a length increase of $0.14 \%$. Kaity et al. fitted their data for materials between the phase transformations using three polynomials (Equation 56, Equation 57, and Equation 58), which are shown in Figure 38. 
The corresponding mean coefficient of thermal expansion for the U-15Pu alloy between 300 and $823 \mathrm{~K}$ is $18.58 \times 10^{-6} \mathrm{~K}^{-1}$ [95]. This value is smaller than those reported for U-10 Pu by Kelman et al. [91, 112] $\left(19.4 \times 10^{-6}\right.$ per ${ }^{\circ} \mathrm{C}$ from $25^{\circ} \mathrm{C}$ to the first phase transformation, and $25.6 \times 10^{-6 \circ}$ per ${ }^{\circ} \mathrm{C}$ from the end of the transformation to $\left.720^{\circ} \mathrm{C}\right)$ and for U-20 Pu by Boucher et al. $[105,106]\left(21 \times 10^{-6}\right.$ per ${ }^{\circ} \mathrm{C}$ from $20-500^{\circ} \mathrm{C}$ ). However, all of the determinations of the thermal expansion coefficient agree closely enough that it seems reasonable to consider the average coefficient of thermal expansion determined by Kaity et al. [95] to be a reasonable estimate for U-Pu alloys with up to $\sim 20 \% \mathrm{Pu}$.

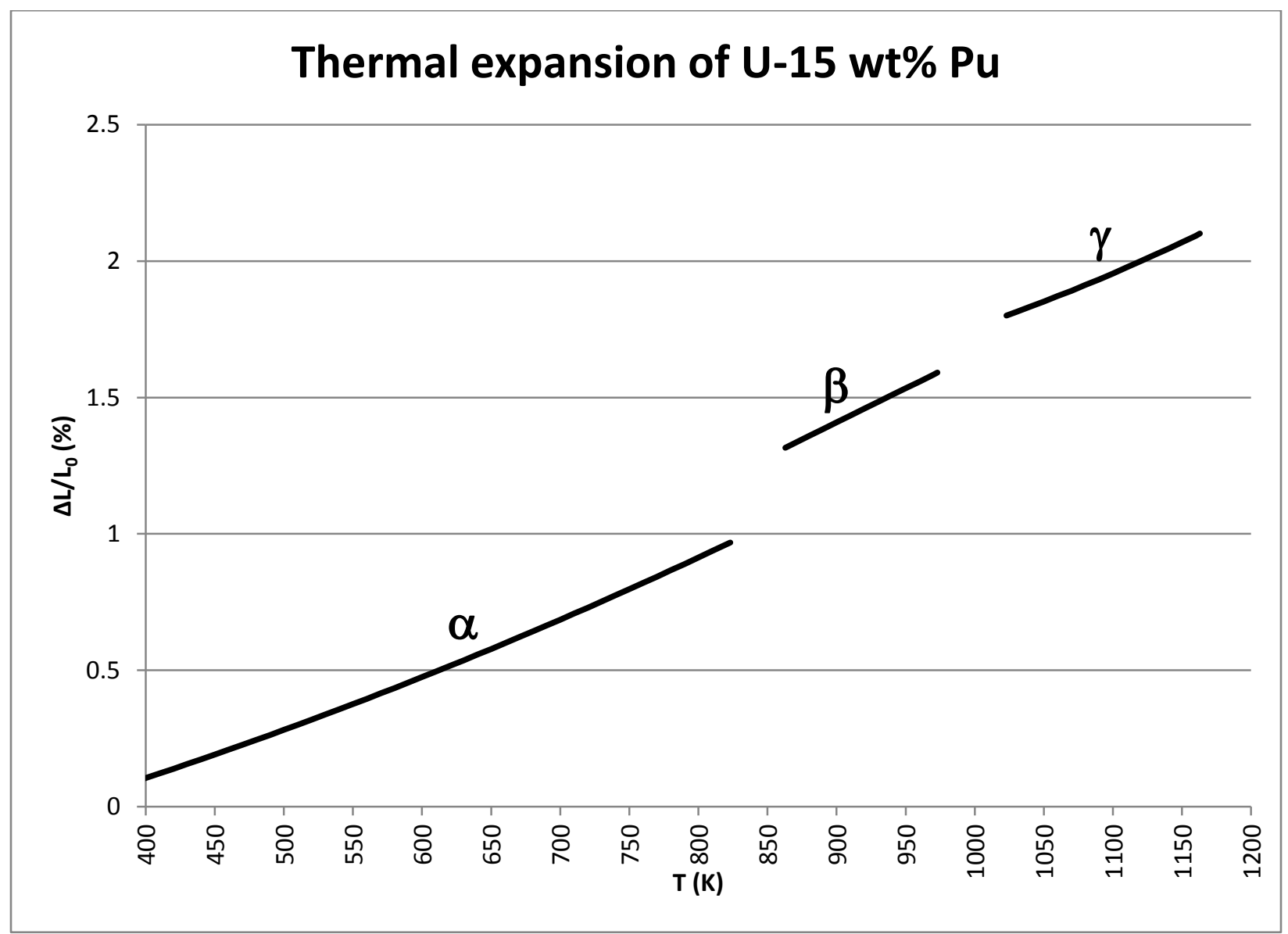

Figure 38. Thermal expansion of U-15 wt\% (15 at\%) Pu, calculated using Equation 56, Equation 57, and Equation 58

Equation 56. Thermal expansion of $(\alpha-\mathrm{U})$ in $\mathrm{U}-15 \mathrm{wt} \%-\mathrm{Pu}$ (thermal expansion in \%, $\mathrm{T}$ in $\mathrm{K}$, $\mathrm{T}$ from 393 to $823 \mathrm{~K}, \mathrm{~L}_{0}$ is length at $300 \mathrm{~K}, \mathrm{~L}$ is length at temperature T) [95]

$$
\left(\mathrm{L}-\mathrm{L}_{0}\right) / \mathrm{L}_{0}=-0.431+1.000 \times 10^{-3} \times \mathrm{T}+8.509 \times 10^{-7} \times \mathrm{T}^{2}
$$

Equation 57. Thermal expansion of $(\beta-\mathrm{U})$ in $\mathrm{U}-15 \mathrm{wt} \% \mathrm{-Pu}$ (thermal expansion in $\%$, $\mathrm{T}$ in $\mathrm{K}$, $\mathrm{T}$ from 863 to $973 \mathrm{~K}, \mathrm{~L}_{0}$ is length at $300 \mathrm{~K}, \mathrm{~L}$ is length at temperature T) [95]

$$
\left(\mathrm{L}-\mathrm{L}_{0}\right) / \mathrm{L}_{0}=-0.976+2.790 \times 10^{-3} \times \mathrm{T}-1.562 \times 10^{-7} \times \mathrm{T}^{2}
$$

Equation 58. Thermal expansion of $(\gamma-\mathrm{U})$ in $\mathrm{U}-15 \mathrm{wt} \%$-Pu (thermal expansion in $\%$, $\mathrm{T}$ in $\mathrm{K}$, $\mathrm{T}$ from 1023 to $1163 \mathrm{~K}, \mathrm{~L}_{0}$ is length at $300 \mathrm{~K}, \mathrm{~L}$ is length at temperature T) [95]

$$
\left(\mathrm{L}-\mathrm{L}_{0}\right) / \mathrm{L}_{0}=2.249-2.710 \times 10^{-3} \times \mathrm{T}+22.204 \times 10^{-7} \times \mathrm{T}^{2}
$$




\subsubsection{Thermal expansion of $\zeta-(\mathrm{U}, \mathrm{Pu})$}

Lattice parameters of $\zeta-(\mathrm{U}, \mathrm{Pu})$ in a sample with composition $\mathrm{Pu}_{0.60} \mathrm{U}_{0.40}$ were measured at temperatures between $\sim 302$ and $650 \mathrm{~K}$ using high-resolution neutron diffraction [93 Figure 8]. The lattice parameter $a$ increased with temperature, and the rhombohedral angle $\alpha$ decreased, changing the shape of the unit cell and increasing its volume slightly (Table 11).

Table 11. Lattice parameters and unit-cell volume for $\zeta-(\mathrm{U}, \mathrm{Pu})$ as a function of temperature, based on data read from [93 Figure 8]

\begin{tabular}{cccc}
\hline $\mathrm{T}(\mathrm{K})$ & $a(\AA)$ & $\alpha$ (degrees) & Volume $\left(\AA^{3}\right)$ \\
\hline 302 & 10.684 & 89.74 & 1220 \\
430 & 10.704 & 89.71 & 1226 \\
580 & 10.756 & 89.53 & 1244 \\
630 & 10.772 & 89.45 & 1250 \\
675 & 10.783 & 89.33 & 1254 \\
\hline
\end{tabular}

Based on this table, the mean volumetric coefficient of expansion $\Delta \mathrm{V} /\left(\mathrm{V}_{0} \times \Delta \mathrm{T}\right)$ is $\sim 7.5 \times 10^{-5} / \mathrm{K}$ for temperatures between 302 and $675 \mathrm{~K}$.

\section{$5.7 \quad$ U-Pu-Zr alloys}

\subsubsection{Introduction}

Published measurements of thermal expansion coefficients for U-Pu-Zr alloys were originally reported by researchers at CEA [105] and Argonne National Laboratory (ANL) [144]. Other publications (e.g., $[4,91,106,112,145])$ repeat these data. All of the published data are from alloys with $11-20 \mathrm{wt} \%$ $\mathrm{Pu}$ and $6-15 \mathrm{wt} \% \mathrm{Zr}$. Within this composition range, there is generally good agreement about thermal expansion coefficients and thermal expansion associated with phase transformations. No data about thermal expansion of other compositions are available.

U-Pu-Zr alloys have been reported to experience "catastrophic" events (including density losses of almost $0.7 \mathrm{~g} / \mathrm{cm}^{3}$ and catching fire) during thermal cycling experiments at temperatures as low as $\sim 650-750^{\circ} \mathrm{C}[101,105]$. Thermal cycling phenomena are strongly dependent on the starting microstructure (particularly centerline porosity and preferred orientation) [101].

\subsubsection{Thermal Expansion Coefficients}

The published measurements generally fall within two temperature ranges separated by phase transformations: room temperature to $\sim 600^{\circ} \mathrm{C}$, and above $\sim 660^{\circ} \mathrm{C}$ (Table 12, Table 13). Reported coefficients of thermal expansion below the phase transformations range from $16.3 \times 10^{-6} /{ }^{\circ} \mathrm{C}$ to $18.3 \times 10^{-6} /{ }^{\circ} \mathrm{C}$, and reported coefficients of thermal expansion above the phase transformations range from $18.1 \times 10^{-6} /{ }^{\circ} \mathrm{C}$ to $20.1 \times 10^{-6} /{ }^{\circ} \mathrm{C}$. In view of the relatively small variation in the reported values and the lack of an obvious correlation between thermal expansion coefficients and composition, it seems reasonable to estimate the thermal expansion coefficients of alloys with $\sim 10-20 \mathrm{wt} \% \mathrm{Pu}$ and $5-15 \mathrm{wt} \% \mathrm{Zr}$ by using the average values of the reported data $\left(17.4 \times 10^{-6} /{ }^{\circ} \mathrm{C}\right.$ below the phase transformations and $19.4 \times 10^{-6} /{ }^{\circ} \mathrm{C}$ above). 
Table 12. Thermal expansion coefficients for $\mathrm{U}-\mathrm{Pu}-\mathrm{Zr}$ alloys between room temperature and $600^{\circ} \mathrm{C}$.

\begin{tabular}{llccc}
\hline $\begin{array}{c}\text { Composition } \\
(\mathrm{wt} \%)\end{array}$ & $\begin{array}{c}\text { Composition } \\
(\mathrm{at} \%)\end{array}$ & $\begin{array}{c}\text { Coefficient of } \\
\text { Thermal Expansion } \\
\times 10^{6}\left(\mathrm{per}^{\circ} \mathrm{C}\right)\end{array}$ & $\begin{array}{c}\text { Temperature } \\
\text { Range } \\
\left({ }^{\circ} \mathrm{C}\right)\end{array}$ & References \\
\hline $\mathrm{U}-11.1 \mathrm{Pu}-6.3 \mathrm{Zr}$ & $\mathrm{U}-10 \mathrm{Pu}-15 \mathrm{Zr}$ & 18.3 & $25-595$ & {$[4,91,112,144]$} \\
$\mathrm{U}-15 \mathrm{Pu}-10 \mathrm{Zr}$ & $\mathrm{U}-13 \mathrm{Pu}-22.5 \mathrm{Zr}$ & 17.6 & $25-595$ & {$[4,91,112,144]$} \\
$\mathrm{U}-15 \mathrm{Pu}-10 \mathrm{Zr}$ & $\mathrm{U}-13 \mathrm{Pu}-22.5 \mathrm{Zr}$ & 16.3 & $20-600$ & {$[4,91,105,106]$} \\
$\mathrm{U}-20 \mathrm{Pu}-10 \mathrm{Zr}$ & $\mathrm{U}-17 \mathrm{Pu}-23 \mathrm{Zr}$ & 17.3 & $20-586$ & {$[4,91,105,106$,} \\
& & & & $145]$ \\
$\mathrm{U}-18.5 \mathrm{Pu}-14.1 \mathrm{Zr}$ & $\mathrm{U}-15 \mathrm{Pu}-30 \mathrm{Zr}$ & 17.5 & $25-595$ & {$[4,91,112,144]$} \\
$\mathrm{U}-17.1 \mathrm{Pu}-3.4 \mathrm{Zr}{ }^{1}$ & $\mathrm{U}-15 \mathrm{Zr}-15 \mathrm{Pu}$ & 21.2 & $25-570$ & {$[144]$} \\
\multicolumn{1}{c}{ Average } & & $\mathbf{1 7 . 4}$ & $\mathbf{2 0 - 6 0 0}$ & \\
\hline
\end{tabular}

${ }^{1}$ Weight and atomic percentages are inconsistent. Assuming atomic percentages are correct, this alloy contains $\sim 6.3 \mathrm{wt} \% \mathrm{Zr}$. This alloy is not included in the average value because the range of measured temperatures does not include a gap for phase transformations.

Table 13. Thermal expansion coefficients for U-Pu-Zr alloys above $600^{\circ} \mathrm{C}$.

\begin{tabular}{|c|c|c|c|c|}
\hline $\begin{array}{c}\text { Composition } \\
(\mathrm{wt} \%)\end{array}$ & $\begin{array}{c}\text { Composition } \\
(\mathrm{at} \%)\end{array}$ & $\begin{array}{c}\text { Coefficient of Thermal } \\
\text { Expansion } \\
\times 10^{6}\left(\text { per }{ }^{\circ} \mathrm{C}\right) \\
\end{array}$ & $\begin{array}{c}\text { Temperature } \\
\text { Range } \\
\left({ }^{\circ} \mathrm{C}\right)\end{array}$ & References \\
\hline $\mathrm{U}-11.1 \mathrm{Pu}-6.3 \mathrm{Zr}$ & $\mathrm{U}-10 \mathrm{Pu}-15 \mathrm{Zr}$ & 18.1 & $680-950$ & {$[91,112,144]$} \\
\hline $\mathrm{U}-15 \mathrm{Pu}-10 \mathrm{Zr}$ & $\mathrm{U}-12.9 \mathrm{Pu}-22.5 \mathrm{Zr}$ & 20.1 & $665-950$ & $\begin{array}{l}{[4,91,112,} \\
144]\end{array}$ \\
\hline $\mathrm{U}-18.5 \mathrm{Pu}-14.1 \mathrm{Zr}$ & $\mathrm{U}-15 \mathrm{Pu}-30 \mathrm{Zr}$ & 20.0 & $660-950$ & $\begin{array}{l}{[4,91,112,} \\
144]\end{array}$ \\
\hline U-Pu17.1-Zr3.4 ${ }^{1}$ & $\mathrm{U}-15 \mathrm{Zr}-15 \mathrm{Pu}$ & 16.4 & $570-860$ & [144] \\
\hline Average & & 19.4 & $660-950$ & \\
\hline
\end{tabular}

\subsubsection{Thermal Expansion as a Result of Phase Transformations}

Table 14 shows reported changes in length associated with phase transformations in U-Pu-Zr alloys. The total thermal expansion associated with phase transformations between $\sim 585$ and $680^{\circ} \mathrm{C}$ is generally reported as $\sim 0.5 \%$ in data originally published by ANL [144] and $\sim 0.3 \%$ in data originally published by CEA [105]. However, reference [105] recognizes two phase transformations within this temperature range and only reports expansion due to the larger of the two, while reference [144] reported only one transformation. Thus, it seems reasonable to assume that the total thermal expansion $\left(\Delta \mathrm{L} / \mathrm{L}_{0}\right)$ related to all of the phase transformations between $\sim 585$ and $680^{\circ} \mathrm{C}$ is $\sim 0.5 \%$ for alloys with $\sim 10-20 \mathrm{wt} \% \mathrm{Pu}$ and $5-15$ $\mathrm{wt} \% \mathrm{Zr}$. 
Table 14. Length changes (in \%) from phase transformations in U-Pu-Zr alloys.

\section{Composition} (wt \%)

U-11.1Pu-6.3Zr

U-15Pu-10Zr

$\mathrm{U}-15 \mathrm{Pu}-10 \mathrm{Zr}$

$\mathrm{U}-20 \mathrm{Pu}-10 \mathrm{Zr}$

U-18.5Pu-14.1Zr

U-Pu17.1-Zr3.4

\section{Length Change}

$\left(\Delta \mathrm{L} / \mathrm{L}_{0}, \%\right)$

0.51

0.52

$0.3^{1}$

$0.3^{1}$

0.50

0.93

\section{Temperature Range}

$\left({ }^{\circ} \mathrm{C}\right)$

595-680

595-665

$645^{1}$

$650^{1}$

595-660

570-780
References

[91, 112, 144]

$[91,112,144]$

[105]

[105]

$[91,112,144]$

[144]

${ }^{1}$ Refers to only one of two transformations.

${ }^{2}$ Weight and atomic percentages are inconsistent. Assuming atomic percentages are correct, this alloy contains $\sim 6.3 \mathrm{wt} \% \mathrm{Zr}$. Its length change is not included in discussion, as data do not report thermal expansion from phase transformations separately. 


\section{THERMAL CONDUCTIVITY AND THERMAL DIFFUSIVITY}

\section{$6.1 \mathrm{U}$}

\subsubsection{Introduction}

At least 100 measurements of the thermal conductivity of $U$ have been made, with most of them published before 1970. Recommended values in a 2014 review by Kim et al. [146] are in excellent agreement with a 2012 measurement not included in the review [62]. There is also excellent agreement that the thermal conductivity increases by $\sim 0.02 \mathrm{~W} / \mathrm{m} \cdot \mathrm{K}$ between $\sim 290$ and $1173 \mathrm{~K}$, a temperature range that includes the $\alpha-\beta$ phase transformation. However, a 2008 compilation of data by the IAEA [117] recommends thermal conductivity values that are 10-20\% lower than those recommended by Kim et al. The good agreement between the new measurements and the recommended values of Kim et al. suggests that the review may be a better representation of the actual thermal conductivity than the values in the IAEA tabulation. However, more research is needed to resolve this issue.

\subsubsection{Thermal Conductivity}

Reviews of the thermal conductivity of U include those by Touloukian et al. [7], Kim et al. [146], and the IAEA [147]. The review of Kim et al. includes the data used by Touloukian et al. as well as data from Takahashi et al. [148], but does not include the measurements reported by Kaity et al. [62]. The IAEA report provides three estimates of thermal conductivity based on different weightings of the same data, with one of the three being used in a recent IAEA compilation of data [117].

Figure 39 compares thermal conductivity determinations from the reviews by Kim et al. and the IAEA and a recent original measurement not included in either of the reviews $[62,117,146]$. Plotted values from all three sources have similar slopes, which indicate that that the thermal conductivity increases by $\sim 0.02 \mathrm{~W} / \mathrm{m} \mathrm{K}$ within the range of each of the curves; however, the thermal conductivity from the IAEA tabulation is $\sim 10-20 \%$ lower than either of the other curves. The good agreement between the new measurements of Kaity et al. [62] and the recommended thermal conductivity in the review by Kim et al. [146] suggests that the Kim et al. review may be a better representation of the actual thermal conductivity than the values in the IAEA tabulation. However, more research is needed to resolve this issue. 


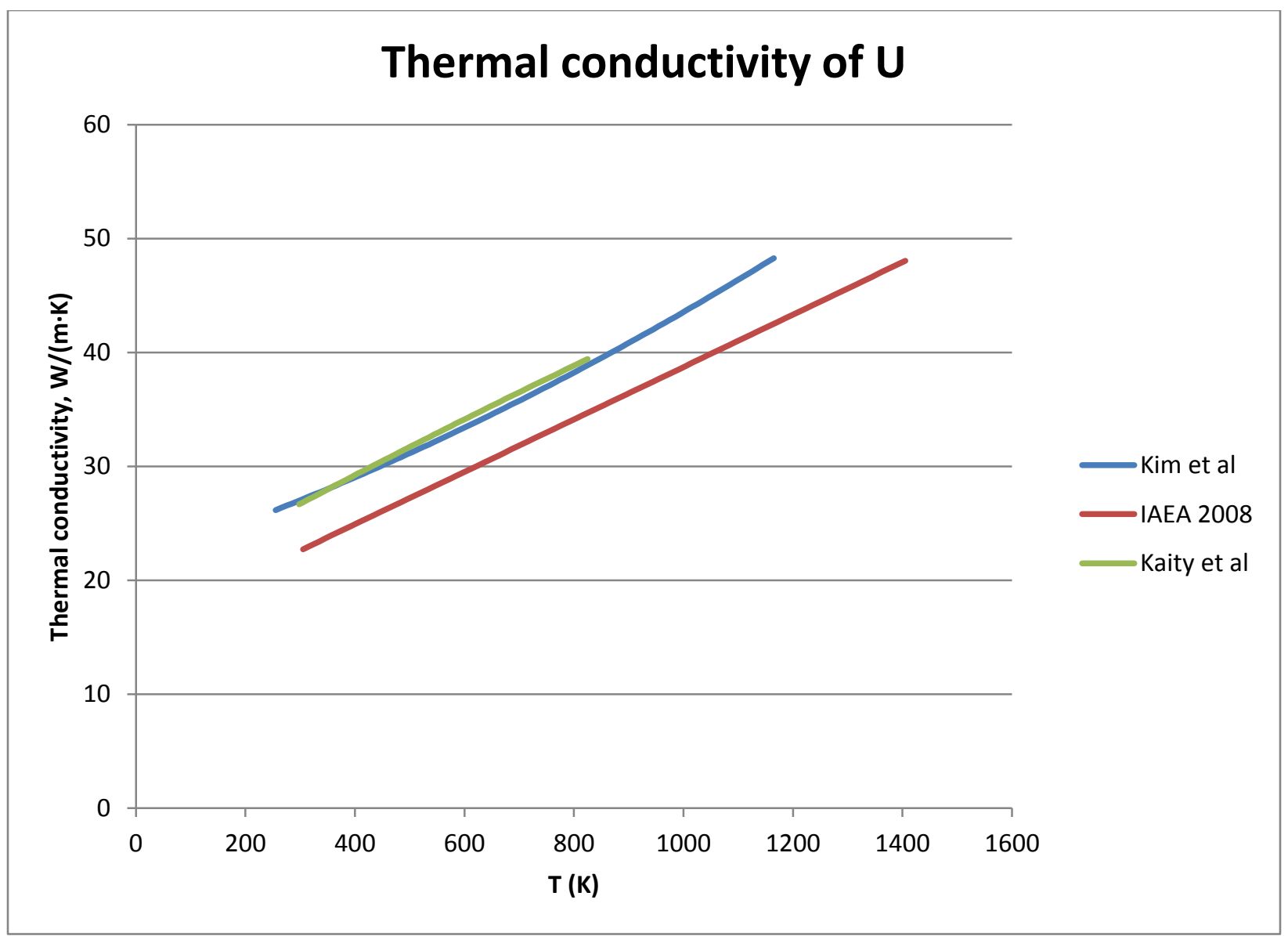

Figure 39. Thermal conductivity of U (Equation 59, Equation 60, and Equation 61).

The equations used to generate the data in the plot are:

Equation 59. Thermal conductivity of $U$ [146] (thermal conductivity in $\mathrm{W} / \mathrm{m}-\mathrm{K}, \mathrm{T}$ in $\mathrm{K}$, $\mathrm{T}$ from 255 to $1173 \mathrm{~K})$

$\mathrm{k}=21.73+1.591 \times 10^{-2} \times \mathrm{T}+5.907 \times 10^{-6} \times \mathrm{T}^{2}, \mathrm{k}_{\mathrm{U}}$ in W/m-K, $\mathrm{T}$ in $\mathrm{K}$, and $\mathrm{T}$ between 255 and $1173 \mathrm{~K}$

Equation 60. Thermal conductivity of $U$ [62] (thermal conductivity in $\mathrm{W} / \mathrm{m}-\mathrm{K}$, $\mathrm{T}$ in $\mathrm{K}, \mathrm{T}$ from 298 to $823 \mathrm{~K})$

$\mathrm{k}=18.890+2.678 \times 10^{-2} \times \mathrm{T}-2.302 \times 10^{-6} \times \mathrm{T}^{2}, \mathrm{k}_{\mathrm{U}}$ in W/m-K, $\mathrm{T}$ in $\mathrm{K}$, and $\mathrm{T}$ between 298 and $823 \mathrm{~K}$

Equation 61. Thermal conductivity of $U$ [117] (thermal conductivity in W/m-K, $T$ in $K$, $T$ from 293 to $1405 \mathrm{~K})$

$$
\mathrm{k}=22+0.023 \times(\mathrm{T}-273), \mathrm{k}_{\mathrm{U}} \text { in } \mathrm{W} / \mathrm{m}-\mathrm{K}, \mathrm{T} \text { in } \mathrm{K} \text {, and } \mathrm{T} \text { between } 293 \text { and } 1405 \mathrm{~K}
$$

\section{2 $\mathrm{Pu}$}

\subsubsection{Introduction}

There are very few studies of the thermal conductivity or diffusivity of $\mathrm{Pu}$, and almost all were published before 1980. However, in 2008, Alexander and Wood [149] reported thermal conductivities of 
all of the solid Pu phases based on new measurements of thermal diffusivities of two Pu samples. They determined that the thermal conductivity of each phase except $\delta^{\prime}$-Pu (which is difficult to study because of its narrow temperature range of stability) increased approximately linearly with temperature, and that the thermal conductivity of $\delta^{\prime}-\mathrm{Pu}$ decreased with temperature. They also noted that all of their data could be fitted to within an error of $\sim 5 \%$ by a single quadratic equation.

Kim et al. [146] recently reviewed the thermal conductivity of $\mathrm{Pu}$, and agreed with values determined by Alexander and Wood [149] to within $\sim 10 \%$ for all phases except $\delta^{\prime}-\mathrm{Pu}$. The two studies apparently have no data in common. Both of these assessments have thermal conductivity values that are significantly higher than those in a recent IAEA data summary [117] for all solid Pu phases except $\alpha-\mathrm{Pu}$. However, the good agreement between the thermal conductivities determined by Alexander and Wood and by Kim et al. suggests that these studies are good approximations of the actual behavior of $\mathrm{Pu}$, with preference given to the results of Alexander and Wood because they are based on direct measurements of well-characterized starting materials. Either of these studies is probably a more accurate representation of the actual behavior of $\mathrm{Pu}$ than the values in the IAEA tabulation. Unless phase-specific information is required, the single quadratic equation developed by Alexander and Wood is a convenient approximation.

\subsubsection{Thermal Conductivity}

Recent attempts to determine the thermal conductivity of Pu have taken different approaches: Alexander and Wood [149] calculated thermal conductivity based on their new measurements of the thermal diffusivity of zone-refined $\mathrm{Pu}$ and heat-capacity, density, and thermal-expansion data from previous publications. In contrast, Kim et al. [146] relied on older publications with thermal-conductivity values for $\alpha-\mathrm{Pu}, \beta-\mathrm{Pu}$, and $\gamma-\mathrm{Pu}$ and estimated the thermal conductivity of other phases based on their electrical resistivity and Lorenz number. Despite the difference in approaches and lack of common data, the two studies produced similar results (Figure 40). 


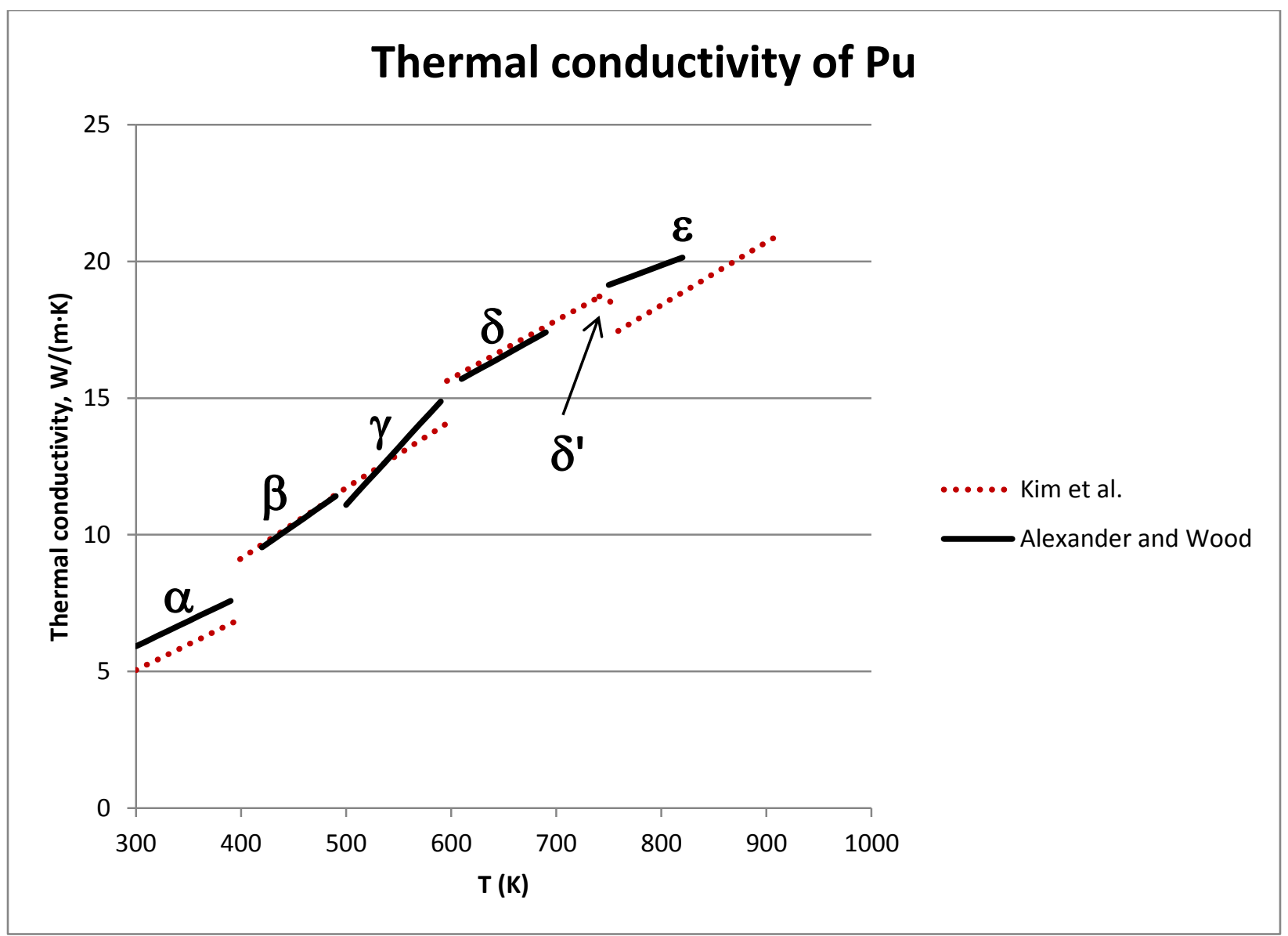

Figure 40. Thermal conductivity of Pu. Data from Alexander and Wood were calculated from Equation 62 through Equation 66.

Alexander and Wood fitted their data for all phases except $\delta^{\prime}$-Pu to linear equations, each of which matched all of their measured data points to within $5 \%$. These equations are:

Equation 62. Thermal conductivity of $\alpha-\mathrm{Pu}$ [149] (thermal conductivity in $\mathrm{W} / \mathrm{m}-\mathrm{K}, \mathrm{T}$ in $\mathrm{K}, \mathrm{T}$ from 294 to $394 \mathrm{~K})$

$$
\mathrm{k}=0.01844 \times \mathrm{T}+0.390
$$

Equation 63. Thermal conductivity of $\beta-\mathrm{Pu}$ [149] (thermal conductivity in $\mathrm{W} / \mathrm{m}-\mathrm{K}$, $\mathrm{T}$ in $\mathrm{K}$, $\mathrm{T}$ from 415 to $490 \mathrm{~K})$

$$
\mathrm{k}=0.02679 \times \mathrm{T}-1.716
$$

Equation 64. Thermal conductivity of $\gamma-\mathrm{Pu}$ [149] (thermal conductivity in $\mathrm{W} / \mathrm{m}-\mathrm{K}$, $\mathrm{T}$ in $\mathrm{K}$, $\mathrm{T}$ from 491 to $595 \mathrm{~K})$

$$
\mathrm{k}=0.04201 \times \mathrm{T}-9.909
$$

Equation 65. Thermal conductivity of $\delta$ - $\mathrm{Pu}$ [149] (thermal conductivity in $\mathrm{W} / \mathrm{m}-\mathrm{K}$, $\mathrm{T}$ in $\mathrm{K}, \mathrm{T}$ from 602 to $696 \mathrm{~K})$

$$
\mathrm{k}=0.02131 \times \mathrm{T}+2.697
$$


Equation 66. Thermal conductivity of $\varepsilon$-Pu [149] (thermal conductivity in $\mathrm{W} / \mathrm{m}-\mathrm{K}, \mathrm{T}$ in $\mathrm{K}, \mathrm{T}$ from 750 to $822 \mathrm{~K})$

$$
\mathrm{k}=0.01428 \times \mathrm{T}+8.423
$$

Alexander and Wood noted that their data for all phases except $\delta^{\prime}$ from temperatures between 400 and $820 \mathrm{~K}$ could be matched to within $\sim 5.4 \%$ by a quadratic equation (Equation 67 ), which provides a convenient approximation across a wide temperature range. This equation is:

Equation 67. Approximate thermal conductivity of $\mathrm{Pu}[149]$ (thermal conductivity in $\mathrm{W} / \mathrm{m}-\mathrm{K}, \mathrm{T}$ in $\mathrm{K}, \mathrm{T}$ from 400 to $820 \mathrm{~K}$ )

$$
\mathrm{K}_{\mathrm{Pu}}=-8.162+4.841 \times 10^{-2} \times \mathrm{T}-0.1614 \times 10^{-4} \times \mathrm{T}^{2}
$$

\section{$6.3 \mathrm{Zr}$}

\subsubsection{Introduction}

Several hundred measurements of the thermal conductivity and diffusivity of $\mathrm{Zr}$ were reviewed in 1995 by Fink and Leibowitz [150], and a polynomial that fit the most of data to within $\sim 10 \%$ across a temperature range from $298-2000 \mathrm{~K}$ was developed. This polynomial shows a decrease in conductivity from 298 to an inflection point at $\sim 530 \mathrm{~K}$, and an increase from $\sim 530 \mathrm{~K}$ to $2000 \mathrm{~K}$, with no changes due to the $\alpha-\beta$ phase transformation. It was adopted by later reviews including those of Kim et al. [146] and the IAEA [117].

\subsubsection{Thermal Conductivity}

Reviews of the thermal conductivity and diffusivity of $\mathrm{Zr}$ include those by Touloukian et al. [6,7], Fink and Leibowitz [150], Kim et al. [146], and the IAEA [117]. The Fink and Leibowitz review included an assessment of all published data available at that time, including that used by Touloukian et al., and led to development of a widely accepted polynomial expressing the thermal conductivity of $\mathrm{Zr}$ at temperatures between 298 and $2000 \mathrm{~K}$ (Figure 41, Equation 68). More recent estimates of thermal conductivity based on diffusivity measurements by Milošević \& Maglić [118] give somewhat higher values, particularly at higher temperatures. However, because of the large numbers of measurements included in the Fink and Leibowitz review, the data of Milošević \& Maglić should probably be considered as outliers unless future measurements indicate otherwise. 


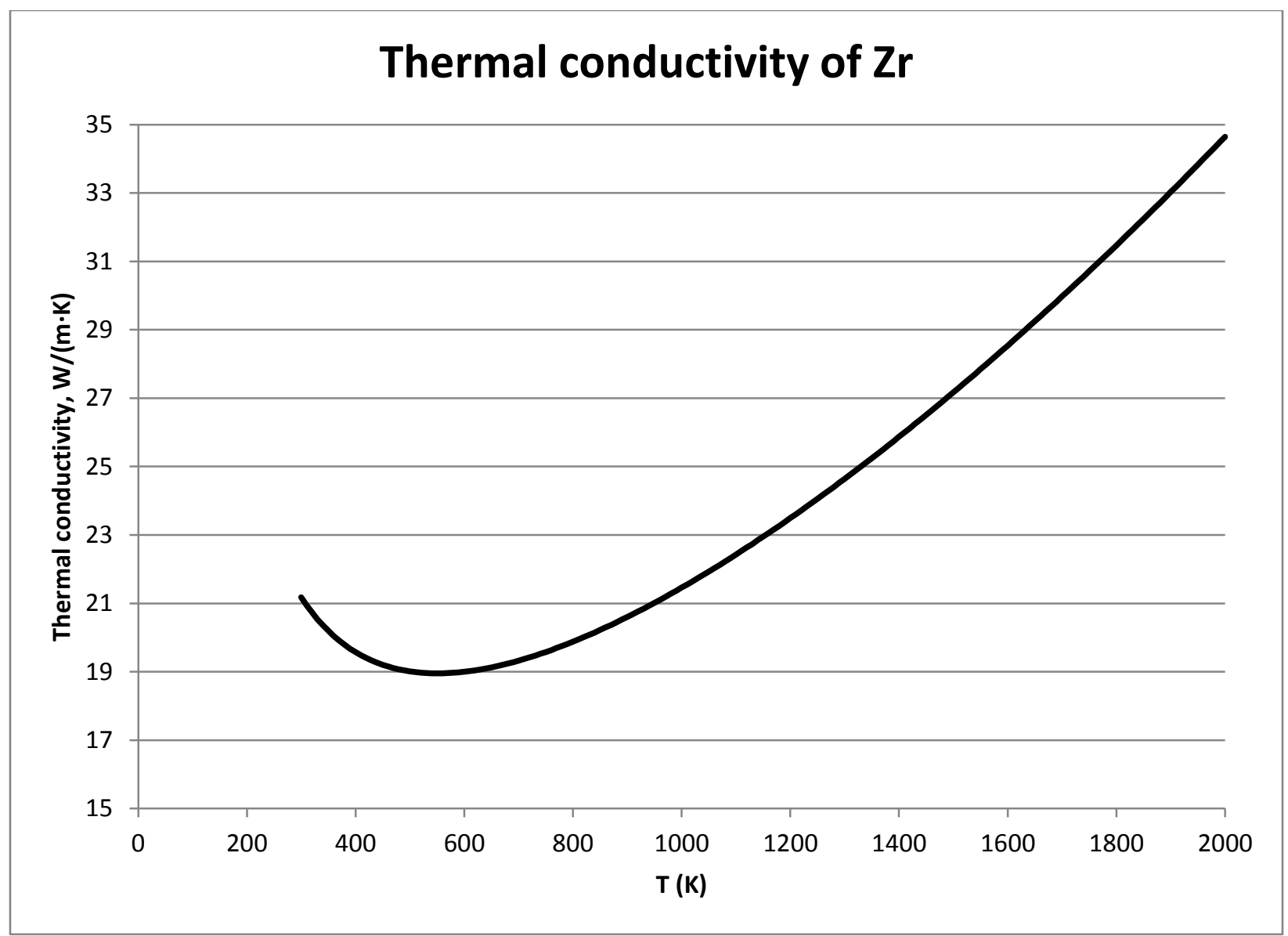

Figure 41. Thermal conductivity of Zr [150], plotted using Equation 68.

Equation 68. Approximate thermal conductivity of $\mathrm{Pu}[150]$ (thermal conductivity in $\mathrm{W} / \mathrm{m}-\mathrm{K}, \mathrm{T}$ in $\mathrm{K}$, $\mathrm{T}$ from 298 to $2000 \mathrm{~K}$ )

$$
\mathrm{k}=8.857+7.0820 \times 10^{-3} \times \mathrm{T}+2.5329 \times 10^{-6} \times \mathrm{T}^{2}+2.9918 \times 10^{3} \times \mathrm{T}^{-1}
$$

\section{$6.4 \quad \mathrm{U}-\mathrm{Zr}$ Alloys}

\subsubsection{Introduction}

Experimental determinations of the thermal conductivity of $\mathrm{U}-\mathrm{Zr}$ alloys with $\mathrm{Zr}$ concentrations between 1 and $79 \mathrm{wt} \%$ (2.5-91 at\%) Zr have been reported at temperatures up to $1200 \mathrm{~K}$. Thermal conductivities for $\mathrm{U}-\mathrm{Zr}$ alloys increase with temperature. Conductivities for alloys with different compositions decrease with increasing concentration of $\mathrm{Zr}$ to a minimum value at $\sim 72.4$ at $\%$ (possibly reflecting the very low conductivity of $\left.\delta-\mathrm{UZr}_{2}\right)$ [148] and may increase again in high-Zr compositions.

Three research groups have developed equations to predict the thermal conductivity of $\mathrm{U}-\mathrm{Zr}$ alloys as functions of composition and temperature. One of these equations is not considered because it was developed before much of the data were available. The other two produce similar results for compositions of interest for nuclear fuels $(\sim 10-15 \mathrm{wt} \% \mathrm{Zr})$. 


\subsubsection{Thermal Conductivity}

Experimentally determined thermal conductivity values for $\mathrm{U}-\mathrm{Zr}$ alloys with $\sim 1-2,5,6,9,11,17,20$, $29,40,52$, and $79 \mathrm{wt} \% \mathrm{Zr}$ have been reported $[7,61,62,148,151]$. Thermal conductivity was measured directly by ANL [151] and Kaity et al.[62], while thermal conductivity measurements reported by Takahashi et al. [148] and Matsui et al. [61] were calculated from density, thermal diffusivity, and heat capacity. Other researchers have attempted to use the Wiedeman-Franz law to estimate thermal conductivity from the Lorentz number and electrical resistivity; however, it appears that the actual Lorentz number of the sample material may not be known well enough for this approach to be successful $[34,35,61]$.

Figure 42 summarizes published thermal conductivity data for U-Zr alloys. It shows that thermal conductivity decreases with increasing concentration of $\mathrm{Zr}$ for samples with less than $\sim 40-50$ at $\% \mathrm{Zr}$ and is essentially the same for samples with $\sim 50-90$ at $\% \mathrm{Zr}$. Takahashi et al. suggested that the thermal conductivity of $\mathrm{U}-\mathrm{Zr}$ alloys had a minimum at $\sim 72.4 \mathrm{at} \%$, which was due to the low thermal conductivity of $\delta$-( $\left(\mathrm{UZr}_{2}\right)$; however, thermal conductivity measurements of well-characterized samples known to consist of this phase have not been reported.

For each alloy, thermal conductivity increases with temperature within the measurement range. The thermal conductivity of most compositions is smaller than that of $\mathrm{Zr}$ at relatively low temperatures (below $\sim 300 \mathrm{~K}$ for alloys with $\sim 4 \mathrm{at} \% \mathrm{Zr}$, and below $\sim 675 \mathrm{~K}$ for alloys with $\sim 40$ at $\% \mathrm{Zr}$ ).

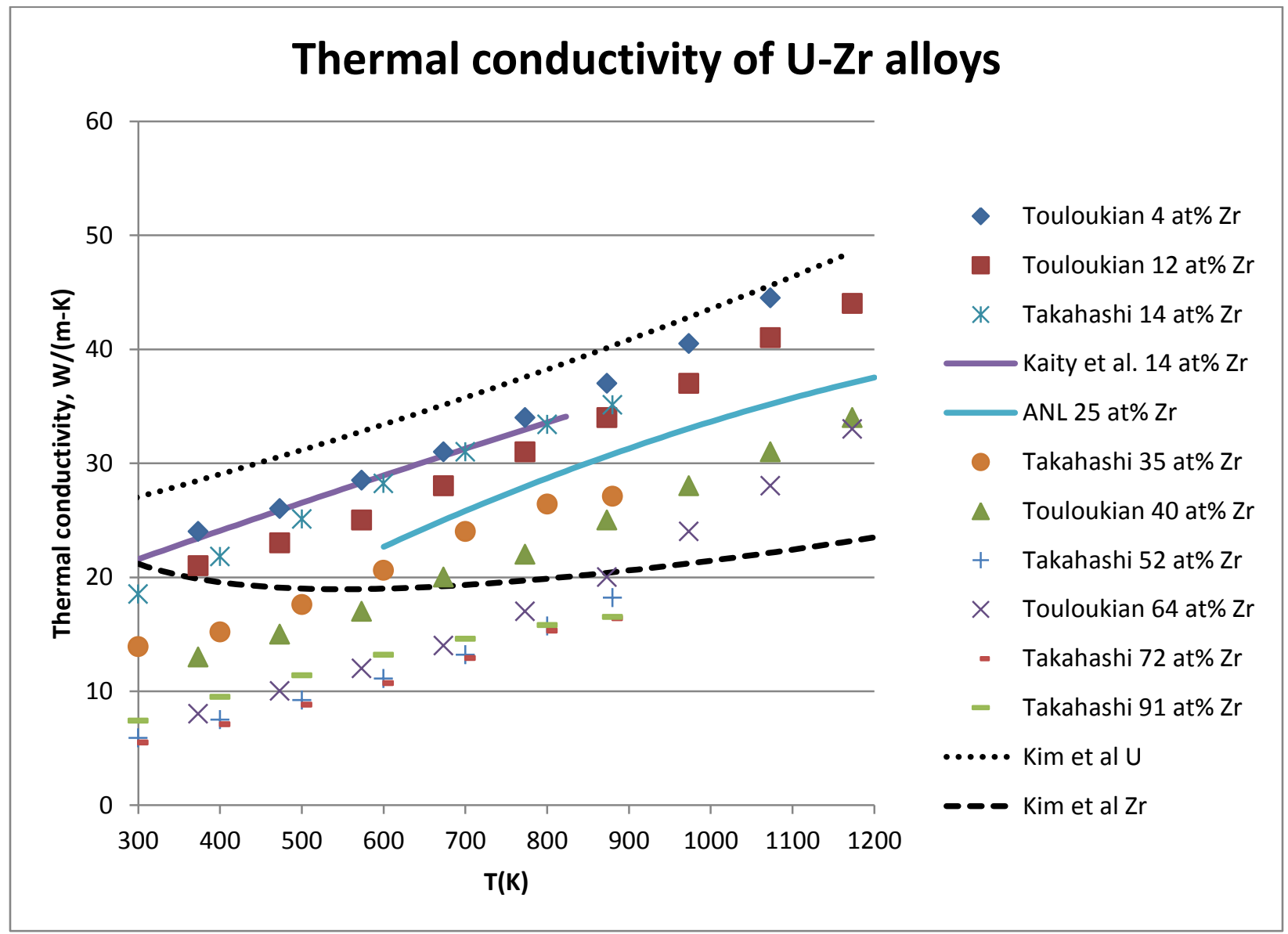

Figure 42. Thermal conductivity of $\mathrm{U}-\mathrm{Zr}$ alloys, with conductivity of $\mathrm{U}$ and $\mathrm{Zr}$ for comparison [7, 62, $146,148,151]$ 
Billone et al. [152], Ogata [58], and Kim et al. [146] developed equations to represent the conductivity of arbitrary $\mathrm{U}-\mathrm{Zr}$ alloys as a function of temperature and composition. (The Ogata equation is reprinted in [4] with a change in sign of one of the terms. Comparison to the data suggests that the equation in reference [58] is correct.) The Billone et al. equation is not considered further because it was developed too early to consider the extensive measurements made by Takahashi et al. [148].

The equations proposed by Kim et al. and Ogata produce similar results for alloys with concentrations of interest for nuclear fuels ( $10 \mathrm{wt} \% \mathrm{Zr}$ ) (Figure 43), and both are plausible approximations to the actual thermal conductivity of alloys with this composition. The Ogata equation (Equation 69) [58] is far simpler, and, therefore, is preferred based on the currently available data for compositions with relatively low concentrations of Zr. However, the non-linear shape and built-in adjustment factor of the Kim et al. equation may make it worth considering if adjustments to accommodate new data are required.

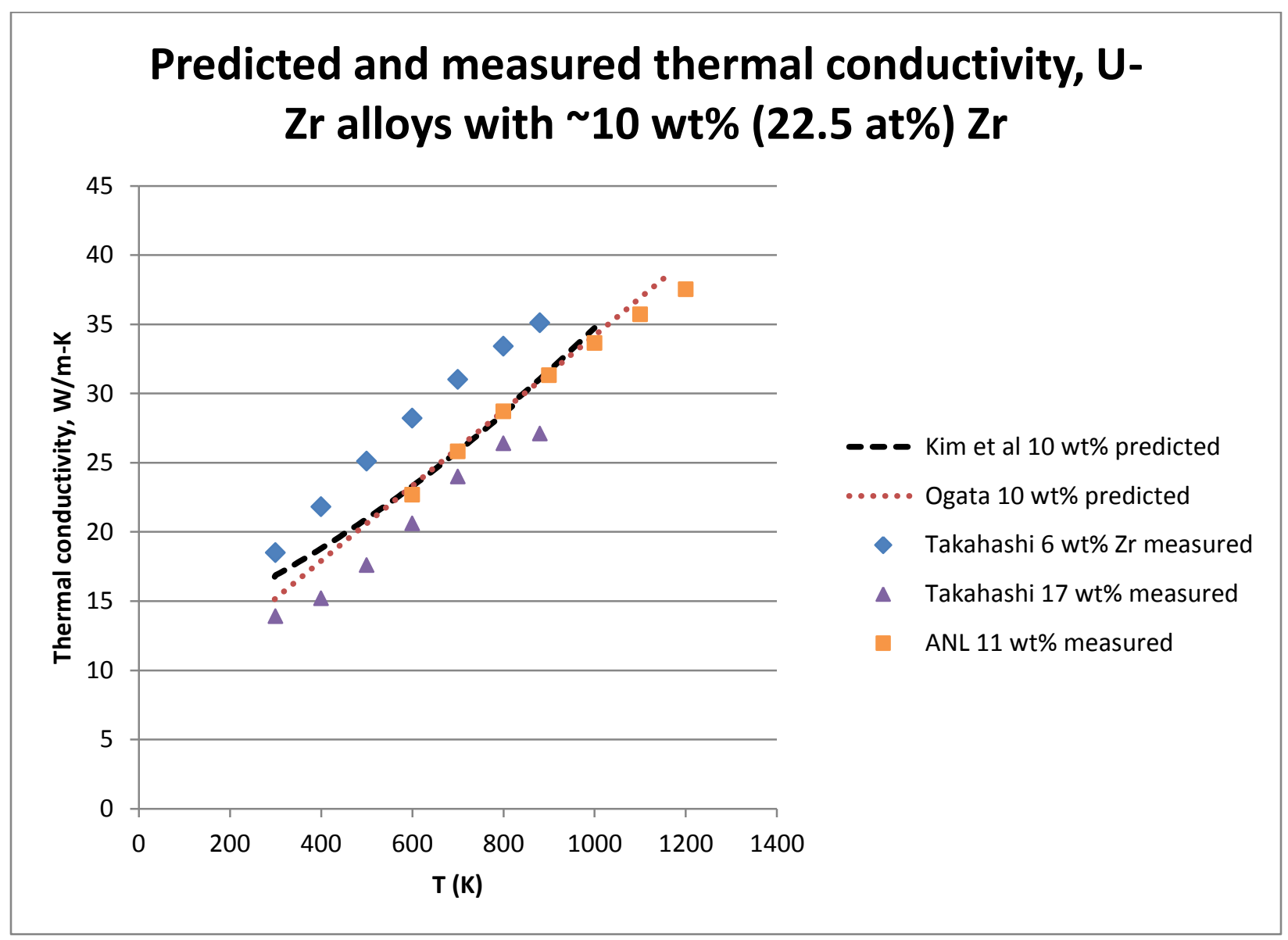

Figure 43. Measured and predicted thermal conductivity for $\mathrm{U}-\mathrm{Zr}$ alloys with $6-17 \mathrm{wt} \% \mathrm{Zr}$. Ogata's predicted value is from Equation 69.

Equation 69. Estimated thermal conductivity of U-Zr alloys [58] (thermal conductivity in $\mathrm{W} / \mathrm{m}-\mathrm{K}, \mathrm{C}_{\mathrm{Zr}}$ is atomic fraction of $\mathrm{Zr}, \mathrm{C}_{\mathrm{Zr}}<0.72, \mathrm{~T}$ in $\mathrm{K}, \mathrm{T}<1173 \mathrm{~K}$ )

$$
\mathrm{k}=16.309+0.02713 \times \mathrm{T}-46.27 \times \mathrm{C}_{\mathrm{Zr}}+22.985 \times \mathrm{C}_{\mathrm{Zr}}^{2}
$$




\subsection{Pu-Zr Alloys}

\subsubsection{Introduction}

There are apparently no published measurements of the thermal conductivity or diffusivity of any $\mathrm{Pu}-\mathrm{Zr}$ alloy. Preliminary INL measurements of alloys with 10 and $30 \mathrm{wt} \% \mathrm{Zr}$ indicate that the thermal diffusivity of both alloys increases with temperature (although perhaps not smoothly), and that the diffusivity of the alloy with $30 \% \mathrm{Zr}$ is lower than that of the alloy with $10 \% \mathrm{Zr}$.

Further measurements are clearly needed.

\subsubsection{Thermal Diffusivity}

INL researchers have made three preliminary laser-flash diffusivity measurements of Pu-Zr alloys: two measurements of an alloy with $10 \mathrm{wt} \%$ (23 at $\%) \mathrm{Zr}$ and one of an alloy with $30 \mathrm{wt} \%$ (53 at $\%) \mathrm{Zr}$. The data suggest that thermal diffusivity increases with temperature for both compositions, and that the diffusivity of the alloy with $30 \mathrm{wt} \%$ is smaller than that of the alloy with $10 \mathrm{wt} \% \mathrm{Zr}$ by up to $\sim 0.005 \mathrm{~cm}^{2} / \mathrm{s}$ (Figure 44).

Consideration of the $\mathrm{Pu}-\mathrm{Zr}$ phase diagram (Section 3.5.3)suggests that the "hump" in the $\mathrm{Pu}-30 \mathrm{Zr}$ data at about $200^{\circ} \mathrm{C}$ may be due to formation of the $\delta-(\mathrm{Pu}-\mathrm{Zr})$ phase. The upward curve in data for this alloy at $\sim 650^{\circ} \mathrm{C}$ does not correspond to an obvious phase transformation but is approximately the melting temperature of pure $\mathrm{Pu}$.

Further investigation of the thermal conductivity and diffusivity of $\mathrm{Pu}-\mathrm{Zr}$ alloys is clearly needed. 


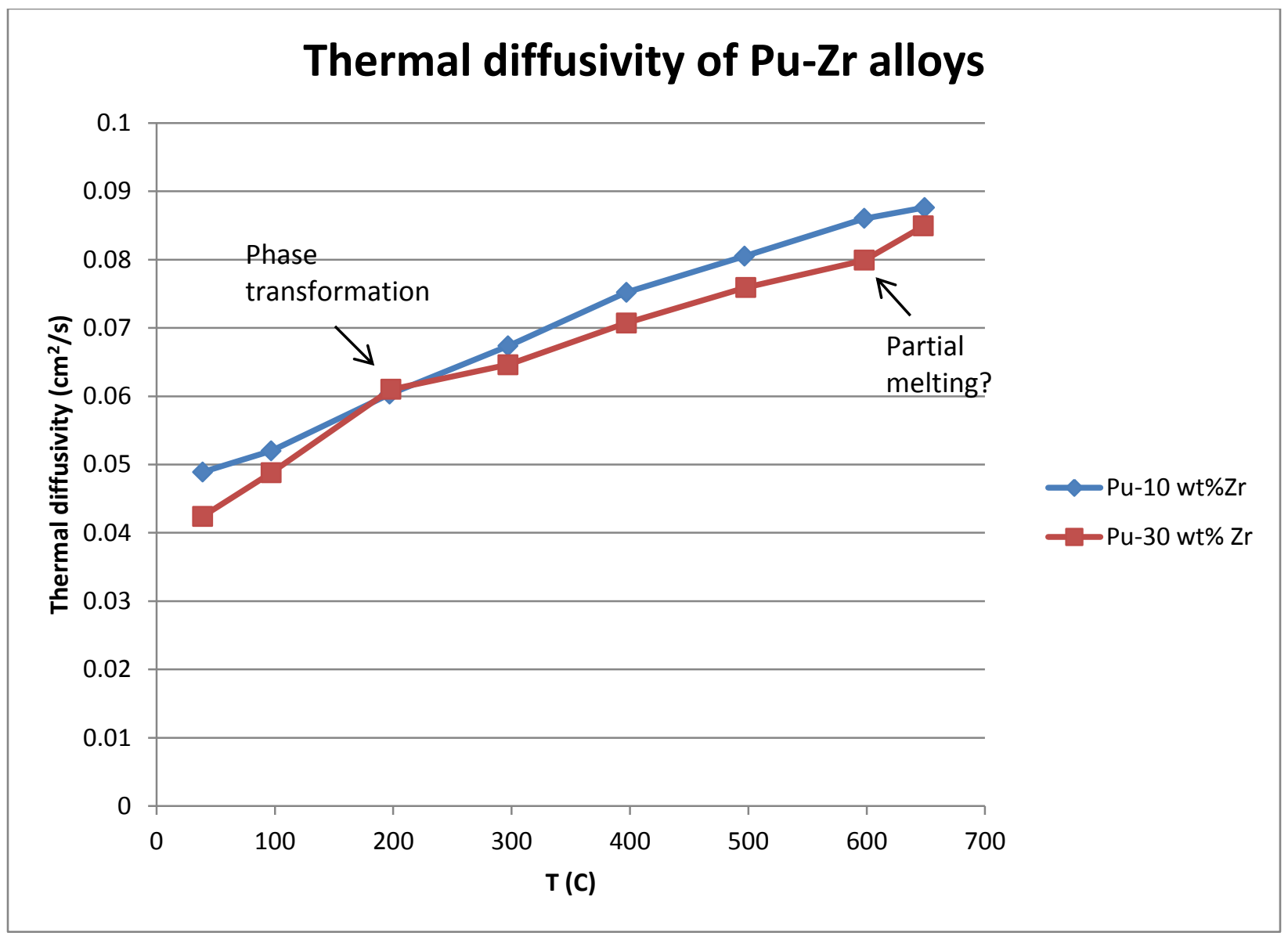

Figure 44. Thermal diffusivity of Pu-10 wt $\% \mathrm{Zr}$ and $\mathrm{Pu}-30 \mathrm{wt} \% \mathrm{Zr}$ alloys (INL preliminary data). Data for $\mathrm{Pu}-10 \mathrm{wt} \%$ alloy are the average of two measurements.

\subsection{U-Pu Alloys}

\subsubsection{Introduction}

The only published data for thermal conductivity of any U-Pu alloy are for a composition with 10 $\mathrm{wt} \%(10 \mathrm{at} \%) \mathrm{Pu}$. Thermal conductivity of this alloy increases with temperature, and is $\sim 15 \%$ below the thermal conductivity of $U$ as reported in the same publication. More measurements on this and other alloys are clearly needed.

\subsubsection{Thermal Conductivity}

Kelman et al. [112] and [144 Figure 7] published what seems to be the only thermal conductivity data for any U-Pu alloy. Kittel et al. [91 Table 17] repeated these data except for the thermal conductivity at $200^{\circ} \mathrm{C}$, which they appear to have erroneously carried over from an adjacent column of the same table.

According to Kelman et al., the thermal conductivity of an alloy with $10 \mathrm{wt} \%$ (10 at $\%) \mathrm{Pu}$ is $\sim 15 \%$ below that of the thermal conductivity of $U$. Since the thermal conductivity of $U$ reported by Kelman et al. [112] is in good agreement with recent publications [62, 146], it seems likely that the thermal conductivity values for $\mathrm{U}-10 \mathrm{Pu}$ in Table 15 represent the actual behavior of the alloy. 
Table 15. Thermal conductivity of U-10Pu [112].

\begin{tabular}{cc}
\hline $\mathrm{T}\left({ }^{\circ} \mathrm{C}\right)$ & $\begin{array}{c}\text { Thermal Conductivity } \\
(\mathrm{W} / \mathrm{m} \cdot \mathrm{K})\end{array}$ \\
\hline 200 & 23.43 \\
400 & 28.86 \\
600 & 36.39 \\
800 & 41.83 \\
\hline
\end{tabular}

\subsection{U-Pu-Zr Alloys}

\subsubsection{Introduction}

Researchers at ANL, Los Alamos Scientific Laboratory, and CEA published measurements of the thermal conductivity of U-Pu-Zr alloys with $\sim 15-20 \mathrm{wt} \% \mathrm{Pu}$ and $\sim 3.4-14 \mathrm{wt} \% \mathrm{Zr}$ in the 1960s [101, 105, 144, 153]. Later publications (e.g., [4, 58, 91, 106]) repeat the data.

Thermal conductivity measurements differ by $\sim 25-30 \%$ within the range of compositions represented in the data. The data indicate that thermal conductivity increases with temperature for a given composition, and suggest that increasing the concentration of Pu may lower the thermal conductivity.

Several researchers have published equations for calculating thermal conductivity of U-Pu-Zr alloys with arbitrary compositions. None of these equations seems a good choice for calculating the thermal conductivity of U-Pu-Zr alloys with $15-20 \mathrm{wt} \% \mathrm{Pu}$ and $10-15 \mathrm{wt} \% \mathrm{Zr}$. It is recommended that new curves be fitted after thermal conductivity values for a particular application have been determined.

\subsubsection{Thermal Conductivity}

Figure 45 shows the published measurements of thermal conductivity of U-Pu-Zr alloys [101, 105, 144, 153]. Conductivity increases with temperature for each of the materials studied. Although there are exceptions, conductivity tends to be lower in materials with higher concentrations of $\mathrm{Pu}$. 


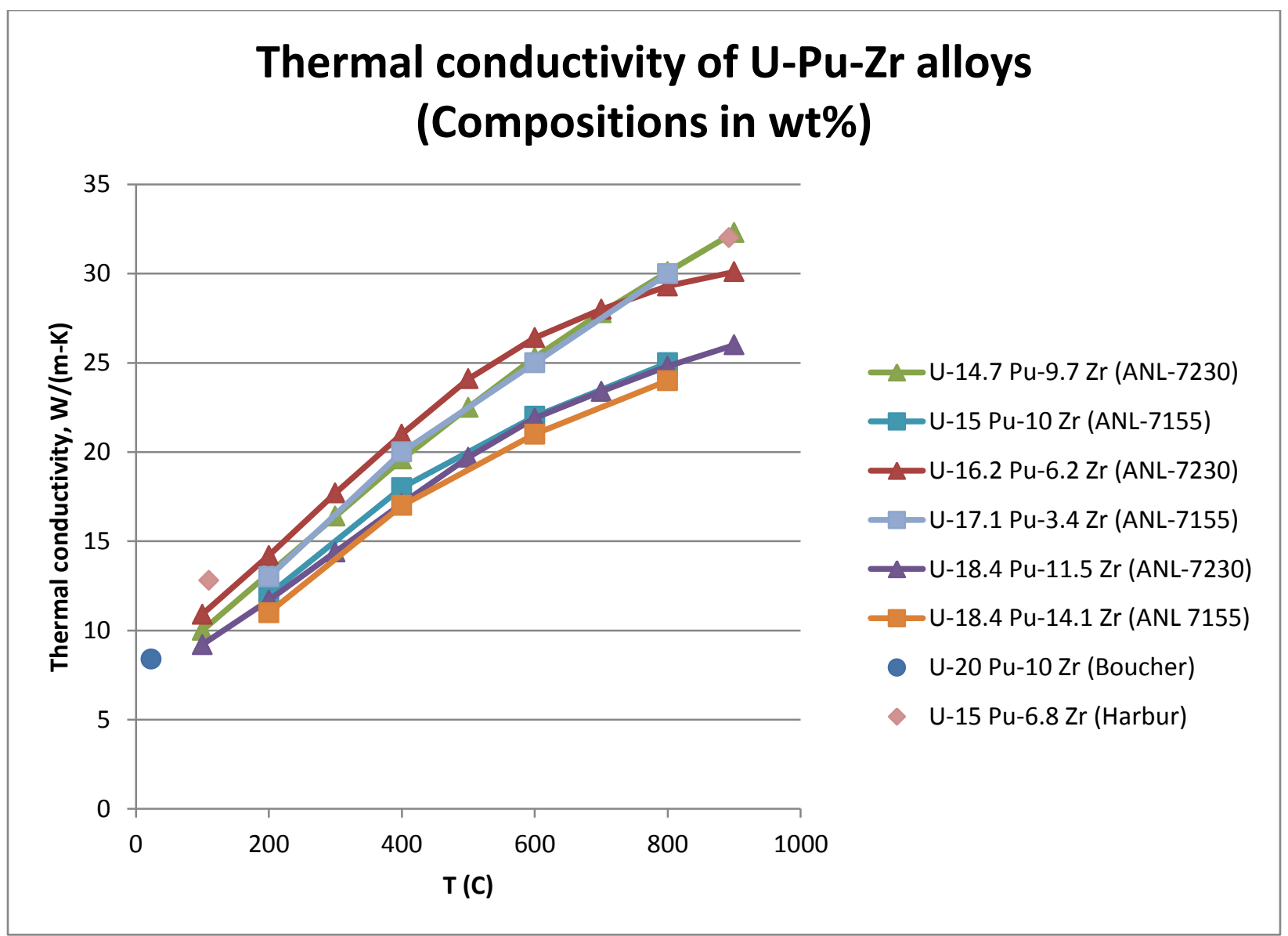

Figure 45. Thermal conductivity of U-Pu-Zr alloys. [101, 105, 144, 153]

Billone et al. [152], Kim et al. [146], and Ogata [4, 58] have developed equations to predict the thermal conductivity of U-Pu-Zr alloys. The Billone et al. model was developed to allow the LIFE-METAL fuel performance code to be used for U-Pu-Zr alloys, and represents the thermal conductivity of an alloy as a quadratic equation in T. The Kim et al. model incorporates "fitting factors" to allow a widely used model for thermal conductivity of a two-phase mixture to be extended to solid solutions, and calculates thermal conductivity based on temperature, composition, and the thermal conductivities of the elements involved. The Ogata model is purely empirical, and represents the thermal conductivities of compositions with less than $72 \mathrm{at} \% \mathrm{Zr}$ and $16 \mathrm{at} \% \mathrm{Pu}$ as linear functions of temperature.

Figure 46 compares the Billone et al. and Ogata models to measured thermal conductivity for alloys with compositions close to $\mathrm{U}-15 \mathrm{Zr}-10 \mathrm{Pu}$ (green) and $\mathrm{U}-18 \mathrm{Pu}-20 \mathrm{Zr}$ (turquoise). The Kim et al. model is not included because the practical difficulties involved in calculating it do not seem justified without a better knowledge of the required thermal conductivity values. The Billone et al. model is a reasonable representation of the available data for $\mathrm{U}-15 \mathrm{Zr}-10 \mathrm{Pu}$, but neither model is a good approximation for the U-18.4-14.1Zr data. Given the widespread availability of curve-fitting software, the best approach is probably to fit a curve to the desired thermal conductivity values rather than using a previously published model. 


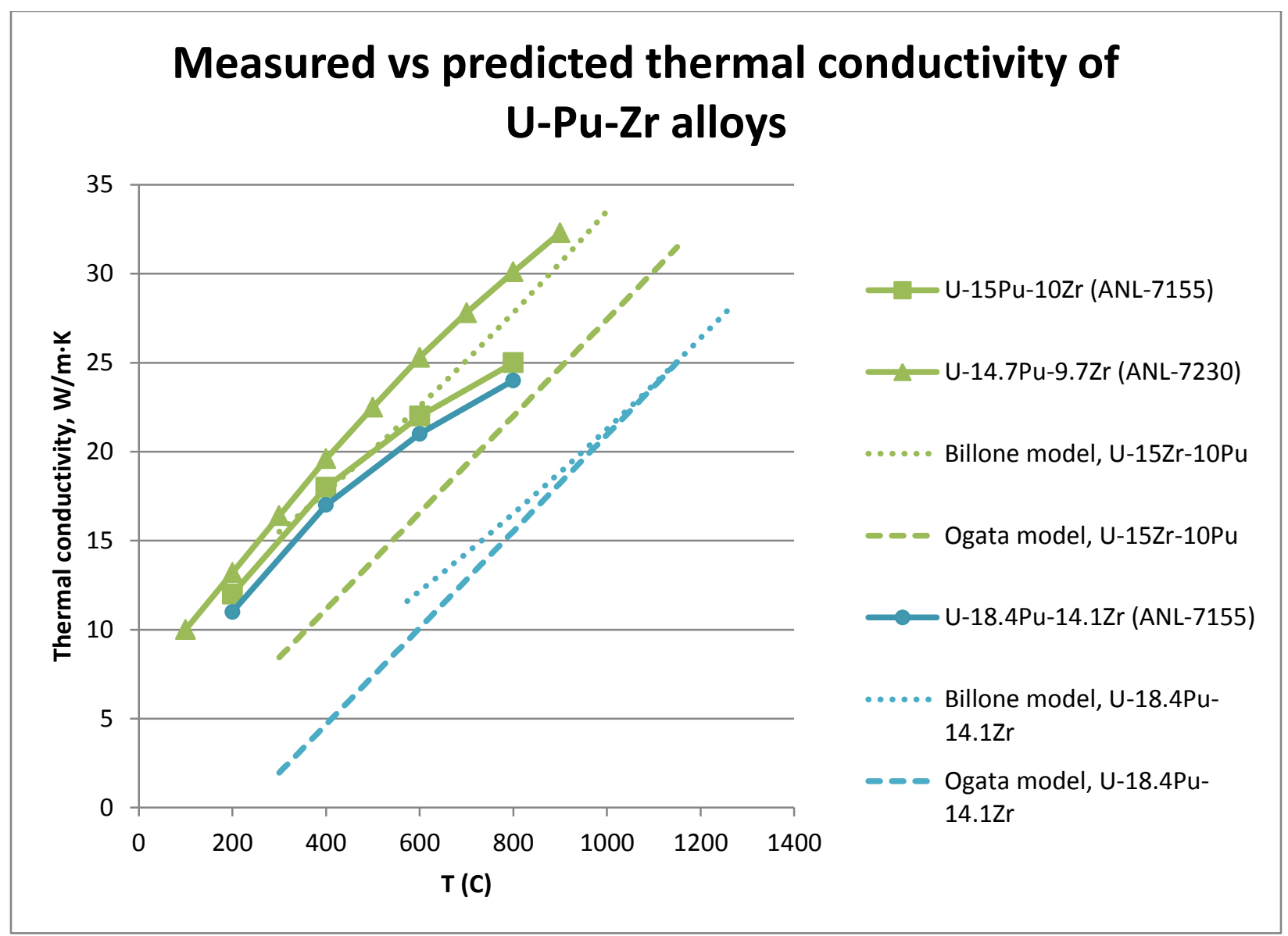

Figure 46. Comparison of measured and predicted thermal conductivity of U-Pu-Zr alloys.

There are no measurements of thermal conductivities of individual U-Pu-Zr phases. However, R.J. Dunworth suggested that the thermal conductivity of $\alpha-(\mathrm{U}, \mathrm{Pu})$ and $\delta-(\mathrm{U}, \mathrm{Pu}) \mathrm{Zr}_{2}$ is about twice that of $\zeta_{-}(\mathrm{U}, \mathrm{Pu})$ based on a comparison between thermal conductivity measurements and volume fractions of phases determined from an isothermal section of the U-Pu-Zr phase diagram at $500^{\circ} \mathrm{C}$ [144 page 19]. Since he believed that increasing the concentration of $\mathrm{Pu}$ should increase the proportion of $\zeta-(\mathrm{U}, \mathrm{Pu})$ and decrease that of $\alpha-(\mathrm{U}, \mathrm{Pu})$, Dunworth inferred that alloys with higher proportions of $\mathrm{Pu}$ would have lower thermal conductivities. This suggestion is qualitatively consistent with the data in Figure 45. 


\section{REFERENCES}

[1] R.J.M. Konings, O. Beneš, The Thermodynamic Properties of the f-Elements and Their Compounds. I. The Lanthanide and Actinide Metals, Journal of Physical and Chemical Reference Data, 39 (2010) 043102.

[2] R.J.M. Konings, O. Beneš, J.-C. Griveau, The actinides elements: properties and characteristics, in: R.J.M. Konings (Ed.) Comprehensive Nuclear Materials, volume 2, Elsevier, 2012, pp. 1-20.

[3] F.L. Oetting, M.H. Rand, R.J. Ackermann, The chemical thermodynamics of actinide elements and compounds, part 1: The actinide elements, International Atomic Energy Agency, Vienna, Austria, 1976.

[4] T. Ogata, Metal Fuel, in: R.J.M. Konings (Ed.) Comprehensive Nuclear Materials, volume 3, Elsevier, 2012, pp. 1-40.

[5] Y.S. Touloukian, R.K. Kirby, R.E. Taylor, P.D. Desai, Thermal Expansion: Metallic elements and alloys (Thermophysical Properties of Matter vol. 12), IFI/Plenum, New York, 1975.

[6] Y.S. Touloukian, P.W. Powell, C.Y. Ho, M.C. Nicolaou, Thermal Diffusivity (Thermophysical Properties of Matter vol. 10), IFI/Plenum, 1973.

[7] Y.S. Touloukian, R.W. Powell, C.Y. Ho, P.G. Klemens, Thermal Conductivity (Thermophysical Properties of Matter vol. 1), IFI/Plenum, New York, 1970.

[8] W.M. Haynes, ed., Conversion factors, CRC Press/Taylor and Francis, Boca Raton, FL,2016.

[9] A.C. Lawson, C.E. Olsen, J.W. Richardson Jr., M.H. Mueller, G.H. Lander, Structure of $\beta$-uranium, Acta Crystallographica, B44 (1988).

[10] J.W. Ward, P.D. Kleinschmidt, D.E. Peterson, Thermochemical properties of the actinide elements and selected actinide-noble metal intermetallics, in: A.J. Freeman, C. Keller (Eds.) Handbook on the Physics and Chemistry of the Actinides, Elsevier, 1986, pp. 309-412.

[11] I. Grenthe, J. Fuger, R.J.M. Konings, R.J. Lemire, A.B. Muller, C. Nguyen-Trung, H. Wanner, Chemical Thermodynamics of Uranium, Elsevier North-Holland, Amsterdam, 1992.

[12] S.S. Hecker, M. Stan, Properties of plutonium and its alloys for use as fast reactor fuels, Journal of Nuclear Materials, 383 (2008) 112-118.

[13] D.L. Clark, S.S. Hecker, G.D. Jarvinen, M.P. Neu, Plutonium, in: L.R. Morss, N.M. Edelstein, J. Fuger (Eds.) The Chemistry of the Actinide and Transactinide Elements, Springer, Dordrecht, The Netherlands, 2010, pp. 813-1264.

[14] A. Saxena, T. Lookman, R.C. Albers, Landau free energy for structural phase transitions in Pu, in: J.M. Howe, D.E. Laughlin, J.K. Lee (Eds.) Proceedings of an International Conference on Solid State Phase Transformations in Organic Materials 2005, 2006, pp. 69-74.

[15] G.V. Ionov, F.A. Sapozhnikov, V.V. Dremov, D.L. Preston, M.A. Zocher, The generalized embedded atom model of interatomic interaction and its application to $\alpha-\mathrm{Pu}$, Journal of Nuclear Materials, 436 (2013) 10-16.

[16] P. Söderlind, A. Landa, J.E. Klepeis, First-principles electronic and elastic properties of plutonium metal, in: Actinides 2009, Institute of Physics, Temple Back, Bristol, United Kingdom, San Francisco, CA, 2010.

[17] P. Söderlind, First-principles phase stability, bonding, and electronic structure of actinide metals, Journal of Electron Spectroscopy and Related Phenomena, 194 (2014) 2-7.

[18] A.V. Karavaev, V.V. Dremov, MD study of the finite temperature effects on the phase ordering, stacking fault energy, and edge dislocation core structure in elemental $\mathrm{Pu}$ and $\mathrm{Pu}-\mathrm{Ga}$ alloys, Journal of Nuclear Materials, 457 (2015) 94-99.

[19] T. Hahn, ed., International Tables for Crystallography, Volume A: Space-Group Symmetry, Springer, Dordrecht, The Netherlands,2005.

[20] R.J. Lemire, J. Fuger, H. Nitsche, P. Potter, M.H. Rand, J. Rydberg, K. Spahiu, J.C. Sullivan, W.J. Ullman, P. Vitorge, H. Warner, Chemical Thermodynamics of Neptunium and Plutonium, Elsevier North Holland, Amsterdam, The Netherlands, 2001.

[21] S.M. Ennaceur, The effects of thermal conditioning and recovery processes on the $\delta \rightarrow \gamma$ phase transformation mechanisms in plutonium, Thermochimica Acta, 565 (2013) 151-158. 
[22] S.M. Ennaceur, Methodology for describing the $\alpha \rightarrow \beta$ phase transformation in plutonium, Thermochimica Acta, 539 (2012) 84-91.

[23] S.M. Ennaceur, Study of the $\gamma \rightarrow \delta$ phase transformation kinetics and reaction mechanism in plutonium, Thermochimica Acta, 566 (2013) 181-185.

[24] S.M. Ennaceur, A differential scanning calorimetry study of the kinetics of the $\beta \rightarrow \gamma$ phase transformation in plutonium, Thermochimica Acta, 547 (2012) 99-105.

[25] W.M. Haynes, ed., Crystal structures and lattice parameters of allotropes of the elements, CRC Press/Taylor and Francis, Boca Raton, FL,2016.

[26] A. Cezairliyan, F. Righini, Thermodynamic studies of the $\alpha \rightarrow \beta$ phase transformation in zirconium using a subsecond pulse heating technique, Journal of Research of the National Bureau of Standards, 79A (1974) 81-84.

[27] W.M. Haynes, ed., Density of molten elements and representative salts, CRC Press/Taylor and Francis, Boca Raton, FL,2016.

[28] P.F. Paradis, W.K. Rhim, Thermophysical properties of zirconium at high temperature, Journal of Materials Research, 14 (1999) 3713-3719.

[29] W.M. Haynes, ed., Enthalpy of fusion, CRC Press/Taylor and Francis, Boca Raton, FL,2016.

[30] R.I. Sheldon, D.E. Peterson, The U-Zr (uranium-zirconium) system, Bulletin of Alloy Phase

Diagrams, 10 (1989) 165-171, 205-206.

[31] R.I. Sheldon, D.E. Peterson, U-Zr (uranium-zirconium), in: T.B. Massalski (Ed.) Binary Alloy Phase Diagrams, II ed., 1990, pp. 3520-3523.

[32] S. Ahn, S. Irukuvarghula, S.M. McDeavitt, Thermophysical investigations of the uranium-zirconium alloy system, Journal of Alloys and Compounds, 611 (2014) 355-362.

[33] S. Ahn, S.M. McDeavitt, Transformation Enthalpies of Uranium-Zirconium Alloy System, Transactions of the American Nuclear Society, 106 (2012) 239-241.

[34] F.A. Rough, An evaluation of data on zirconium-uranium alloys (Battelle Memorial Institute Report BMI-1030), 1955.

[35] A.A. Bauer, ed., An evaluation of the properties and behavior of zirconium-uranium alloys (report no. BMI-1350), Battelle Memorial Institute, Columbus, OH, 1959.

[36] F.A. Rough, A.A. Bauer, Constitution of uranium and thorium alloys (Battelle Memorial Institute Report BMI-1300), 1958.

[37] M. Akabori, A. Itoh, T. Ogawa, F. Kobayashi, Y. Suzuki, Stability and structure of the $\delta$ phase of the U-Zr alloys, Journal of Nuclear Materials, 188 (1992) 249-254.

[38] M. Akabori, T. Ogawa, A. Itoh, Y. Morii, The lattice stability and structure of $\delta-\mathrm{UZr}_{2}$ at elevated temperatures, Journal of Physics: Condensed Matter, 7 (1995) 8249-8257.

[39] J.T. McKeown, S. Irukuvarghula, S. Ahn, M.A. Wall, L.L. Hsiung, S. McDeavitt, P.E.A. Turchi, Coexistence of the $\alpha$ and $\delta$ phases in an as-cast uranium-rich U-Zr alloy, Journal of Nuclear Materials, 436 (2013) 100-104.

[40] S.T. Zegler, The uranium-rich end of the uranium-zirconium system (Argonne National Laboratory report ANL-6055), 1962.

[41] C.B. Basak, Microstructural evolution of U-rich U-Zr alloys under near-equilibrium condition, Journal of Nuclear Materials, 416 (2011) 280-287.

[42] C.B. Basak, S. Neogy, D. Srivastava, G.K. Dey, S. Banerjee, Disordered bcc gamma-phase to deltaphase transformation in Zr-rich U-Zr alloy, Philosophical Magazine, 91 (2011) 3290-3306.

[43] C.B. Basak, N. Prabhu, M. Krishnan, On the formation mechanism of $\mathrm{UZr}_{2}$ phase, Intermetallics, 18 (2010) 1707-1712.

[44] M. Kurata, Thermodynamic database on U-Pu-Zr-Np-Am-Fe alloy system I - Re-evaluation of U-PuZr alloy, IOP Conference Series: Materials Science and Engineering, 9 (2010) 1-8.

[45] J. Belak, J.1. Fattebert, A. Landa, P. Söderlind, L. Zepeda-Ruiz, P. Turchi, Modeling UZr metallic fuels: coupling thermodynamics with microstructure, Transactions of the American Nuclear Society, 102 (2010) 841-842. 
[46] P.Y. Chevalier, E. Fischer, B. Cheynet, Progress in the thermodynamic modelling of the O-U-Zr ternary system, CALPHAD: Computer Coupling Phase Diagrams and Thermochemistry, 28 (2004) 1540.

[47] M. Kurata, Thermodynamic assessment of the Pu-U, Pu-Zr, and Pu-U-Zr systems, CalphadComputer Coupling of Phase Diagrams and Thermochemistry, 23 (1999) 305-337.

[48] M. Kurata, T. Ogata, K. Nakamura, T. Ogawa, Thermodynamic assessment of the Fe-U, U-Zr, and Fe-U-Zr systems, Journal of Alloys and Compounds, 271/273 (1998) 636-640.

[49] M. Kurata, Phase diagrams of actinide alloys, in: R.J.M. Konings (Ed.) Comprehensive Nuclear Materials, volume 2, Elsevier, 2012, pp. 139-195.

[50] A. Landa, P. Söderlind, B. Grabowski, P.E.A. Turchi, A.V. Ruban, L. Vitos, Ab Initio Study of Advanced Metallic Nuclear Fuels for Fast Breeder Reactors, Actinides and Nuclear Energy Materials, 1444 (2012) 67-78.

[51] A. Landa, P. Söderlind, P.E.A. Turchi, Density-functional study of the U-Zr system, Journal of Alloys and Compounds, 478 (2009) 103-110.

[52] A. Landa, P. Söderlind, P.E.A. Turchi, Density-functional study of U-Mo and U-Zr alloys, Journal of Nuclear Materials, 414 (2011) 132-137.

[53] L. Leibowitz, E. Veleckis, R.A. Blomquist, A.D. Pelton, Solidus and liquidus temperatures in the uranium-plutonium-zirconium system, Journal of Nuclear Materials, 154 (1988) 145-153.

[54] L. Leibowitz, R.A. Blomquist, A.D. Pelton, Thermodynamics of the uranium zirconium system, Journal of Nuclear Materials, 167 (1989) 76-81.

[55] T. Ogawa, J.K. Gibson, R.G. Haire, M.M. Gensini, M. Akabori, Thermodynamic analysis of Zr-U and $\mathrm{Zr-Np}$ alloys in view of f-d interaction, Journal of Nuclear Materials, 223 (1995) 67-71.

[56] T. Ogawa, T. Iwai, Thermochemical modelling of U-Zr alloys, Journal of the Less-Common Metals, 170 (1991) 101-108.

[57] W. Xiong, W. Xie, C. Shen, D. Morgan, Thermodynamic modeling of the U-Zr system -- a revisit, Journal of Nuclear Materials, 2013 (2013).

[58] T. Ogata, Irradiation behavior and thermodynamic properties of metallic fuel, Journal of Nuclear Science and Technology, 39 Supplement 3 (2002) 675-681.

[59] J.G. Huber, P.H. Ansari, The superconductivity of BCC U-Zr alloys, Physica, 135B (1985) 441-444.

[60] S.M. McDeavitt, A.A. Solomon, Preparation and performance of U-10Zr alloy nuclear fuel using powder metallurgy techniques, in: J.M. Capus (Ed.) Advances in Powder Metallurgy, 1992, pp. 109-123.

[61] T. Matsui, T. Natsume, K. Naito, Heat capacity measurements of $\mathrm{U}_{0.80} \mathrm{Zr}_{0.20}$ and $\mathrm{U}_{0.80} \mathrm{Mo}_{0.20}$ alloys from room temperature to $1300 \mathrm{~K}$, Journal of Nuclear Materials, 167 (1989) 152-159.

[62] S. Kaity, J. Banerjee, M.R. Nair, K. Ravi, S. Dash, T.R.G. Kutty, A. Kumar, R.P. Singh, Microstructural and thermophysical properties of U-6 wt.\%Zr alloy for fast reactor application, Journal of Nuclear Materials, 427 (2012) 1-11.

[63] Y. Takahashi, K. Yamamoto, T. Ohsato, H. Shimada, T. Terai, M. Yamawaki, Heat capacities of uranium-zirconium alloys from 300 to $1100 \mathrm{~K}$, Journal of Nuclear Materials, 167 (1989) 147-151.

[64] P. Chiotti, V.V. Akhachinskij, I. Ansara, M.H. Rand, The Chemical Thermodynamics of Actinide Elements and Compounds, Part 5: The actinide binary alloys, IAEA, Vienna, Austria, 1981.

[65] D. Summers-Smith, Journal of the Institute of Metals, 83 (1954-1955) 277.

[66] M. Kanno, M. Yamawaki, T. Koyama, N. Morioka, Thermodynamic activity measurements of U-Zr alloys by Knudsen effusion mass spectrometry, Journal of Nuclear Materials, 154 (1988) 154-160.

[67] A. Maeda, Y. Suzuki, T. Ohmichi, Uranium activity of uranium-rich U-Zr alloys by Knudsen effusion mass spectrometry, Journal of Alloys and Compounds, 179 (1992) L21-L24.

[68] H. Okamoto, Pu-Zr (plutonium-zirconium), Journal of Phase Equilibria, 14 (1993) 400-401.

[69] H. Okamoto, Pu-Zr (plutonium-zirconium), Journal of Phase Equilibria, 16 (1995) 287-288.

[70] J.A.C. Marples, The plutonium-zirconium phase diagram, Journal of the Less-Common Metals, 2 (1960) 331-351.

[71] J.A.C. Marples, The lattice parameters of some $\delta$ - and $\varepsilon$-plutonium alloys, Journal of Physics and Chemistry of Solids, 25 (1964) 521-534. 
[72] A.F. Berndt, The theta phase in the plutonium-zirconium system, Journal of the Less-Common Metals, 12 (1967) 82-83.

[73] A.A. Bochvar, S.T. Konobeevskii, V.I. Kutaitsev, T.S. Men'shikova, N.T. Chebotarev, Interaction between plutonium and other metals in connection with their arrangement in Mendeleev's periodic table, in: Proceedings of the UN International Conference on Peaceful Uses of Atomic Energy, 1958, pp. 11771191.

[74] D. Calais, M. Dupuy, M. Mouchnino, A.Y. Portnoff, A. Van Craeynest, Diffusion of plutonium in the solid state, in: A.E. Kay, M.B. Waldron (Eds.) Plutonium 1965, Chapman and Hall, 1965, pp. 358391.

[75] Monsanto Research Corporation, Reactor Fuels and Materials Development Plutonium Research: January-June, 1967 (Mound Laboratory Report MLM-1445), Miamisburg, OH, 1967.

[76] Y. Suzuki, A. Maeda, T. Ohmichi, Phase diagram of the Pu-Zr system in the Zr-rich region, Journal of Alloys and Compounds, 182 (1992) L9-L14.

[77] J.C. Lauthier, N. Housseau, A. Van Craeynest, D. Calais, Contribution a l'etude du diagramme de phases plutonium-zirconium, Journal of Nuclear Materials, 23 (1967) 313-319.

[78] F.H. Ellinger, C.C. Land, On the plutonium-zirconium phase diagram, Nucl. Metall., 17 (1971) 686698.

[79] D.T. Cromer, The crystal structure of $\zeta-\mathrm{Pu}-\mathrm{Zr}$, ideal formula $\mathrm{Pu}_{28} \mathrm{Zr}$, Acta Crystallographica, B35 (1979) 14-19.

[80] J.M. Taylor, Plutonium-zirconium equilibrium diagram from 0 to 10 at $\% \mathrm{Zr}$, Journal of Nuclear Materials, 30 (1969) 346-350.

[81] J.C. Walden, P.L. Wallace, J.W. Magana, X-ray spectometric analysis of plutonium-zirconium alloys, Applied Spectroscopy, 29 (1975) 175-178.

[82] A. Maeda, Y. Suzuki, Y. Okamoto, T. Ohmichi, Vaporization behavior of plutonium-zirconium binary alloy, Journal of Alloys and Compounds, 205 (1994) 35-38.

[83] D.E. Peterson, E.M. Foltyn, The Pu-U (plutonium-uranium) system, Bulletin of Alloy Phase Diagrams, 10 (1989) 160-164.

[84] Y. Okamoto, A. Maeda, Y. Suzuki, T. Ohmichi, Investigation of the Pu-U phase diagram, Journal of Alloys and Compounds, 213/214 (1994) 372-374.

[85] F.H. Ellinger, R.O. Elliott, E.M. Cramer, The plutonium-uranium system, Journal of Nuclear Materials, 1 (1959) 233-243.

[86] L. Leibowitz, R.A. Blomquist, A.D. Pelton, Thermodynamic modeling of the phase equilibria of the plutonium-uranium system, Journal of Nuclear Materials, 184 (1991) 59-64.

[87] T. Ogawa, Alloying behaviour among U, Np, Pu and Am predicted with the Brewer valence bond model, Journal of Alloys and Compounds, 194 (1993) 1-7.

[88] A. Landa, P. Söderlind, P.E.A. Turchi, L. Vitos, O.E. Peil, A.V. Ruban, Density-functional study of bcc Pu-U, Pu-Np, Pu-Am, and Pu-Cm alloys, Journal of Nuclear Materials, 408 (2011) 61-66.

[89] A. Perron, P.E.A. Turchi, A. Landa, P. Söderlind, B. Ravat, B. Oudot, F. Delaunay, The Pu-U-Am system: An ab initio informed CALPHAD thermodynamic study, Journal of Nuclear Materials, 458 (2015) 425-441.

[90] A. Perron, P.E.A. Turchi, A. Landa, P. Söderlind, B. Ravat, B. Oudot, F. Delaunay, M. Kurata, Thermodynamic re-assessment of the $\mathrm{Pu}-\mathrm{U}$ system and its application to the ternary $\mathrm{Pu}-\mathrm{U}-\mathrm{Ga}$ system, Journal of Nuclear Materials, 454 (2014) 81-95.

[91] J.H. Kittel, J.E. Ayer, W.N. Beck, M.B. Brodsky, D.R. O'Boyle, S.T. Zegler, F.H. Ellinger, W.N. Miner, F.W. Schonfeld, R.D. Nelson, Plutonium and plutonium alloys as nuclear fuel materials, Nuclear Engineering and Design, 15 (1971) 373-440.

[92] A.F. Berndt, Room temperature lattice constants of alloys of plutonium in alpha-uranium, Journal of Nuclear Materials, 9 (1963) 53-58.

[93] A.C. Lawson, J.A. Goldstone, B. Cort, R.J. Martinez, F.A. Vigil, T.G. Zocco, J.W. Richardson Jr., M.H. Mueller, Structure of $\zeta$-phase plutonium-uranium, Acta Crystallographica B: Structural Science, 52 (1996) 32-37. 
[94] H. Savage, The heat content and specific heat of some metallic fast-reactor fuels containing plutonium, Journal of Nuclear Materials, 25 (1968) 249-259.

[95] S. Kaity, J. Banerjee, K. Ravi, R. Keswani, T.R.G. Kutty, A. Kumar, G.J. Prasad, Characterization and property evaluation of U-15 wt\% Pu alloy for fast reactor, Journal of Nuclear Materials, 433 (2013) 206-214.

[96] Monsanto Research Corporation, Reactor Fuels and Materials Development Plutonium Research: 1966 Annual Report (Mound Laboratory Report MLM-1402), Miamisburg, OH, 1967.

[97] H. Okamoto, Pu-U (plutonium-uranium), Journal of Phase Equilibria, 17 (1996) 372b.

[98] D.R. O'Boyle, A.E. Dwight, The uranium-plutonium-zirconium ternary alloy system, in: W.N. Miner

(Ed.) Plutonium 1970 and Other Actinides, Metallurgical Society of AIME, 1970, pp. 720-732.

[99] A. Landa, P. Söderlind, P.E.A. Turchi, L. Vitos, A. Ruban, Density-functional study of Zr-based actinide alloys: 2. U-Pu-Zr system, Journal of Nuclear Materials, 393 (2009) 141-145.

[100] Z. Wenzhong, C. Unal, U-Pu-Zr fuel properties and thermal performance modeling for sodium fast reactors, Transactions of the American Nuclear Society, 106 (2012) 264-264.

[101] D.R. Harbur, J.W. Anderson, W.J. Maraman, Studies on the U-Pu-Zr alloy system for fast breeder reactor applications (Los Alamos National Laboratory Report LA-4512), 1970.

[102] M. Kurata, T. Inoue, C. Sari, Redistribution behavior of various constituents in U-Pu-Zr alloy and $\mathrm{U}-\mathrm{Pu}-\mathrm{Zr}$ alloy containing minor actinides and rare-earths in a temperature-gradient, Journal of Nuclear Materials, 208 (1994) 144-158.

[103] Argonne Nationa Laboratory, Reactor development program progress report, September 1965 (Report ANL-7105), Argonne, IL, 1965.

[104] M.H. Mueller, J.W. Richardson Jr., R.V. Strain, G.L. Hofman, Phase analysis of metallic plutonium-containing fuel alloys using neutron diffraction, in: C.S. Barrett, J.V. Gilfrich, I.C. Noyan, T.C. Huang, P.K. Predecki (Eds.) Advances in X-ray analysis, Plenum, Steamboat Springs, CO, 1991, pp. 447-457.

[105] R. Boucher, P. Barthelemy, Comparaison del alliages U-Pu-Mo, U-Pu-Nb, U-Pu-Ti, U-Pu-Zr (CEA Report CEA-R-2531), translated into English by B. Blumenthal as "Comparison of the Alloys U-Pu-Mo, U-Pu-Nb, U-Pu-Ti, U-Pu-Zr" (ANL-TRANS-138), 1964.

[106] R. Boucher, P. Barthelemy, C. Milet, A study of plutonium-based alloys carried out at Fontenayaux-Roses, in: A.E. Kay, M.B. Waldron (Eds.) Plutonium 1965: Proceedings of the third international conference on plutonium, London, 1965, Chapman and Hall for The Institute of Metals, London, 1965, pp. 485-509.

[107] P.A. Tucker, D.E. Etter, J.M. Gebhart, Phase study of uranium-plutonium-zirconium alloys, Transactions of the American Nuclear Society, 11 (1968) 99.

[108] M.C. Petri, M.A. Dayananda, Isothermal diffusion in uranium-plutonium-zirconium alloys, Journal of Nuclear Materials, 240 (1997) 131-143.

[109] Y.H. Sohn, M.A. Dayananda, G.L. Hofman, R.V. Strain, S.L. Hayes, Analysis of constituent redistribution in the gamma (bcc) U-Pu-Zr alloys under gradients of temperature and concentrations, Journal of Nuclear Materials, 279 (2000) 317-329.

[110] G.L. Hofman, R.G. Pahl, C.E. Lahm, D.L. Porter, Swelling behavior of U-Pu-Zr fuel, Metallurgical Transactions A (Physical Metallurgy and Materials Science), 21A (1990) 517-528.

[111] D.E. Hobart, J.R. Peterson, Berkelium, in: L.R. Morss, N.M. Edelstein, J. Fuger (Eds.) The Chemistry of the Actinide and Transactinide Elements, Springer, Dordrecht, The Netherlands, 2010, pp. 1444-1498.

[112] L.R. Kelman, H.V. Rhude, J.G. Schnizlein, H. Savage, Status of metallic plutonium fast powerbreeder fuels, in: A.E. Kay, M.B. Waldron (Eds.) Plutonium 1965: Proceedings of the third international conference on plutonium, London, 1965, Chapman and Hall for The Institute of Metals, London, 1965, pp. $458-484$.

[113] I. Grenthe, J. Drożdżyński, T. Fujino, E.C. Buck, T.E. Albrecht-Schmitt, S.F. Wolf, Uranium, in: L.R. Morss, N.M. Edelstein, J. Fuger (Eds.) The Chemistry of the Actinide and Transactinide Elements, Springer, Dordrecht, The Netherlands, 2010, pp. 253-698. 
[114] F.L. Oetting, R.O. Adams, The chemical thermodynamics of nuclear materials VII. The hightemperature heat capacity of unalloyed plutonium metal, Journal of Chemical Thermodynamics, 15 (1983) 537-554.

[115] L.J. Wittenberg, C.R. Hudgens, T.K. Engel, D.L. Roesch, D.B. Sullenger, P.A. Tucker, D.E. Etter, K.D. Phipps, W.G. Rohr, J.E. Selle, G.A. Vaughn, Reactor fuels and materials development, Plutonium research: April-September, 1966 (Report MLM-1347), (1967).

[116] M.W. Chase Jr., NIST-JANAF Thermochemical Tables, Fourth Edition, Part II (Cr-Zr), Journal of Physical and Chemical Reference Data, Monograph No. 9 (1998).

[117] International Atomic Energy Agency (IAEA), Thermophysical Properties of Materials for Nuclear Engineering: A Tutorial and Collection of Data, International Atomic Energy Agency (AEA), Vienna, Austria, 2008.

[118] N.D. Milošević, K.D. Maglić, Thermophysical properties of solid phase zirconium at high temperatures, International Journal of Thermophysics, 27 (2006) 1140-1159.

[119] G.B. Fedorov, E.A. Smirnov, Heat capacity of uranium-zirconium systems, Atomnaya Énergiya vol 25 no. 1 pp. 54-56, July 1968, 25 (1968) 795-797.

[120] S. Dash, K. Ghoshal, T.R.G. Kutty, Thermodynamic investigations of uranium-rich binary and ternary alloys, Journal of Thermal Analysis and Calorimetry, 112 (2013) 179-185.

[121] Mu Yeh Wu, J. Wadsworth, O.D. Sherby, Internal stress superplasticity in anisotropic polycrystalline zinc and uranium, Metallurgical Transactions A (Physical Metallurgy and Materials Science), 18A (1987) 451-462.

[122] C.A. Calhoun, J.A. Wollmershauser, D.W. Brown, R.P. Mulay, E. Garlea, S.R. Agnew, Thermal residual strains in depleted $\alpha-U$, Scripta Materialia, 69 (2013) 566-569.

[123] D.W. Brown, M.A.M. Bourke, B. Clausen, D.R. Korzekwa, R.C. Korzekwa, R.J. McCabe, T.A. Sisneros, D.F. Teter, Temperature and direction dependence of internal strain and texture evolution during deformation of uranium, Materials Science and Engineering a-Structural Materials Properties Microstructure and Processing, 512 (2009) 67-75.

[124] H.H. Klepfer, P. Chiotti, Characteristics of the solid state transformations in uranium (Ames Laboratory, report ISC-893 to the United States Atomic Energy Commission), 1957.

[125] C. Basak, G.J. Prasad, H.S. Kamath, N. Prabhu, An evaluation of the properties of as-cast U-rich UZr alloys, Journal of Alloys and Compounds, 480 (2009) 857-962.

[126] J. Thewlis, An X-ray powder study of $\beta$-uranium, Acta Crystallographica, 5 (1952) 790-794.

[127] N.M. Edelstein, J. Fuger, J.J. Katz, L.R. Morss, Summary and comparison of the properties of the actinide and transactinide elements, in: L.R. Morss, N.M. Edelstein, J. Fuger (Eds.) The Chemistry of the Actinide and Transactinide Elements, Springer, Dordrecht, The Netherlands, 2010, pp. 1753-1832. [128] S.M. Ennaceur, Phase stability of $\alpha^{\prime}$-phase in a Pu-1at\% Ga alloy following low temperature treatment, Thermochimica Acta, 593 (2014) 22-29.

[129] T. Lee, M.I. Baskes, A.C. Lawson, S.P. Chen, S.M. Valone, Atomistic modeling of the negative thermal expansion in $\delta$-plutonium based on the two-state description, Materials, 5 (2012) 1040-1054. [130] A. Solontsov, V.P. Antropov, Effects of spin fluctuations and anomalous thermal expansion of delta-Pu, Physical Review B, 81 (2010) 214402.

[131] A.C. Lawson, J.A. Roberts, B. Martinez, Invar model for $\delta$-phase Pu: Thermal expansion, elastic and magnetic properties, Philosophical Magazine, 86 (2006) 2713-2733.

[132] W.A. Harrison, Theory of the thermal properties of delta-plutonium, Physical Review B, 69 (2004) 224109-224101-224109.

[133] A. Migliori, I. Mihut-Stroe, J.B. Betts, Plutonium elastic moduli, electron localization, and temperature, in: D.C. Shuh, B.W. Chung, T. Albrecht-Schmitt (Eds.) Actinides 2008--Basic Science, Applications, and Technology Materials Research Society, San Francisco, CA, 2008, pp. 249-252. [134] F.W. Schonfeld, R.E. Tate, The thermal expansion behavior of unalloyed plutonium (Los Alamos National Laboratory Report LA-13034-MS), 1996.

[135] O.J. Wick, ed., Plutonium Handbook, Gordon and Branch, New York,1967. 
[136] V. Petukhov, Thermal expansion of zirconium in the solid phase, High Temperatures-High Pressures, 35/36 (2003/2004) 15-23.

[137] S.V. Boyarskii, Internal friction and coefficient of linear expansion of zirconium and cobalt in the phase transition region, Journal of Engineering Physics, 50 (1986) 444-447.

[138] Y.-J. Hao, L. Zhang, X.-R. Chen, L.-C. Cai, Q. Wu, D. Alfe, Ab initio calculations of the thermodynamics and phase diagram of zirconium, Physical Review B, 78 (2008) 134101.

[139] K. Masuda-Jindo, Vu Van Hung, P.E.A. Turchi, Application of statistical moment method to thermodynamic properties and phase transformations of metals and alloys, Diffusion and Defect Data Part B (Solid State Phenomena), 138 (2008) 209-239.

[140] W.M. Haynes, ed., Physical constants of inorganic compounds, CRC Press/Taylor and Francis, Boca Raton, FL,2016.

[141] H.A. Saller, R.F. Dickerson, W.E. Murr, Uranium alloys for high-temperature application (Battelle Memorial Institute Report BMI-1098), (1956).

[142] K.A. Gschneidner Jr., R.O. Elliott, J.T. Waber, Influence of alloying on the negative thermal expansion of delta plutonium, Acta Metallurgica, 11 (1963) 947-955.

[143] R.O. Elliott, K.A. Gschneidner Jr., C.A. Kempter, Thermal expansion of some delta plutonium solid solution alloys, in: E. Grison, W.B.H. Lord, R.D. Fowler (Eds.) Plutonium 1960, Cleaver-Hume Press, London, 1961, pp. 142-155 (Paper no. 134).

[144] Argonne National Laboratory, Metallurgy Division annual progress report for 1965 (Report ANL7155), Argonne, IL, 1965.

[145] Y.S. Kim, G.L. Hofman, A.M. Yacout, Migration of minor actinides and lanthanides in fast reactor metallic fuel, Journal of Nuclear Materials, 392 (2009) 164-170.

[146] Y.S. Kim, T.W. Cho, D.-S. Sohn, Thermal conductivities of actinides (U, Pu, Np, Cm, Am) and uranium-alloys (U-Zr, U-Pu-Zr, and U-Pu-TRU-Zr), Journal of Nuclear Materials, 445 (2014) 272-280. [147] International Atomic Energy Agency (IAEA), Thermophysical properties of materials for watercooled reactors (IAEA-TECDOC-949), 1997.

[148] Y. Takahashi, M. Yamawaki, K. Yamamoto, Thermophysical properties of uranium-zirconium alloys, Journal of Nuclear Materials, 154 (1988) 141-144.

[149] C.A. Alexander, V.E. Wood, Thermal conductivity of plutonium above room temperature, Journal of Applied Physics, 103 (2008) 063704-063701 to 063704-063707.

[150] J.K. Fink, L. Leibowitz, Thermal conductivity of zirconium, Journal of Nuclear Materials, 226

(1995) 44.

[151] Argonne National Laboratory, Chemical Technology Division Annual Technical Report for 1986 (Report ANL-87-19), Argonne, IL, 1987.

[152] M.C. Billone, Y.Y. Liu, E.E. Gruber, T.H. Hughes, J.M. Kramer, Status of fuel element modeling codes for metallic fuels, in: Proceedings of the International Conference on Reliable Fuels for Liquid Metal Reactors, Tucson, AZ, 7-11 Sept, American Nuclear Society, La Grange Park, IL, 1986. [153] Argonne National Laboratory, Reactor Development Progress Report (Report ANL-7230), Argonne, IL, 1966. 